$P N L-54 z 5$

NUREG / CR-4248 PNL-5435

\title{
Recommendations for NRC Policy on Shift Scheduling and Overtime at Nuclear Power Plants
}

Prepared by P. M. Lewis

Pacific Northwest Laboratory

Operated by

Battelle Memorial Institute

Prepared for

U.S. Nuclear Regulatory

Commission 


\section{NOTICE}

This report was prepared as an account of work sponsored by an agency of the United States Government. Neither the United States Government nor any agency thereof, or any of their employees, makes any warranty, expressed or implied, or assumes any legal liability of responsibility for any third party's use, or the results of such use, of any information, apparatus, product or process disclosed in this report, or represents that its use by such third party would not infringe privately owned rights.

The views expressed in this report are not necessarily those of the U.S. Nuclear Regulatory Commission.

\section{NOTICE}

Availability of Reference Materials Cited in NRC Publications

Most documents cited in NRC publications will be available from one of the following sources:

1. The NRC Public Document Room, 1717 H Street, N.W. Washington, DC 20555

2. The Superintendent of Documents, U.S. Government Printing Office, Post Office Box 37082 , Washington, DC 20013-7982

3. The National Technical Information Service, Springfield, VA 22161

Although the listing that follows represents the majority of documents cited in NRC publications, it is not intended to be exhaustive.

Referenced documents available for inspection and copying for a fee from the NRC Public Document Room include NRC correspondence and internal NRC memoranda; NRC Office of Inspection and Enforcement bulletins, circulars, information notices, inspection and investigation notices; Licensee Event Reports; vendor reports and correspondence; Commission papers; and applicant and licensee documents and correspondence.

The following documents in the NUREG series are available for purchase from the NRC/GPO Sales Program: formal NRC staff and contractor reports, NRC-sponsored conference proceedings, and NRC booklets and brochures. Also available are Regulatory Guides, NRC regulations in the Code of Federal Regulations, and Nuclear Regulatory Commission Issuances.

Documents available from the National Technical Information Service include NUREG series reports and technical reports prepared by other federal agencies and reports prepared by the Atomic Energy Commission, forerunner agency to the Nuclear Regulatory Commission.

Documents available from public and special technical libraries include all open literature items, such as books, journal and periodical articles, and transactions. Federal Register notices, federal and state legislation, and congressional reports can usually be obtained from these libraries.

Documents such as theses, dissertations, foreign reports and translations, and non-NRC conference proceedings are available for purchase from the organization sponsoring the publication cited.

Single copies of NRC draft reports are available free, to the extent of supply, upon written request to the Division of Technical Information and Document Control, U.S. Nuclear Regulatory Commission, Washington, DC 20555.

Copies of industry codes and standards used in a substantive manner in the NRC regulatory process are maintained at the NRC Library, 7920 Norfolk Avenue, Bethesda, Maryland, and are available there for reference use by the public. Codes and standards are usually copyrighted and may be purchased from the originating organization or, if they are American National Standards, from the American National Standards Institute, 1430 Broadway, New York, NY 10018. 
NUREG/CR-4248

PNL-5435

\section{Recommendations for NRC Policy on Shift Scheduling and Overtime at Nuclear Power Plants}

Manuscript Completed: May 1985

Date Published: July 1985

Prepared by

P. M. Lewis

Pacific Northwest Laboratory

Richland, WA 99352

Prepared for

Division of Human Factors Safety

Office of Nuclear Reactor Regulation

U.S. Nuclear Regulatory Commission

Washington, D.C. 20555

NRC FIN B2360 



\section{ABSTRACT}

This report contains the Pacific Northwest Laboratory's (PNL's) recommendations to the U.S. Nuclear Regulatory Commission (NRC) for an NRC policy on shift scheduling and hours of work (including overtime) for control room operators and other safety-related personnel in nuclear power plants. First, it is recommended that NRC make three additions to its present policy on overtime: 1) limit personnel to 112 hours of work in a 14-day period, 192 hours in 28 days, and 2,260 hours in one year; exceeding these limits would require plant manager approval, 2) add a requirement that licensees obtain approval from NRC if plant personnel are expected to exceed 72 hours of work in a 7-day period, 132 hours in 14 days, 228 hours in 28 days, and 2,300 hours in one year, and 3) make the policy a requirement, rather than a nonbinding recommendation. Second, it is recommended that licensees be required to obtain NRC approval to adopt a routine 12-hour/day shift schedule. Third, it is recommended that NRC add several nonbinding recommendations concerning routine 8-hour/day schedules. Finally, because additional data can strengthen the basis for future NRC policy on overtime, five methods are suggested for collecting data on overtime and its effects.

NOTICE

The views expressed in this report are not necessarily those of the U.S. Nuclear Regulatory Comission. 



\section{EXECUTIVE SUMMARY}

The objective of the Shift Scheduling Project, conducted by the Pacific Northwest Laboratory (PNL) for the Nuclear Regulatory Commission, is to recommend to NRC new or modified guidelines on shift scheduling and hours of work (including overtime) for nuclear power plant personnel that perform safetyrelated work in nuclear power plants. This report presents those recommendations and the data and analysis that forms the basis for the recommendations. Although the project's scope includes all safety-related personnel, the focus is on control room operators.

\section{FOUR RECOMMENDATIONS}

This report makes four recommendations, one for each of the following four aspects of shift scheduling and hours of work:

1. limits on hours of work (including overtime)

2. routine 8 -hour/day shift schedules

3. routine 12-hour/day shift schedules

4. the total number of control room operators at a plant.

of these four recommendations, the first recommendation is the most important in the sense that its adoption would result in the greatest change from the status quo.

Recommendation Concerning Limits on Hours of Work (Including Overtime)

The essence of the recommendation concerning hours of work is presented in Table S.1. This recommendation is similar to present NRC policy in several ways. The limits on hours of work for 1, 2, and 7 days in Column $A$ are approximately the same as present NRC limits (Table S.2). As with present NRC policy, plant manager approval is required to exceed the limits in Column $A$. Also, in the recommendation, the circumstances under which overtime is approved ("problem during operation," "extended shutdown," and "very unusual circumstances") are defined, or left undefined, much as they are in present NRC policy.

The recommendation clarifies an important aspect of present NRC policy. Present NRC policy states that under certain circumstances safety-related personnel may work 72 hours a week, but only on "a temporary basis." Without clarification, a licensee can, without documented plant manager approval, have its operators work 72 hours a week for a month, 6 months, or for an indefinite period. Such cases would be contrary to the intent of NRC policy. The recommendation clarifies the intent of present NRC policy by adding limits on hours of work for periods of 14 days, 28 days, and 1 year in such a way that heavy overtime may be worked temporarily, but not indefinitely.

Present NRC policy sets no upper 1 imits on the amount of additional overtime a plant manager may approve. By contrast, Column $B$ of the recominendation 
TABLE S.1. Project Staff Recommendations for Limits on Hours of Work (including overtime) (a)

\begin{tabular}{|c|c|c|}
\hline & Column A & Column B \\
\hline & $\begin{array}{l}\text { Plant Manager Approval } \\
\text { Required Before Exceeding } \\
\text { These Guidelines (hours) } \\
\end{array}$ & $\begin{array}{l}\text { NRC Approval Required } \\
\text { Before Exceeding These } \\
\text { Guidelines (hours) }\end{array}$ \\
\hline 1 day $(d)$ & $12(16)^{(e)}$ & -- \\
\hline 2 days & 24 & -- \\
\hline 7 days & 60 & 72 \\
\hline 4 days & 112 & 132 \\
\hline 8 days & 192 & 228 \\
\hline 1 year & 2260 & 2300 \\
\hline
\end{tabular}

(a) The guidelines in Columns $A$ and $B$ exclude shift turnover time.

(b) Overtime may be required because of a problem during operation or because of an extended shutdown. 1n either case, overtime shall not exceed the guidelines stated in Column A. Unusual circumstances may arise that require deviation from the guidelines in Column A. Such deviations shall be authorized by the plant manager. (This authorization must be documented and made available for NRC inspection.) An extended shutdown shall not be considered unusual circumstances.

(c) Very unusual circumstances may arise that require deviation from the guidelines in Column $B$. Such deviations shall be authorized, up to specified limits, by NRC. [NRC may wish to define "very unusual circumstances" using the categories found in each plant's Emergency Plan Implementing Procedures (EPIPs)].

(d) The term "one day" is a shortened notation for "any period of 24 consecutive hours." The terms for $2,7,14$, and 28 days, and 1 year, are similar shortened notations.

(e) In the case of a problem during operation, such as the unexpected absence of an operator, overtime may be worked on an individual basis, but no individual should be allowed to work more than 16 hours straight. No individual should be approved to work more than one 16-hour day in a 7-day period, or more than two 16-hour days in a 28 -day period. 
TABLE S.2. Present NRC Policy on Hours of Hork (a)

Time Period

1 day

2 days

7 days
Limit on

Hours of Work

16 hours

24 hours

72 hours

\section{(a) NOTE: \\ 1. In case of a problem during operation, limits for overtime apply to individuals only; limits for routine operation apply to the remainder of the crew. \\ 2. During an extended shutdown, overtime limits apply to the entire crew. \\ 3. During very unusual circumstances, over- time linits may be exceeded if the plant manager approves.}

hours allowed by these limits are high, human error may also be high. Only "very unusual circumstances" would justify exceeding these limits. In such circumstances, however, NRC may allow licensee employees to exceed them.

The project staff recommends that NRC policy on hours of work be made an enforceable requirement for all licensees, not a recommendation that licensees may or may not adopt.

Publicly available information on overtime in the nuclear industry is limited. In one survey of nuclear power plant personnel (Bauman et al. 1983, p. 3-4), nearly $40 \%$ of the respondents had worked more than 400 hours of overtime, $16 \%$ had worked more than 600 hours of overtime, and $6 \%$ had worked mare than 800 hours of overtime in the previous year. Several unpublished reports from the nuclear industry make judgments that understaffing at particular plants has led to considerable amounts of overtime. Control room operators have told PNL staff that in the past their operating crews have been understaffed, and that operations personnel have worked considerable overtime. For example, one control room operator told PNL that he had worked 84 hours a week for 3 months and 72 hours a week for the remainder of the year; this totals about 3,900 hours of work in the year. Another operator at a different plant told PNL that personnel at this plant averaged $25 \%$ to $30 \%$ overtime per year. Taken as a whole, these verbal and written reports suggest that the implementation of the recommendation on hours of work could limit overtime in the nuclear industry.

The project staff believes that the recomended policy on hours of work will improve NRC policy for the following reasons: 1) presently, considerable 
overtime is often incurred by industry personne1; 2) the recommended policy would be a requirement for all licensees; 3 ) the recommended policy would reduce or eliminate excessive overtime while maintaining flexibility for emergencies.

The details of the recommendation on hours of work (including overtime) are presented in Chapter 1 ; the basis for the recommendation is presented in Chapter 2.

Recommendation Concerning Routine 8-Hour/Day Shift Schedules

The project staff recommends that NRC's policy on routine 8-hour/day shift schedules remain essentially as is and remain a nonbinding recommendation, but that several specific recomendations be added, including the following:

1. The schedule should be limited to a maximum of 7 consecutive days of work.

2. The schedule should not exceed 21 days of work (including training) in any 4-week period.

3. The schedule should include at least 2 consecutive full days off in any period of 9 consecutive days.

The details of this recommendation are presented in Chapter 1; the basis for the recommendation is presented in Chapter 3.

Recommendation Concerning Routine 12-Hour/Day Shift Schedules

The project staff recommends that licensees be required to obtain NRC approval to adopt a routine 12-hour/day shift schedule and that NRC establish criteria for granting such authorization, including the following criteria:

1. The basic 12-hour/day schedule should be "2-on, 2-off," "3-on, 3-off," or "4-on, 4-off."

2. The plant should have the capability to cover unexpected absences satisfactorily without having individuals work more than 12 hours per day.

3. The general safety record of the plant should be satisfactory, based on general criteria such as those used in NRC's Systematic Assessment of Licensee Performance (SALP) ratings.

The details of this recomnendation are presented in Chapter 1; the basis for the recommendation is presented in Chapter 4.

Recommendation Concerning the Total Number of Control Room Operators at a Plant

We considered a requirement that each nuclear power plant have enough control room operators to staff six shift crews. This requirement would reduce 
overtime, because with a larger number of operators, overtime for individual operators can be reduced. Although this alternative is simple and easy to enforce, we rejected it, primarily because setting limits on hours of work is a more direct way to deal with overtime and fatigue. Also, a full assessment of such a policy is beyond the scope of this project. However, because a close relationship exists between the number of operators and overtime, and because some nuclear power plants may have been understaffed in the recent past, we recommend that NRC collect data on the number of control room operators currently on staff at nuclear power plants, in order to assess the degree to which understaffing may be a basic cause of overtime in the nuclear industry.

The details of this recommendation are presented in Chapter 1; the basis for the recommendation is presented in Chapter 5.

SOURCES AND QUALITY OF DATA

The primary sources of evidence for the four recormendations are as follows:

- research reports on non-nuclear occupations (such as airline pilots, truck drivers, railroad operators, medical doctors, and radar screen monitors); laboratory experiments on reading speed, vigilance, mathematical ability; and scores on a variety of cognitive tests. [Most of these reports were reviewed in the Shift Scheduling Project's literature review (Lewis 1985).] Non-nuclear occupations were examined in industries having similarities to the nuclear industry because little research has been conducted on shift scheduling and overtime in nuclear power plants.

- the experience of nine well-known administrators, researchers, and medical doctors, who are professionally concerned with fatigue and who participated in a panel meeting for this project.

- fatigue indexes that were developed for airline pilots. (A fatigue index is an algorithm that estimates the level of fatigue or performance based on factors that cause fatigue, especially hours of work.)

- interviews with employees in the nuclear industry and in non-nuclear industries.

The degree to which the project staff relied on one source of evidence or another is explained for each recommendation in Chapters 2 through 5 . In general, the recommendations are based on a judgmental evaluation of accumulated evidence from many sources, rather than on any single piece of evidence. In this regard, our approach was influenced by the experience of other branches of the federal government, which have also studied fatigue. According 
to the U.S. Naval Flight Surgeon's Manual (pp. 20-1, 20-2), (a) "Literally millions of dollars have been spent in studying fatigue, yet its essential nature remains more unknown than known .... Although operational fatigue is difficult to define with precision, there is no doubt that it is real." The U.S. Navy and other branches of the federal government deal with fatigue, illdefined though it may be, by adopting well-defined limits on hours of work for certain types of work.

If as a part of its regulatory activities NRC should require additional data on overtime and performance, such data can be obtained. Several potential methods for collecting those data are described in chapter 6 .

(a) Not available to the public. 


\section{CONTENTS}

ABSTRACT

EXECUTIVE SUMMARY

\section{v}

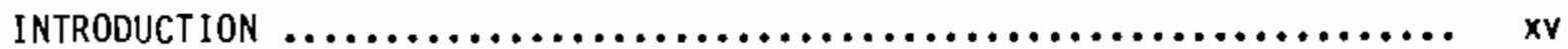

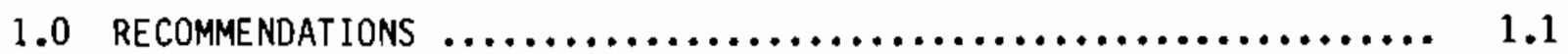

1.1 RECOMMENDED NRC POLICY STATEMENT ON ROUTINE

SHIFT SCHEDULES AND OVERTIME $\ldots \ldots \ldots \ldots \ldots \ldots \ldots \ldots \ldots \ldots \ldots, 1.1$

1.2 ADDITIONAL RECOMMENDATIONS $\ldots \ldots \ldots \ldots \ldots \ldots \ldots \ldots \ldots \ldots \ldots, 1.5$

2.0 BASIS FOR RECOMMENDATION ON LIMITS ON HOURS OF WORK (INCLUDING

OVERTIME) $\ldots \ldots \ldots \ldots \ldots \ldots \ldots \ldots \ldots \ldots \ldots \ldots \ldots \ldots \ldots \ldots \ldots \ldots \ldots \ldots \ldots, 2.1$

2.1 EXPLANATION OF RECOMMENDATION ON HOURS OF WORK $\ldots \ldots \ldots \ldots .2 .1$

2.2 BASIS FOR THE RECOMMENDATION $\ldots \ldots \ldots \ldots \ldots \ldots \ldots \ldots \ldots \ldots . \ldots \ldots \ldots . .2$

2.3 Alternative A: MOdification OF PANEL'S RECOMMENDATION $\ldots . . .2 .10$

2.4 ALTERNATIVE B: MAINTAIN THE STATUS QUO--PRESENT NRC POLICY .......................................... 2.13

2.5 ALTERNATIVE C: REQUIRE THAT LICENSEES INFORM NRC WHEN SAFETY-RELATED PERSONNEL EXCEED SPECIFIED HOURS OF WORK .... 2.15

2.6 ALTERNATIVE D: SET LIMITS ON HOURS OF HORK THAT ARE LEGALLY ENFORCED ................................ 2.15

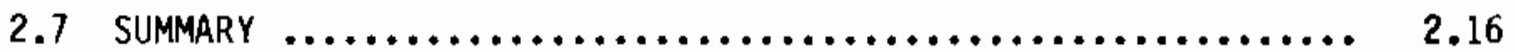

3.0 BASIS FOR RECOMMENDATION ON ROUTINE 8-HOUR/DAY SCHEDULES $\ldots \ldots \ldots .3 .1$

3.1 PROJECT STAFF RECOMMENDATION $\ldots \ldots \ldots \ldots \ldots \ldots \ldots \ldots \ldots \ldots \ldots, 3.1$

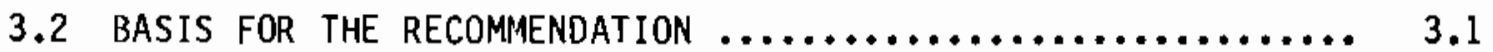

3.3 ALTERNATIVE A: PANEL RECOMMENDATION--REQUIRE NRC APPROVAL TO DEVIATE FROM GUIDELINES $\ldots \ldots \ldots \ldots \ldots \ldots \ldots \ldots \ldots, \quad 3.6$

3.4 ALTERNATIVE B: MAINTAIN THE STATUS QU0---PRESENT NRC POLICY $\ldots \ldots \ldots \ldots \ldots \ldots \ldots \ldots \ldots \ldots \ldots \ldots \ldots \ldots \ldots \ldots \ldots \ldots \ldots \ldots, \quad 3.6$

3.5 SUMMARY $\ldots \ldots \ldots \ldots \ldots \ldots \ldots \ldots \ldots \ldots \ldots \ldots \ldots \ldots \ldots \ldots \ldots \ldots, \quad 3.6$ 
4.0 BASIS FOR RECOMMENOATION ON ROUTINE 12 -HOUR/OAY SCHEDULES $\ldots \ldots \ldots \quad 4.1$

4.1 RECOMMENDATION: REQUIRE NRC APPROVAL TO ADOPT ROUTINE

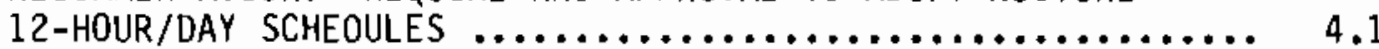

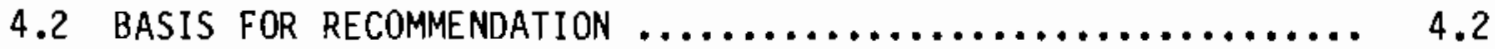

4.3 CRITERIA FOR ALLOWING ROUTINE 12-HOUR/DAY SCHEDULE $\ldots \ldots \ldots \ldots .4 .5$

5.0 BASIS FOR RECOMMENDATION ON THE TOTAL NUMBER OF CONTROL ROOM

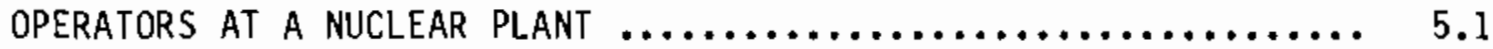

5.1 RECOMMENDATION: GATHER DATA $\ldots \ldots \ldots \ldots \ldots \ldots \ldots \ldots \ldots \ldots \ldots \ldots \ldots \ldots \ldots \ldots \ldots$

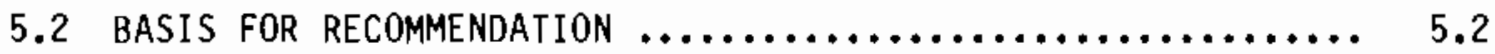

5.3 ALTERNATIVE A: REQUIRE THAT EACH PLANT MAVE A SPECIFIED

5.4 Alternative B: MAINTAIN THE STATUS QUO--PRESENT NRC POLICY 5.3

5.5 RELATIONSHIP TO RECOMMENDATION ON HOURS OF WORK $\ldots \ldots \ldots \ldots .5 .4$

6.0 METHOOS FOR COLLECTING INFORMATION ON OVERTIME, NUMBER OF OPERATORS, FATIGUE, AND PERFORMANCE $\ldots \ldots \ldots \ldots \ldots \ldots \ldots \ldots \ldots \ldots \ldots . \ldots \ldots$

6.1 COLLECT DATA FROM OOCUMENTS OF APPROVAL TO EXCEED

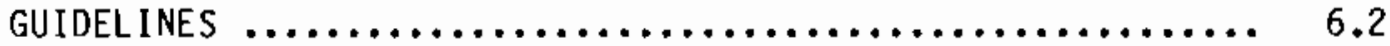

6.2 WHEN A LICENSEE EVENT REPORT INDICATES HUMAN ERROR, GATHER DATA ON HOURS OF HORK .......................... 6.2

6.3 ESTABLISH A NUCLEAR SAFETY REPORTING SYSTEM ........... 6.3

6.4 EXPAND THE ALLEGATION TRACKING SYSTEM .............. 6.3

7.0 SUMMARY COMPARISON OF NRC'S POLICIES ANO PROJECT STAFF

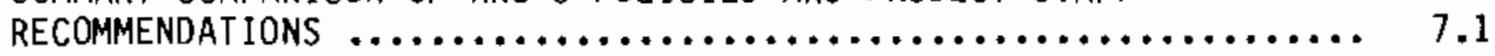

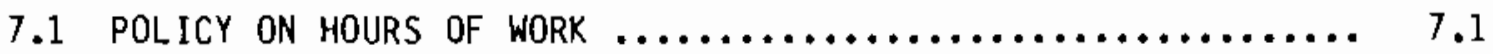

7.2 POLICY ON ROUTINE 8-HOUR/DAY SHIFT SCHEDULES $\ldots \ldots \ldots \ldots \ldots \ldots .7 .2$

7.3 POLICY ON ROUTINE 12-HOUR/DAY SHIFT SCHEDULES $\ldots \ldots \ldots \ldots \ldots \ldots .2$

7.4 POLICY ON NUMBER OF CONTROL ROOM OPERATORS AT A PLANT $\ldots . . .7 .3$ 
APPENDIX A - PANEL MEETING ON SHIFT SCHEDULING IN THE NUCLEAR POWER

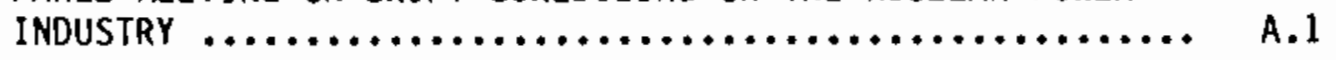

APPENDIX B - SOURCES OF EVIDENCE ON ROUTINE 12-HOUR/DAY SHIFT SCHEDULES ................................ B.1

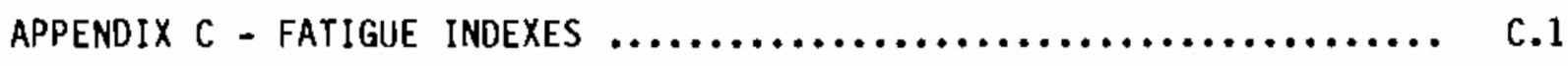

APPENDIX D - REPORTS OF FATIGUE AMONG AIRPLANE CREW AND CONTROLLERS .. D.1

APPENDIX E - PAST AND PRESENT NRC POLICIES ON SHIFT SCHEDULING AND

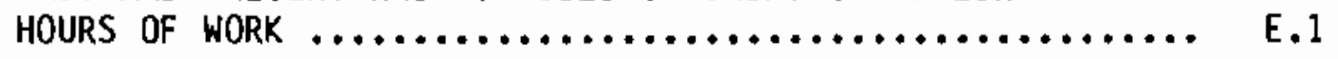

APPENDIX F - FEDERAL REGULATIONS ON HOURS OF WORK FOR NON-NUCLEAR INDUSTRIES AND FOR THE ARMED FORCES ............... F.1

APPENDIX G - SAMPLE SHIFT SCHEDULES $\ldots \ldots \ldots \ldots \ldots \ldots \ldots \ldots \ldots \ldots \ldots \ldots \ldots \ldots . \ldots \ldots$

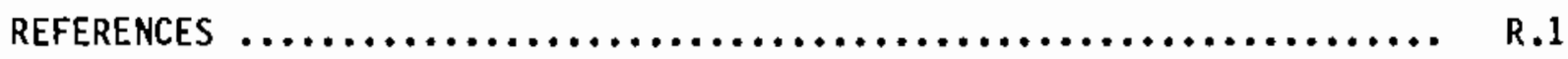




\section{TABLES}

S.1 Project Staff Recommendations for Limits on Hours of Work ...... vi

S.2 Present NRC Policy on Hours of Work $\ldots \ldots \ldots \ldots \ldots \ldots \ldots \ldots \ldots \ldots$ vii

1.1 Limits on Hours of Work $\ldots \ldots \ldots \ldots \ldots \ldots \ldots \ldots \ldots \ldots \ldots \ldots \ldots \ldots$

2.1 Alternative A--Modification of Panel's Recommendations on Hours of Work in Overtime Situations $\ldots \ldots \ldots \ldots \ldots \ldots \ldots \ldots \ldots . . . \ldots \ldots$

2.2 Panel's Recommendation on Limits on Hours of Work ........... 2.12

2.3 Present NRC Policy on Hours of Work $\ldots \ldots \ldots \ldots \ldots \ldots \ldots \ldots \ldots \ldots . . \ldots \ldots$

2.4 Comparison of Limits on Hours of Work $\ldots \ldots \ldots \ldots \ldots \ldots \ldots \ldots \ldots$

2.5 Comparison of Legal Status of Limits on Hours of Work ........ 2.17

3.1 Characteristics of Six Shift Schedules ................... 3.3

3.2 Comparison of Policies for Routine 8 -Hour/Day Schedules ....... 3.7

4.1 Potential Advantages and Disadvantages of 12 -Hour Schedules $\ldots . .4 \quad 4.7$ 


\section{INTRODUCTION}

In any industry, working on rotating shifts is generally more fatiguing than working on a straight-day schedule. Adding overtime work can increase the fatigue. In the nuclear industry, the issue of fatigue is particularly important because of the implications of human error for public health and safety. A survey of 233 nuclear power plant employees (Bauman et al. 1983, p. A-5) indicates that nearly $40 \%$ of the employees worked more than 400 hours of overtime in the previous year; $6 \%$ worked more than 800 hours overtime. The survey also indicated ( $p . A-6$ ) that overtime can have safety implications. In response to the question, "Have you noticed any negative effects from working overtime?", 15\% of the respondents indicated that they had noticed "safety problems."

In response to this situation, NRC sponsored research related to hours of work and fatigue (Price, Wallace, Bauman, and Smith 1980). On July 31, 1980, NRC announced its policy on overtime requirements in a letter from $D$. $G$. Eisenhut (Director, Division of Licensing, NRC) to licensees. In November, 1980, NRC revised its policy to make it more flexible (NUREG-0737, p. 3-6), and revised it again in 1982 in Generic Letters 82-12 and 82-16 (See Appendix E).

In 1983, NRC began its sponsorship of the Shift Scheduling Project at Pacific Northwest Laboratory. The objective of that project is to build on earlier research to formulate a basis for confirming or modifying present NRC policy. This report presents the recommendations of that project. From that project, a review and analysis of relevant literature (Lewis 1985) has also been issued, and a regulatory analysis of the recommendations in this report will be issued.

\section{REPORT CONTENTS}

Chapter 1 presents the four recommendation for NRC policy on shift scheduling and hours of work (including overtime). Chapters 2 through 5 provide the bases for each of the four recommendations, provide further explanation, and evaluate alternatives. Chapter 6 discusses four methods that NRC could use to collect information on overtime, number of operators, fatigue, and performance for future NRC policy on shift scheduling and overtime. Chapter 7 contains a summary comparison of NRC's policy and the project staff's recommendations.

Appendix A reports the discussion and results of a panel meeting on shift scheduling in the nuclear industry. The panel meeting was heid May 15-16, 1984, in washington, D.C. The panel consisted of nine well-known and respected administrators, researchers, and medical doctors who are from various industries and organizations in the United States and Canada and who are professionally concerned with the effects of fatigue on performance.

Appendix B summarizes some of the principal sources of evidence on routine 12-hour/day schedules. Appendix $C$ discusses four fatigue indexes that PNL adapted to calculate maximum allowable hours of work and minimum hours of rest 
for rotating shift workers. Included are sumaries of the four indexes and the results of PNL's calculations. Appendix D discusses fatigue among airplane crew and air traffic controllers. It presents sample reports from the Federal Aviation Administration's Aviation Safety Reporting System, and presents excerpts from the U.S. Naval Flight Surgeon's Manual. Appendix E contains excerpts on NRC's past and present policies, as taken from NUREG-0737 and Generic Letters 82-12 and 82-16. Federal regulations on hours of work for nonnuclear industries and for the Armed Forces are summarized in Appendix F. Finally, Appendix $G$ contains sample shift schedules from the nuclear industry and the petrochemical industry. 


\subsection{RECOMMENDATIONS}

Chapter 1 contains the project staff's four recommendations on shift scheduling and hours of work. Section 1.1 contains a recommendation for an NRC policy statement to be issued to licensees. Section 1.2 contains additional recommendations that are not covered directly by the policy statement.

\subsection{RECOMMENDED NRC POLICY STATEMENT ON ROUTINE SHIFT SCHEDULES AND OVERTIME}

This section contains a recommendation for an NRC policy statement on 1) hours of work (including overtime), 2) routine 8-hour/day shift schedules, and 3) routine 12-hour/day shift schedules. The objective of this section is to present a policy statement that NRC $c$ an, if it so chooses, adopt verbatim as its own. The wording of this recommended policy statement adopts much of the language of NRC's present policy statements on shift scheduling and hours of work, which are contained in NRC Generic Letters 82-12 and 82-16. These letters are reprinted in Appendix E.

Presently, NRC recommends that licensees write into their technical specifications controls similar to those found in Generic Letters 82-12 and 82-16. The controls are enforceable only if they are written into each licensee's technical specifications. We recommend that NRC strengthen its policy by making the writing of such controls into each licensee's technical specifications a requirement, not a recommendation.

The recomended policy statement is as follows: 


\section{POLICY ON FACTORS CAUSING FATIGUE OF OPERATING PERSONNEL AT NUCLEAR POLER PLANTS}

Administrative procedures shall be developed and implemented to limit the working hours of unit staff wo perform safety-related functions. The procedures shall apply to the plant operating staff (i.e., auxiliary operators, and licensed reactor operators and senior reactor operators wo operate the plant from the control room) and to other staff wo perform safety-related functions (e.g., health physicists and key maintenance personnel).

The objective of the procedures shall be to assure that, to the extent practicable, personnel are not assigned to shift duties while in a fatigued condition that could significantly reduce their mental alertness or their decision-making capability.

\section{LIMITS ON HOURS OF WORK (INCLUDING OVERTIME)}

Enough plant operating personnel should be employed to maintain adequate shift coverage without routine heavy use of overtine. The objective is to have operating personnel work routine schedules that conform to the criteria presented below in the section on routine schedules. If overtime is required, overtime may be wrked subject to the conditions stated in Table 1.1 and in the footnotes to that table.

In requesting NRC approval to exceed the guidelines in Column B of Table 1.1 , the utility should explain the circumstances that require deviation from the guidelines. If KRC authorizes the deviation, its authorization will specify limits for the additional number of hours of wrk; those limits will be determined on a case-by-case basis, considering the effect on public health and safety, the safety record of the plant, the level of fatigue among the personnel working overtime, the circumstances requiring overtime, and the possibility of resolving the original problem by means other than working heavy overtime. NRC considers it unlikely that a utility will be faced with a situation for which NRC would authorize plant personnel to exceed the following limits on hours of work:

$\begin{array}{rr}7 \text { days } & 84 \text { hours } \\ 14 \text { days } & 144 \text { hours } \\ 28 \text { days } & 264 \text { hours } \\ 1 \text { year } & 2400 \text { hours }\end{array}$


TABLE 1.1. Limits on Hours of Work (including overtime) (a)

\begin{tabular}{|c|c|c|}
\hline & Column A & Column B \\
\hline & $\begin{array}{l}\text { Plant Manager Approval } \\
\text { Requi red Before Exceeding } \\
\text { These Guidel ines (hours) }\end{array}$ & $\begin{array}{l}\text { NRC Approval Required } \\
\text { Before Exceeding These } \\
\text { Guidelines (hours) }(c)\end{array}$ \\
\hline 1 day $(d)$ & $12(16)^{(e)}$ & $\rightarrow$ \\
\hline 2 days & 24 & -- \\
\hline 7 days & 60 & 72 \\
\hline 14 days & 112 & 132 \\
\hline 28 days & 192 & 228 \\
\hline 1 year & 2260 & 2300 \\
\hline
\end{tabular}

(a) The guidelines in Columns $A$ and $B$ exclude shift turnover time.

(b) Overtime may be required because of a problem during operation or because of an extended shutdown. In either case, overtime shall not exceed the guidelines stated in Column A. Unusual circumstances may arise that require deviation from the guidelines in CoTumn A. Such deviations shall be authorized by the plant manager. (This authorization must be documented and made available for NRC inspection.) An extended shutdown shall not be considered unusual circumstances.

(c) Very unusual circumstances may arise that require deviation from the guidelines in Column $B$. Such deviations shall be authorized, up to specified limits, by NRC. [NRC may wish to define "very unusual circumstances" using the categories found in each plant's Emergency Plan Implementing Procedures (EPIPs)].

(d) The term "one day" is a shortened notation for "any period of 24 consecutive hours." The terms for $2,7,14$, and 28 days, and one year, are similar shortened notations.

(e) In the case of a problem during operation, such as the unexpected absence of an operator, overtime may be worked on an individual basis, but no individual should be allowed to work more than 16 hours straight. No individual should be allowed to work more than one 16-hour day in a 7-day period, or more than two 16-hour days in a 28 -day period. 


\section{RECOMENDATIONS FOR ROUTINE 8-HOUR/DAY SCHEDULES}

NRC recomends that nuclear power plants adopt routine 8-hour/day shift schedules that conform to the following guidelines:

1. The schedule should be limited to a maximum of 7 consecutive days of work.

2. The schedule should not exceed 21 days of work (including training) in any 4-week period.

3. The schedule should include at least 2 consecutive full days off in any period of 9 consecutive days.

4. Night shifts should be followed by at least 2 full days of rest.

5. The schedule should rotate forward, not backward.

GUIDELINES FOR ROUTINE 12-HOUR/DAY SCHEDULES

If a licensee wishes to adopt a routine 12-hour/day schedule for its operating personnel, it must first obtain authorization from NRC. In evaluating the licensee's application, MRC will use the following primary criteria.

1. The schedule should contain a maximum of 4 consecutive 12-hour work days.

2. Four consecutive 12-hour work days should be followed by no fewer than 4 days of $f$.

3. The basic 12-hour/day schedule should be "2-on, 2-off," "3-on, 3-off," "4-on, 4-off," or a systematic combination of these such as the "every-other-weekend-off" schedule, wich combines "2-on, 2-off" with "3-on, 3-off."

4. The general safety record of the plant should be satisfactory, based on criteria such as those used in NRC's Systematic Assessment of Licensee Performance (SALP) ratings.

5. The plant should have the capability to cover unexpected absences satisfactorily without requiring any individual to work more than 12 hours per day.

6. The round-trip commute times for the operators should not exceed $21 / 2$ hours. 


\subsection{ADDITIONAL RECOMMENDATIONS}

In addition to recommending that NRC deal with overtime directly by limiting hours of work, we recommend that NRC collect data on the number of control room operators currently on staff at nuclear power plants. If, however, NRC chooses not to deal with overtime directly by setting limits on hours of work, then we recommend that NRC deal with overtime indirectly, by requiring that each nuclear power plant have a specified minimum total number of control room operators. (The number of control room operators at the plant is distinguished from the number of control room operators on shift. NRC already has regulations concerning the latter.) This recomendation is explained further in Chapter 5.

Finally, it is recommended that NRC consider adopting one or more of the following methods for gathering additional data on overtime, fatigue, and performance:

- collect data from documents of approval to exceed the limits on hours of work described above

- when a Licensee Event Report (LER) indicates human error, gather information on hours of work

- establish a Nuclear Safety Report System

- expand the Allegation Tracking System.

These four methods of gathering data are explained in Chapter 6 . 



\subsection{BASIS FOR RECOMMENDATION ON LIMITS ON HOURS OF WORK (INCLUDING OVERTIME)}

The recommendation for an NRC policy statement on hours of work (including overtime) was presented in Section 1.1. In this chapter, the recommendation is discussed in more detail. Section 2.1 provides additional explanation of the recommendation; Section 2.2 presents the basis for the recommendation; Section 2.3 presents an alternative to the recommendation (this alternative is a modification of the Shift Scheduling Project panel's recommendation); Section 2.4 summarizes another alternative--present NRC policy. Sections 2.5 and 2.6 present alternatives that can be considered to be variations on the project staff recommendation. The last section compares the project staff recommendations with the major alternatives and with limits on hours of work for other industries.

\subsection{EXPLANATIDN OF RECOMMENDATION ON HOURS OF WORK}

Implementing the recommendation on hours of work would have a greater impact on costs and benefits than implementing the other three recommendations in this report. Preliminary quantitative estimates (the final estimates will be reported later in the regulatory analysis) indicate that implementing the recommendation on hours of work would reduce the number of human errors and lower the probability of core melt. Preliminary estimates further indicate that the reduction in human error could also lead to fewer forced outages, which would be a major cost savings for licensees. The net result of implementing the recommendation, therefore, would not be an increase, but a decrease in the operating costs of licensees. We also believe that adoption of the recommended policy would improve working conditions for plant personnel. Improved working conditions would help attract the best candidates for operating crews, helo retain the best and most experienced operators, and help resolve a wide variety of personnel problems.

In Table 1.1, the term "problem during operation" refers primarily to unexpected absences of operators due to iliness, injury, etc. However, it also refers to a (temporary) lack of an adequate number of operators on the staff. (The intention of present NRC policy is that the utility make the shortage temporary by hiring and training more operators.) The term "extended shutdown" refers to periods of shutdown for refueling, major maintenance, or major plant modification. The term "unusual circumstances" refers to circumstances other than an "extended shutdown," which may create a more pressing need for additional hours of work. The term "very unusual circumstances" refers to a subset of "unusual circumstances" that create an even more pressing need for additional hours of work. NRC may wish to define "very unusual circumstances" using the four categories of emergency defined for each $\rho$ lant in its Emergency Plan Implementing Procedures (EPIPS). The four categories are: 1) Notification of Unusual Event, 2) Alert, 3) Site Area Emergency, and 4) General Emergency (NUREG-0654, Rev. 1, p. 1-3). 
The recommendation on hours of work is intended to apply to all plants, whether their routine schedules are 8-hour/day or 12-hour/day schedules.

\subsection{BASIS FOR THE RECOMMENDATION} below.

The basis for the various features of the recommendation are presented

\subsubsection{Basis for Two Sets of Limits on Hours of Work}

Two sets of ilimits are recommended on hours of work, i.e., the limits in Columns A and B of Table 1.1. Plant manager approval is required before personnel may exceed the first set, and NRC approval is required before personnel may exceed the second set.

The administrative requirements for deviating from the guidelines of column $A$ in Table 1.1 are identical to the requirements in present NRC policy: the deviations shall be authorized by the plant manager, and the authorization shall be documented and made available for NRC inspection. Without additional guidelines, however, once a plant manager has approved deviations from the guidelines set in Column $A$, there would be no quantified upper limit to additional overtime, and NRC would have no official way of knowing the extent to which overtime is being worked.

Because the guidelines in Column $B$ in Table 1.1 are higher than the guidelines in Column $A$, there is an increased likelihood that fatigue may reduce the plant's margin of safety. Therefore, the administrative requirements for deviating from these guidelines are stronger: authorization for exceeding the guidelines must come from NRC.

Two sets of guidelines would allow a degree of flexibility to meet contingencies and a reasonable assurance that fatigue will not reduce the operators' ability to keep the plant in a safe condition. Also, because the first set of limits, Column A, is similar to present NRC policy, adding the second set of limits builds on present policy, rather than overturns present policy.

The alternative to recommending two sets of limits--recommending only one set of limits--is less desirable for the following reasons. If the single set of limits could be exceeded with plant manager approval, as is the case with present NRC policy, NRC would have insufficient control over hours of work. If, on the other hand, the single set of limits could be exceeded only with NRC approval, then there would be no approval process for lesser amounts of overtime, and overtime in excess of the limits in Column A could become a standard practice.

\subsubsection{Basis for Requiring NRC Approval to Exceed Upper Set of Limits}

It is recommended that licensees be required to obtain NRC approval before any of its safety-related personnel exceed the upper set of limits on hours of work (Column B of Table 1.1). The primary advantage here is flexibility: it 
allows NRC the flexibility to choose among alternative decision-making procedures and avoids offering NRC a single prescriptive approach. It is recommended that NRC make its selection of an appropriate decision-making process before issuing a policy statement on hours of work. Several alternative decision-making processes can be considered. Some of these are listed below. Although the regulatory analys is for this project estimated upper and lower bounds for major costs and benefits of the recommendation, it did not consider all of the effects of all of the options listed below.

1. NRC could authorize exceeding the limits in Column $B$ only in cases of an emergency, which can be defined as any of the four levels of emergency specified in the plant's Emergency Plan Implementing Procedures (EPIPs). This is essentially the recommendation of the Shift Scheduling Project's panel on shift scheduling and overtime (see Appen$\operatorname{dix}$ A).

2. NRC could evaluate each application individually, taking account of the particular situation at each plant. In this case, NRC should establish a mechanism for granting authorization on a timely basis. The exact form of the authorization mechanism should be determined by NRC; it may include coordination among NRC headquarters, NRC regional offices, and the NRC Resident Inspectors at each site. The number of times that licensees will require authorization quickly will be reduced by two aspects of the recommended policy: 1) exceeding the limits in column $B$ is allowed only in the case of "very unusual circumstances," and 2) the limits in column B include no limits for oneand two-day periods--the shortest period is one week.

3. NRC could routinely grant all requests for authorization to exceed the limits in Column B, in which case the requirement for authorization is similar to a requirement simply to inform NRC.

4. NRC could begin with the third option and later, after an initial transition period, adopt the second or first option.

\subsubsection{Basis for Distinguishing Among "Problem During Operation," "Extended Shutdown, "Unusual Circumstances," and "Very Unusual circumstances"}

The recommendation on hours of work distinguishes among four situations, "problem during operation," "extended shutdown," "unusual circumstances," and "very unusual circumstances." In general, these terms are undefined, or left only partially defined, much as they are in present NRC policy. In certain circumstances, overly precise definitions can be too long, complex, arbitrary, inflexible and still incomplete. Also, the increasing level of authority required to exceed the limits will in itself tend to ensure that an increased risk of human error due to additional hours of work is assumed only for adequate cause. For these reasons, it is preferable to leave some kinds of circumstances only partially defined. Several important points, however, are clearly defined; for example, an extended outage may not be considered to be "unusual circumstances" in order to justify exceeding the limits in Column A. 
The category "problem during operation" is intended primarily to allow an operator to work two consecutive 8-hour shifts to cover an unexpected absence, especially an unexpected absence on the night shift. Sixteen consecutive hours, under normal conditions, is a long time to remain on the job. However, such an extended period of work is allowed only on an individual basis, which means that most of the crew will be working their normal schedule and therefore will remain at their normal levels of alertness.

The practicality of the 16-hour limit can be shown by comparing its effects with the effects of a 12-hour limit. If the limit were 12 hours, and if an individual on the night shift were unexpectedly absent, the most plausible way to cover the absence would be to keep an individual on the afternoon shift over an extra 4 hours, and call in an individual on the morning shift 4 hours early, i.e., at about 3 a.m. Experience has shown, however, the difficulty of calling an individual to work at $3 \mathrm{a} . \mathrm{m}$. Working 16 consecutive hours, however, can be fatiguing, and so we recommend that it be allowed only once per week and twice per month for any individual. The intention of this provision is to divide the burden of working double shifts among other operators in the same crew, or operators from different crews, including crews that are scheduled for training or days off.

Overtime conditions for operators are different from overtime conditions for maintenance personnel. NRC may wish to consider allowing key maintenance personnel to work 16 consecutive hours to complete a maintenance task. NRC regulations require a minimum number of operators on shift at all times, and therefore, when an unexpected absence might reduce the operating crew below the required minimum, a legal reason exists for asking a replacement operator to work overtime. By contrast, under normal operating conditions, most nuclear power plants have no maintenance crews on the back shifts (i.e., the afternoon and night shifts). Most plants have maintenance crews only on the day shift during weekdays (Chockie et al. 1984, p. 4.5). In plants that have no maintenance crews on backshifts, important maintenance tasks that are not completed during the day shift would have to remain incomplete until the following day, unless the maintenance crew works overtime to complete the task. Partly for this reason, it is not uncommon for maintenance crews to work 16 consecutive hours to complete a maintenance task. In their report to NRC on maintenance staffing, scheduling and overtime in nuclear plants, Chockie et al. (1984) state that one way to reduce overtime for maintenance personnel is to add backshifts for maintenance crews: "... (One) problem with a single maintenance shift is that workload fluctuations result in large amounts of overtime for maintenance personnel" (p. 4.9). Some of the nuclear plants that added backshifts for maintenance crews have noted a reduction in overtime for maintenance personne) (p. 4.7$)$.

For periods of 48 hours or longer, the limits on overtime in Column A apply to both "problem during operation" and "extended shutdown," and apply to the entire crew. The reason for setting the same limits for extended outages is that the work performed during an outage has safety implications that can be as important as those of operations. 
The limits in Column A may be exceeded during "unusual circumstances," with the approval of the plant manager. The normal requirements of an extended outage do not constitute "unusual circumstances." A difficult issue is whether the combination of an extended outage and (temporary) inadequate staffing should together constitute "unusual circumstances." Most likely, NRC will eventually have a chance to review the cases of most plants that have inadequate staffing because most of them probably will, sometime later that same year, apply to NRC to exceed limits in Column B. The limits in Column B may be exceeded during "very unusual circumstances," only with the approval of NRC. "Very unusual circumstances" could be defined using the four classifications of emergencies found in the Emergency Plan Implementation Procedures (EPIPS) for each plant.

\subsubsection{Basis for Limits on Hours Worked in a 24-Hour Period}

In the event of a "problem during operation," the recommended upper limit is 16 consecutjve hours of work, and this would be approved on an individual basis only. By contrast, during an "extended shutdown," the recommended limit is 12 hours of work and would apply to the entire crew. This recommendation is based on the evidence cited below. It is based on the totality of the evidence, rather than on any single piece of evidence, because some of the evidence tends to indicate that under certain circumstances, the limit should be greater than 12 hours, while other evidence tends to indicate that the limit should be less than 12 hours.

Twelve hours per day is the limit recomnended by the Shift Scheduling Project panel (see Appendix A). Twelve hours per day is the maximum allowed by federal regulations for railroad operators (Appendix F). In the U.S. Air Force, 12 hours per day also is the maximum flight duty period for the crew of single control aircraft. [For Air Force planes large enough to allow an "augmented crew" to provide in-flight rest periods for crew members, the maximum number of hours ranges from 14 to 30 , the latter limit being for a jet bomber with dual controls (Appendix F).] According to the project staff's adaptation of Mohler's fatigue index for airline pilots and crew (Appendix C), 12 hours per day is considered acceptable for morning and afternoon shifts (the implications of Mohler's index for the night shift are discussed below).

Other indicators for work comparable to that of a control room operator suggest that 12 hours is too long. For example, the adaptation of Mohler's fatigue index suggests that for the night shift even 6 hours is a high load. Furthermore, federal regulations limit truck drivers to 10 hours of driving and limit airline pilots to 8 hours of flight time (Appendix F).

The following passage from a report by the British Air Ministry (cited in Viteles $1946, p .46$ ) describes one of the many effects of fatigue after 12 hours of work, loss of memory for simple tasks:

The visible signs of fatigue begin to show themselves after about 12 hours of flying (emphas is added) and consist of an increasing irritability and toss of memory for relatively simple tasks. For 
instance, when a change of course is required, the navigator passes to the pilot a slip of paper on which is written the fresh course and the time on which he is to turn onto it. The pilot receives this about 4 minutes before he is to make the change. Normally he has no difficulty in turning onto the course at the given time. As fatigue sets in he will forget to alter the course on time, and 2 or 3 minutes may elapse after the given time before he realizes that he has forgotten. Finally [after additional hours of flying] he will begin to doze and eventually fall asleep. It is possible that some of the aircraft which have disappeared for no known reason may have been lost because of this.

The Shift Scheduling Project literature review (Lewis 1985, Pp. 5-6, and annotated bibliography) reviewed reports on relationships between hours of work and performance. Some of those reports are sumarized below.

Mackie and Miller (1978) conclude that the probability of a truck accident occurring increases with increased driving time. Shannon and Lane (1971) reported that aircraft accidents were associated with more than 8 hours of duty. Hurst (1976) identified pilot errors with duty beyond 8 hours. Vernon (1945) reported that occupational injuries fell significantly when 12-hour shifts were replaced by 8-hour shifts. Wilkinson, Tyler and Varey (1975) noted that more than one-third of junior doctors working 13 hours per day claimed that their efficiency was reduced as a result of the long hours. Colquhoun et a1. (1969) reported an 11\% increase in error rates for radar screen monitoring over 12-hours in duration. Brown, Tickner and Simmonds (1970) conclude that drivers take greater risks after 8 to 12 hours of driving. Zagoruiko and Tambovtsev (1982) reported that speed of reading slowed by $22 \%$ to $73 \%$ over 4 hours.

Higgins et al. (1975) reported increased errors for a complex test battery that included monitoring for more than 12 consecutive hours. Kogi et al. (1975) reported that the performance of nurses on a vigilance task decreased when they changed from 8-hour to 12-hour shifts at night. Mckenzie and Elliot (1965) reported decreased ability to align flight meters in a flight simulator when work extended beyond 8 hours. Mackie and Miller (1978) reported deterioration in a critical tracking task in truck driving after 8 hours. Huxtable (n.d.) (cited in Ray, Martin and Alluisi 1961) reported an increased error rate for repeated mental multiplication that would amount to a $17 \%$ increase over a 24-hour period for a 12-hour shift schedule as opposed to an 8-hour shift schedule. For complex decision making, Wojtczak-Jaroszowa (1977) reported data that indicate such an increase would be approximately $70 \%$. From a tracking task in an aircraft simulator, Mckenzie and Elliot (1965) report data that imply a $6 \%$ increase in errors over 24 hours for 12-hour shifts compared to 8-hour shifts. From a car-driving test, Herbert and Jaynes (1964) report data that imply a $10 \%$ increase in errors for 12 -hour shifts.

Most of the evidence cited in this section supports the conclusion that, for most situations requiring overtime, a limit of 12 hours of work per day is 
appropriate for safety-related nuclear power plant personnel. Only a few research reports suggest, directly or indirectly, that the limit should be higher than 12 hours. For example, Ontario Hydro's review of research reports (Kelly and Schneider 1982) includes only two that found no change in error rates after 8 hours: Platz et al. (1978) reported no change in a vigilance task over 9 hours; Dobbins et al. (1963) also reported no change in a vigilance task for army truckers driving over 9 hours.

The project staff recommends a limit of 12 hours of work in a 24-hour period because that is the limit indicated by most of the evidence cited above. Evidence cited in Chapter 4 on routine 12-hour/day shift schedules is also relevant here. One additional factor is that unlike any other limit between 8 and 12 hours, a limit of 12 hours allows the 24 hours of the day to be divided evenly (between two crews) without a remainder; this feature greatly facilitates the safe and efficient management of continuous (around-the-clock) operations.

\subsubsection{Basis for Limit on Hours Worked in a 48-Hour Period}

The recommended limit for hours worked in a 48-hour period is 24 hours. This is the same as present NRC policy.

The airline fatigue indexes presented in Appendix $C$ indicate that the maximum number of hours of work in a 48-hour period should be between 15 and 30 hours, depending in part on the time of day. Buley's (1970) index indicates that 24 hours of work in 48 hours is reasonable if work begins at 8 a.m. Gerathewoht's (1974) index indicates that 24 hours is too many. Nicholson's (1972) index sets an upper limit of 30 hours. The adaptation of Mohler's (1976) index indicates that for the morning and afternoon shifts, 24 hours is a high load; for the night shift, however, 16 hours is too many.

\subsubsection{Basis for Limit on Hours Worked in a 7-Day Period}

In the case of either a "problem during operation" or an "extended shutdown," a limit of 60 hours of work in a 7-day period is recomnended. Like the other limits in Column A of Table 1.1, this Timit is taken from the Shift Scheduling Project panel's recommendation.

Federal regulations limit airline pilots and crew to 30 hours of duty aloft in a 7-day period and limit truck drivers to 60 hours of work in a 7-day period (Appendix F). Nicholson's work-hours index for airline pilots and crew (Appendix C) sets a limit of 55 hours of duty time (duty time $=$ flight time + ground duty time). The adaptation of Mohler's index for airline pilots and

crew (Appendix C) indicates that 56 hours in 7 days is a high load; 84 hours in 7 days is (much) too many. U.S. Air Force flight crew are limited to 125 hours of flight duty in 30 days, which is an average of 29 hours in 7-days

(Appendix F).

In the case of "unusual circumstances," we recommend a limit of 72 hours in a 7-day period. According to an unpublished report by a nuclear utility, 
"employee productivity begins to drastically decrease after six consecutive days of twelve hour shifts." If productivity decreases drastically, the economic rationale for employees working such long hours decreases drastically, and so must the quality of work.

In the case of "very unusual circumstances," we recommend that NRC authorize no more than 84 hours of work in a 7-day period. Exceeding 84 hours would mean exceeding 7 consecutive 12-hour days. This is far in excess of federal limits for airline and military pilots.

\subsubsection{Basis for Limits on Hours Worked in a 14-Day Period}

Specifying limits for 14-day periods and longer periods is the only way to quantify the stated intention of present NRC policy that overtime be approved "on a temporary basis" only (Appendix E). Specifically, under present NRC policy, during an extended outage, an operating crew may work 72 hours a week, but only on "a temporary basis," and not for an unlimited number of weeks. Even though the general intent is clear, NRC's policy statement does not quantify the term "on a temporary basis." Setting limits for time periods up to one year quantifies the intent of present NRC policy.

The need to quantify present NRC policy is clear. If it is not quantified, the term "on a temporary basis" can be interpreted to extend for almost any period of time. "On a temporary basis" is regularly interpreted to include the entire duration of an extended outage, which is often 3 months. Under those conditions, operators may work 72-hour weeks for the entire 3 months, if not more. In a few cases, at least, an extended outage has apparently been considered "very unusual circumstances," because operators worked not 72 , but 84 hours per week, for the entire 3 months of the outage. Although the reactor is shut down during outages, outages still can have important safety implications, because errors made during outages can cause off-normal events during operations. Furthermore, those off-normal events are likely to occur during startup, but startup is a time when personnel are likely to be fatigued, if they have just completed 12 weeks of heavy overtime during the outage.

Extended outages are not the only periods that have been interpreted as being temporary. One operator told PNL staff that operators at his plant worked at least 72 hours a week for a year. If the term "on a temporary basis" is to have any impact, it must be clearly defined by setting limits on hours of work for periods of time that are longer than one week. In specifying quantified limits for longer periods of time, NRC would not be setting a precedent: the U.S. Air Force sets a quantified limit on flight time in a 30-day period, and the Federal Aviation Administration (FAA) sets a limit on flight time in a 30-day period, and in one year.

In the case of a "problem during operation" or an "extended shutdown," we recommend a limit of 112 hours of work in a 14-day period. Like the other limits in Column A of Table 1.1, this limit is taken from the Shift Scheduling Project panel's recommendation. This 1 imit can be reached by working 60 and 52 hours, respectively, in two successive weeks. It is less than double the 
7-day limit, and thus it quantifies present NRC policy to allow work hours up to the 7-day 1imit "on a temporary basis" only.

That a limit of 112 hours in 14 days is justifiable can also be inferred from the fact that federal regulations limit the flight time of airline pilots and crew to 100 hours in a 30-day period, which averages 47 hours in a 14-day period (Appendix F). The U.S. Air Force limits air crew flight time to 125 hours in a 30-day period, which averages 58 hours in a 14-day period (Appendix F). Nicholson's work-hours index sets an upper limit of 77 hours of duty time in a 14-day period. The adaptation of Mohler's index for airline pilots and crew indicates that 112 hours of duty time in 14-days is a high load; 168 hours is (much) too high (Table C.1).

In the case of "unusual circumstances," we recommend a limit of 132 hours of work in a 14-day period.

In the case of "very unusual circumstances," we recommend that NRC authorize no more than 144 hours of work in a 14-day period. This limit can be reached hy working two 72-hour weeks, e.g., 2 weeks composed of six 12-hour days. As the unpublished report by a nuclear utility indicates, based on the utility's observation of its own personnel, productivity begins to decline "drastically" after six 12-hour days, and it is probable that productivity would be even lower after 2 periods of 6 consecutive 12-hour days separated by only 1 day off.

\subsubsection{Basis for Limits on Hours Worked in a 28-Day Period}

In the case of a "problem during operation" or an "extended shutdown," we recommend a limit of 192 hours of work in a 28-day period. Like the other limits in Column $A$ of Table 1.1, this limit is taken from the Shift Scheduling Project panel's recommendation. This limit can be reached by working 60,52 , 40 , and 40 hours, respectively, in 4 successive weeks. It is less than 4 times the 7-day limit, and thus it quantifies present NRC policy to allow work hours up to the 7-day limit "on a temporary basis" only.

Federal regulations limit airline pilots and crew to 100 hours aloft in a 30-day period (Appendix F). The U.S. Air Force limits pilots and crew to 125 hours of flight time in a 30-day period (Appendix F).

In the case of "unusual circumstances," we recomend a limit of 228 hours of work in a 28-day period. This limit can be reached by working $72,60,48$, and 48 hours, respectively, in 4 successive weeks.

In the case of "very unusual circumstances," we recommend that NRC authorize no more than 264 hours of work in a 28-day period. This limit can be reached by working $72,72,60$, and 60 hours, respectively, for 4 successive weeks. 


\subsubsection{Basis for Limits on Hours Worked in One Year}

In the case of a "problem during operation" or an "extended outage," we recommend a limit of 2,260 hours of work in a 1-year period. Like the other limits in Column A of Table 1.1, this limit is taken from the Shift Scheduling Project panel's recommendation. The panel's justification for this limit is that $20 \%$ overtime in a year is considered to be a maximum in other industries. Twenty percent added to the standard 2,000 hours of work per year is 2,400 hours. In order to compensate for the approximate 30 minutes added to the standard 8-hour day by shift turnover time, 2,400 is multiplied by $8 / 8.5$ to produce 2,260 .

In the case of "unusual circumstances," we recomend a limit of 2,300 hours in 1 year. If the normal year consists of 2,000 hours of work, 2,300 hours would represent $15 \%$ overtime. These figures do not include shift turnover time.

In the case of "very unusual circumstances," we recommend that NRC authorize no more than 2,400 hours of work in 1 year. If the normal year consists of 2,000 hours of work, 2,400 hours of work represents $20 \%$ overtime. Based on their survey of 235 nuclear power plant personnel, Bauman et al. (1983, p. 8-13) conclude that "Four-hundred hours per year overtime appears to be the perceived upper limit for personnel acceptance."

The U.S. Air Force sets a limit of 330 hours of flight time in 1 calendar quarter, which implies a limit of 1,320 hours in a year. The FAA sets a limit of 1,000 hours of flight time in 1 year. That the recommended limits for 1 year are more than double the FAA's limits for 1 year is indirect evidence that the limits are not unreasonably low.

\subsubsection{Basis for Making the Policy a Requirement}

We recommend that NRC policy on hours of work be made a requirement for all licensees--not a recommendation that licensees may or may not adopt. It is recognized that making a policy a requirement is a major step. We recomend it because personnel in the nuclear industry often work overtime, because overtime tends to increase human error, because the nuclear plants that have the most overtime could refuse to adopt a policy that is only a non-binding recommendation, and because in general we estimate that the benefits of such a step are expected to outweigh its costs. Furthermore, even though the term "requirement" sounds rigid, the policy itself allows flexibility by allowing NRC to authorize exceeding the upper limits in certain circumstances. By contrast, most government agencies specify limits on hours of work that are legally enforced with no exceptions allowed (see Section 2.8.2).

\subsection{ALTERNATIVE A: MODIFICATION OF PANEL'S RECOMMENDATION}

Alternative $A$ is a modification of the recommendation found in Appendix $A$, which is a report on the recommendations by the Shift Scheduling Project panel members. A draft report of the meeting was sent to all panel members for 
comment. In that draft we included the statement of the consensus of the panelists' views and minority views. All of the members who commented on the draft said that the report was accurate on all important points. All other suggestions have been incorporated into the final report. Appendix A contains the unabridged final report of the panel meeting, including the pane? members" reasons for their conclusions, minority views, and their resumes.

Alternative $A$ is a modification of the panel's recomendation in Appendix A. One difference is that the limits in Alternative A exclude shift turnover time, whereas the limits in the panel's recommendation include shift turn-

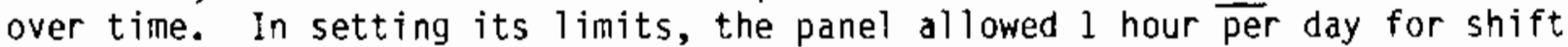
turnover. Thus, to give one example, the panel recommends that limit on hours of work in 1 day in overtime situations be 13 hours, including 1 hour for shift turnover. Alternative A sets the corresponding limit at 12 hours, excluding shift turnover. A second difference is that Alternative A allows overtime for the night shift, whereas the panel's recommendation disallows it.

Alternative $A$ is summarized in Table 2.1. Table 2.2 repeats the information in Table 2.1 and adds some of the calculations (modified to exclude shift

TABLE 2.1. Alternative A--Modification of Panel's Recommendations on Hours of Work in Overtime Situations $(a)$

\begin{tabular}{cr} 
Time Period & Hours of Work \\
\hline 1 day & 12 hours \\
2 days & 20 hours \\
7 days & 60 hours \\
14 days & 112 hours \\
28 days & 192 hours \\
1 year & 2260 hours
\end{tabular}

(a) NOTE:

1. Overtime is allowed for all but one senior reactor operator (SRO), one reactor operator ( $\mathrm{RO})$, and one auxiliary operator (AO) in each unit.

2. In non-emergency situations, exceeding these guidelines is not allowed.

3. In emergency situations, exceeding these guidelines is allowed if the plant manager approves; the utility must subsequently inform NRC and state the reasons. 
TABLE 2.2. Panel's Recommendation on Limits on Hours of Work (including some of the panel's calculations, with modifications) $(a)$

\begin{tabular}{|c|c|c|}
\hline Period & & Hours of Work \\
\hline 1 day & 12 & hrs \\
\hline 2 days & $\begin{array}{r}12 \\
+\quad \frac{8}{20}\end{array}$ & $\begin{array}{l}\text { hrs } \\
\text { hrs }\end{array}$ \\
\hline 7 days & 60 & hrs (see immediately below) \\
\hline 14 days & $\begin{array}{r}12 \\
8 \\
12 \\
8 \\
12 \\
+\quad 8 \\
+\quad 0 \\
60\end{array}$ & $\begin{array}{r}12 \mathrm{hrs} \\
8 \\
12 \\
8 \\
12 \\
0 \\
+\quad 0 \\
+\frac{0}{52}=112 \mathrm{hrs}\end{array}$ \\
\hline 28 days & $\begin{array}{r}60 \\
52 \\
+\quad 40 \\
+\quad 40 \\
192\end{array}$ & $\begin{array}{l}\text { hrs } \\
\text { hrs }\end{array}$ \\
\hline 1 year & $\begin{array}{r}40 \\
\times \quad 50 \\
\times \quad 1 . \\
\times 2400 \\
\times \quad 8 / 8 . \\
2260\end{array}$ & 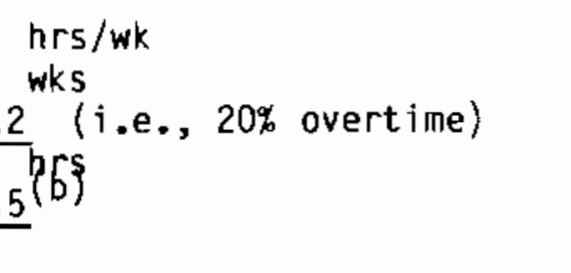 \\
\hline
\end{tabular}

(a) NOTE:

1. Overtime allowed for all but one senior reactor operator (SRO), one reactor operator (RO), and one auxiliary operator $(A O)$ in each unit.

2. In non-emergency situations, exceeding these guidelines is not allowed.

3. In emergency situations, exceeding these guidelines is allowed if the plant manager approves; the utility must subsequently inform NRC and state the reasons.

(b) The ratio $8 / 8.5$ is used to convert the panel's recommended limit including shift turnover time, to the equivalent $l i$ mit excluding shift turnover time. If 30 minutes is allowed for shift turnover time, the length of a working day including shift turnover time becomes 8.5 hours. 
turnover time) that the panel used to derive their recommended limits. For example, Table 2.2 shows that the recommended limit on hours of work in 2 days is 20 hours, which can be reached by working 12 hours one day and 8 hours the next day.

Present NRC policy allows deviation from its stated guidelines in "very unusual circumstances" if the plant manager approves the deviation. The panelists thought that the term "very unusual circumstances" could be interpreted too flexibly, which would allow a plant manager to approve deviations too often, possibly to the point of seriously weakening the original intent of the guidelines. For this reason, the panel recommends that plant personnel be allowed to exceed the guidelines only in the case of a true emergency. Otherwise, the panel recommends that the guidelines be considered a legal limit on hours of work, in the same sense that the guidelines on hours of work for airline pilots, railroad operators, and truckers are legal limits, enforceable under the law.

The panel recommends that whenever the plant manager authorizes deviations from the guidelines, the utility be required to inform NRC and state the reasons why deviation was required.

\subsection{ALTERNATIVE B: MAINTAIN THE STATUS QUO--PRESENT NRC POLICY}

Present NRC policy on hours of work is in one sense a recommendation, which licensees may or may not adopt, and is in another sense a legally enforceable requirement: NRC recommends that licensees incorporate into their technical specifications a one-page statement concerning hours of work. (The one-page statement, entitled "Policy on Factors Causing Fatigue of operating Personnel at Nuclear Reactors," is a part of Generic Letter 82-12, reproduced in Appendix E.) on the other hand, if a licensee incorporates the statement into its technical specifications, the statement's provisions then become legally enforceable requirements for that licensee.

Our interpretation of present NRC policy is summarized in Table 2.3. Table 2.3 indicates, for example, that present NRC policy establishes a maximum of 16 hours of work in a period of 24-consecutive hours (in the event of a "problem during operation").

Present NRC policy distinguishes among four situations: 1) routine operation, 2) unforeseen problem during operation, 3) extended shutdown, and 4) very unusual circumstances. NRC policy for the first situation, routine operation, is discussed in Chapter 3 of this report. NRC's policies for the other three situations are described briefly below.

\subsubsection{Unforeseen Problem During Operation}

An unforeseen problem during operation typically refers to the unexpected absence of an individual due to illness, injury, etc. As is stated in the 
IABLE 2.3. Present NRC Policy on Hours of Work (a)

\begin{tabular}{cc} 
Time Period & Hours of Work \\
\cline { 1 - 1 } 1 day & 16 hours \\
2 days & 24 hours \\
7 days & 72 hours
\end{tabular}
(a) NOTE:
1. In case of a problem during operation, limits for overtime apply to individuals only; limits for routine operation apply to the remainder of the crew.
2. During an extended shutdown, overtime limits apply to the entire crew.
3. During very unusual circumstances, over- time 1 imits may be exceeded if the plant manager approves.

footnote in Table 2.3, in the event of an "unforeseen problem during operation," overtime is allowed on an individual basis only; the remainder of the crew is limited to the (lower) hourly limits of the crew's routine schedule.

\subsubsection{Extended Shutdown}

Plants can have periods of shutdown for one to three months for refueling, major maintenance, or major plant modifications. As is stated in footnote (a) in Table 2.3, however, unlike an "unforeseen problem during operation," the limits for "extended shutdowns" apply to the entire staff on shift, not just to individuals.

\subsubsection{Very Unusual Circumstances}

During "very unusual circumstances," a plant may deviate from the guidelines in Table 2.3, if such deviations are authorized by the plant manager, his deputy, or higher levels of management (See Appendix E).

\subsubsection{Utilities' Administrative Requirements}

According to NRC's policy statement in Generic Letter 82-12 (see Appendix E), plant management must approve deviations from the guidelines in the policy statement, the approval must be documented, and the documents must be available for NRC review. 


\subsection{ALTERNATIVE C: REQUIRE THAT LICENSEES INFORM NRC WHEN SAFETY-RELATED}

PERSONNEL EXCEED SPECIFIED HOURS OF WORK

Alternative $C$ is identical to the recommendation with one exception. In the recommendation, licensees would be required to obtain NRC authorization in order to permit its safety-related personnel to exceed the hours of work in Column $B$ of Table 1.1. In Alternative $C$, however, licensees would only be required to inform NRC if safety-related personnel were expected to exceed the hours of work in Column $B$.

In a sense, Alternative $C$ can be considered a special case of the recommendation. Under the recommendation, one option available to NRC is to adopt a policy of routinely authorizing all requests. Such a policy is, in effect, merely a requirement to inform NRC.

Alternative $C$ has two advantages: 1) because Alternative $C$ limits NRC's options, it makes NRC policy more strictly defined and predictable; and 2) Alternative $C$ does not require that NRC establish a special mechanism that would grant, in a timely manner, authorization to exceed the limits in Column $B$ of Table 1.1. Alternative $C$ is discussed further in the following section.

\subsection{ALTERNATIVE D: SET LIMITS ON HOURS OF WORK THAT ARE LEGALLY ENFORCED}

Like Alternative $C$, Alternative $D$ is identical to the recommendation except in its interpretation of Column B in Table 1.1. In Alternative D, the limits in Column B are legally enforced with no exceptions allowed.

Like Alternative $C$, Alternative $D$ can be considered a special case of the recommendation. Under the recommendation, one option available to NRC is to adopt a policy of routinely denying all requests for authorization to exceed the limits in column B unless the plant is experiencing "very unusual circumstances," which may be defined to be any of the four levels of emergencies specified in the plant's Emergency Plan Implementing Procedures. This option would, in effect, be similar to setting limits that are legally enforced.

Alternatives $C$ and $D$ have the same two advantages: 1) they are more strictly defined and predictable; and 2) they do not require that NRC establish a mechanism that would grant, in a timely manner, authorization to exceed the limits in Column B of Table 1.1.

Even though Alternatives $C$ and $D$ have these advantages, the recommendation has the advantage of flexibility. With this flexibility, NRC could:

- adopt a policy similar to Alternative C

- adopt a policy similar to Alternative D 
- treat each request for authorization to exceed the limits in Column B of Table 1.1 on a case-by-case basis

- modify its policy after an initial transition period

- allow NRC regtonal offices to set policies that are appropriate for their regions.

\subsection{SUMMARY}

The first section of this summary compares the numerical limits on hours of work among the recommendation and the major alternatives. The second section compares the proposed legal status of the same set of alternatives.

\subsubsection{Summary Comparison of Limits on Hours of Work}

Table 2.4 compares limits on hours of work among 1) present NRC policy, 2) project staff recommendations, 3) the panel's recommendations, 4) the U.S. Air Force, 5) the trucking industry, 6) the railroad industry, and 7) the airline industry. Table 2.4 summarizes information found in Tables $1.1,2.1$, $2.3, F .1$, and F.2.

\section{TABLE 2.4. Comparison of Limits on Hours of Work}

\begin{tabular}{|c|c|c|c|c|c|c|c|c|}
\hline & & $\begin{array}{l}\text { Proje } \\
\quad \text { Re } \\
\end{array}$ & $\begin{array}{l}\text { Staff } \\
\text { im. }\end{array}$ & Panel & & & $\begin{array}{l}\text {-Nucl } \\
\text { lustrit }\end{array}$ & \\
\hline & Policy & $\overline{\mathrm{Col} . \mathrm{A}}$ & Col. B & Recomm. & Force $^{(a)}$ & Iruck & $\mathrm{RR}$ & Air \\
\hline 1 day & 16 & $12(16)$ & - & 12 & 12 & 10 & 12 & 8 \\
\hline 2 days & 24 & 24 & - & 20 & {$[24]^{(b)}$} & [20] & [24] & [16] \\
\hline 7 days & 72 & 60 & 72 & 60 & - & 60 & - & 30 \\
\hline 14 days & [144] & 112 & 132 & 112 & - & [120] & - & {$[60]$} \\
\hline $28 \operatorname{days}(c)$ & - & 192 & 228 & 192 & 125 & - & - & 100 \\
\hline 1 qtr. & - & {$[626]$} & [734] & [626] & 330 & - & - & 300 \\
\hline 1 year & - & 2260 & 2300 & 2260 & [1320] & - & - & 1000 \\
\hline
\end{tabular}

(a) The source for information on Air Force is: U.S. Department of Defense, Department of Air Force, January 2, 1975, AFR 60-1, pp. 7-1 to 7-3. This document is not available to the public. For more information on Air Force regulations, see Appendix F.

(b) Numbers in brackets are extrapolations of limits from one time period to the next longer time period.

(c) For Air Force and airline pilots and crew, the time period is 30 days. 
In general, the limits in Table 2.4 are presented in descending order from left to right. Present NRC limits are the highest, our recommended limits are next highest, etc. Of course, any comparison must consider differences in the various occupations. Nonetheless, a comparison of the numerical limits suggests that present NRC limits are high and that our recommended limits are not unreasonably low.

\subsubsection{Comparison of the Legal Status of Limits on Hours of Work}

Table 2.5 compares the legal status of the various policies on hours of work for the same industries and organizations listed in Table 2.4. In Table 2.5, the industries and organizations are arranged in ascending order of the legal status of their policies. The legal status of present NRC policy is lowest because licensees are not legally required to adopt NRC's policy.

The legal status of the Air Force limits and Column A of our recommendation are next lowest because the limits may be exceeded with management approval. (In the Air Force, however, the 1 imits may be exceeded with the approval of no less than the Major Commander of an Air Force Command, of which there are only eight.)

The legal status of the limits in Column B of our recomnendation is unique; they are the only limits that may be exceeded with the approval of a federal regulatory agency, in this case NRC.

Tables 2.4 and 2.5 together suggest that present NRC limits on hours of work are high, that the legal status of NRC's policies is weak compared to that of other agencies of the government, and that our recomenended limits are not unreasonably high, nor is the legal status of our recomended policies unreasonably strong.

TABLE 2.5. Comparison of Legal Status of Limits on Hours of Work

Limits legally enforced
$\begin{aligned} & \text { PRC } \\ & \text { with no exceptions } \\ & \text { allowed }\end{aligned}$

Limits may be exceeded

with approval of

regulatory agency

May be exceeded with

management approval

$x x x \quad x x x$

May be exceeded with

$x \times x$

management approval if

the licensee adopts

NRC's recommendation 



\subsection{BASIS FOR RECOMMENDATION ON ROUTINE 8-HOUR/DAY SCHEDULES}

The recommendation for an NRC policy statement on routine 8-hour/day shift schedules was presented in Section 1.2. Because the recommended policy statement is short, Section 3.1 below repeats its provisions. Section 3.2 presents the basis for the recommendation. Section 3.3 summarizes the Shift Scheduling Project panel's recomendation (the full statement of the panel's recommendations is presented in Appendix A). Section 3.4 describes present NRC policy. Section 3.5 is a sumary comparison, in tabular form, of the project staff's recommendation, the panel's recommendation and present NRC policy.

Although the issue of overtime is probably more salient than routine shift schedules in the nuclear industry at this time, routine schedules can also augment or reduce fatigue, and is an issue of considerable interest to operators. Two types of routine schedule exist: 8-hour/day schedules, which are discussed in this chapter, and 12-hour/day schedules, which are discussed in Chapter 4.

\subsection{PROJECT STAFF RECOMMENDATION}

We recommend that the NRC policy statement on routine 8-hour/day work schedules essentially remain a nonbinding recommendation but that it add the following recommendations:

1. The schedule should be limited to a maximurn of 7 consecutive days of work.

2. The schedule should not exceed 21 days of work (including training) in any 4-week period.

3. The schedule should include at least 2 consecutive full days off in any period of 9 consecutive days.

4. A series of night shifts should be followed by at least 2 full days of rest.

5. The schedule should rotate forward, not backward.

\subsection{BASIS FOR THE RECOMMENDATION}

Section 3.2.1 defines the term "iong change." Sections 3.2.2 through 3.2.4 present the basis for three recommendations that are related to a long change. Sections 3.2.5 through 3.2.8 present the basis for the remainder of the recommendations. 


\subsubsection{A Schedule's "Long Change"}

A "long change" is a series of consecutive days off that is significantly longer than the other series of days off in one cycle of a shift schedule. A long change is typically 4 to 5 days off, although some long changes are 6 to 7 days off. A series of only 3 days off is not very different from the normal weekend and would probably not be considered a long change. Shift cycles are typically 4 to 6 weeks in length. Twelve sample shift schedules are shown in Appendix G. Schedule No. 1 in Appendix $G$ is a typical example; its long change is 4 days, from Saturday through Tuesday, and its cycle is 5 weeks, so the schedule provides 4 consecutive days off once every 5 weeks. Schedule No. 7 is another example; its long change is 4 days, also from Saturday through Tuesday, and its cycle is 4 weeks, so the schedule provides 4 consecutive days off once every 4 weeks.

A schedule need not have a long change; if all of the rest periods in a cycle are the same number of days, then none of the rest periods can be called a long change. For example, the rest periods in Schedule No. 2 are all approximately the same duration, between 2 and 3 days in length.

A long change is often important for the social life, recreation, and morale of shift workers. Whereas rotating shift work often isolates shift workers from family and friends, a long change provides an opportunity to socialize. It also provides an opportunity to travel, to take a short vacation, etc. For these reasons, shift workers often prefer schedules with a long change that is as long as possible.

However, given that shift workers average 40 hours of work per week over the cycle of the shift schedule, every day off added to a long change has to be made up by adding a day of work (or subtracting a day of rest) somewhere else in the schedule. The resulting schedule contains a long string of work days, interrupted by only short rest periods. During this long string of work days, evidence indicates that fatigue accumulates, increasing fatigue on the job. This evidence suggests that schedules without a long change would in general produce Tess fatigue on the job.

Table 3.1 shows how a long change can be gained by scheduling more work into the remaining work period. Table 3.1 shows the greatest number of work days in a 28-day period, the number of hours in the shortest break, and the number of hours in the longest break (i.e., the long change). The schedules, which are currently in use in the nuclear power industry, are Schedules No. 1-5 and 7 in Appendix G. They are listed in descending order of the length of the long change. The figures for the normal work week have been added for comparative purposes.

\subsubsection{Basis for a Maximum of 7 Consecutive Days of Work}

The requirements of continuous operation, 24 hours a day, 7 days a week, are such that rotating shift schedules rarely conform to a standard 5-day work week. Most rotating shift schedules contain series of 6 to 7 consecutive days 
TABLE 3.1. Characteristics of Six Shift Schedules

\begin{tabular}{|c|c|c|c|c|}
\hline $\begin{array}{l}\text { Schedule } \\
\text { Number } \\
\text { (App. G) }\end{array}$ & $\begin{array}{l}\text { Greatest number } \\
\text { of work days } \\
\text { in } 28 \text {-day period }\end{array}$ & $\begin{array}{l}\text { Hours in } \\
\text { shortest } \\
\text { break }(a) \\
\end{array}$ & $\begin{array}{l}\text { Hours in } \\
\text { longest } \\
\text { break a) }\end{array}$ & $=\begin{array}{c}\begin{array}{c}\text { Days + hours } \\
\text { in longest } \\
\text { break }\end{array} \\
\end{array}$ \\
\hline 7 & 20 & 48 & 120 & $=5$ days \\
\hline 5 & 22 & 56 & 120 & 5 days \\
\hline 3 & $23^{(b)}$ & 48 & 112 & 4 days $+16 \mathrm{hrs}$ \\
\hline 1 & 22 & 56 & 104 & 4 days $+8 \mathrm{hrs}$ \\
\hline 4 & 21 & 64 & 88 & 3 days $+16 \mathrm{hrs}$ \\
\hline 2 & 21 & 72 & 72 & 3 days \\
\hline $\begin{array}{l}\text { Norma l } \\
\text { workweek }\end{array}$ & 20 & 64 & 64 & 2 days $+16 \mathrm{hrs}$ \\
\hline
\end{tabular}

(a) As is explained in the introduction to Appendix G, the information on these schedules is incomplete, so the figures might be inaccurate in particular cases. Nonetheless, the mathenatical relationships are the same, and the point of the table is still valid.

(b) Days 22 and 23 are scheduled for training.

of work. Evidence indicates that fatigue accumulates toward the end of such a long series of work days. Even though schedules with 7 consecutive night shifts are common in America, European researchers consider 7 consecut ive night shifts to be "highly unphysiological" (Colquhoun and Rutenfranz 1980, p. 408).

Scheduling 8 consecutive work days is not necessary, because satisfactory schedules with only 7 consecutive work days exist. Schedules with 8 consecutive work days should especially be discouraged if the primary reason for the 8 th work day is to add an extra day to the long change.

\subsubsection{Basis for a Maximum of 21 Hork Days in 4 Weeks}

The reason for recommending a maximum of 21 work days in 4 weeks is similar to the reason for recommending a maximum of 7 consecutive days of work: 1) schedules exist that do not exceed that maximum, 2) the usual reason for wanting to exceed that maximum is to lengthen the long change, but that is accomplished by unduly increasing accumulated fatigue on the job.

Table 3.1 lists the greatest number of work days in a 28-day period for 6 schedules. In one of these schedules the greatest number of work days in 28 consecutive days is 20 ; in two schedules the greatest number is 21 ; and in two schedules the greatest number is 22 . Finally, in one schedule the greatest number is 23 , but in that schedule, days 22 and 23 are scheduled for training. 


\subsubsection{Basis for 2 Full Days off in 9 Consecutive Days}

The term "two full days," as it is used here, refers to the number of hours in a normal weekend, i.e., 64 hours. The basis for the recommendation of 2 full days off in 9 consecutive days is essentially the same as the basis for the previous two recommendations. The usual reason that shift workers want less than 2 full days off is to lengthen the long change. This can only be accomplished, however, by scheduling more work days into the remainder of the shift cycle, and that increases fatigue on the job.

\subsubsection{Basis for Rest Following Night Shift}

A series of 6 or 7 consecutive night shifts should be followed by at least 2 full days off. If the schedule has a long change, it should be scheduled after the night shift.

of the three shifts, the night shift disturbs one's circadian rhythms(a) most. During both the morning and afternoon shifts, one can sleep at approximately normal nighttime hours. During the night shift, however, one must work when one normally would sleep. Furthermore, day sleep is usually more difficult than night sleep, so a sleep deficit accrues. Thus, a longer rest period is advisable after the night shift for two reasons: 1) to readjust one's circadian rhythms to day work and night sleep, and 2) to dispel an accumulated sleep deficit.

\subsubsection{Basis for Forward Rotation}

The theoretical reason for recommending forward, not backward, rotation is that forward rotation (also called rotation by phase delay) allows faster adjustment of circadian rhythms if 1) the worker anticipates the next shift and begins to adjust his sleep/wake cycle before rotation, and 2) the worker maintains the sleep/wake cycle appropriate for work even on days off. Another condition of a successful rotation is a sufficient number of days off between rotations. If these conditions are not met, a forward rotation may fail to reduce fatigue.

The Shift Scheduling Project literature review (Lewis 1985) analyzed the evidence on direction of rotation and concluded as follows ( $p . v)$ :

Direction of rotation (forward vs. backward) is not a major issue in the literature. Although one experiment at a Utah potash factory suggests that forward rotation is preferable, the designers of that

(a) Circadian rhythms are bodily rhythms that oscillate within a period of approximately 1 day (circa = approximately, dian = day). The sleep/wake cycle is the most obvious circadian rhythm. Body temperature, gastric secretions, and many other bodily functions also have circadian rhythms. 
experiment themselves say that more research is needed before applying that result to other industries. If forward rotation has benefits, those benefits are probably sinall compared to the effects of the length and distribution of rest periods between rotations.

This conclusion still holds, as can be seen by the above conditions that are required for a successful forward rotation. Since the writing of the literature review, however, more researchers have expressed their belief, which they admit is without firm evidence, that given the proper conditions, forward rotation is better. [See, for example, the Shift Scheduling Project panel report in Appendix $A$, and Knauth and Rutenfranz in Kogi, Takahashi and Onishi (1982, pp. 361-362)]. Also since the writing of the literature review, project staff have interviewed more operators who do anticipate the next rotation with their sleep/wake schedules. Most of those operators find forward rotation less fatiguing. Finally, the primary reason for desiring a backward rotation is to lengthen the long change; those extra hours or days in the long change, however, are gained at the expense of additional fatigue on work days. Considering this evidence and the necessary conditions for a successful rotation, forward rotation is recommended.

\subsubsection{Basis for Making the Recommendations Nonbinding}

The primary reason for making nonbinding recommendations, instead of enforceable regulations, is that routine schedules can be superseded almost on a routine basis by overtime. When overtime becomes common, the hours people actually work are quite different from the hours of work indicated by the routine schedule, and so the exact form of the routine schedule has little significance.

Present NRC policy states that "enough plant operating personnel should be employed to maintain adequate shift coverage without routine heavy use of overtime," but this policy statement does not explicitly rule out the routine use of light overtime, in which case the routine schedule is still superseded. Even the recommendation concerning limits on hours of work (Chapter 1) does not rule out the routine use of light overtime: in the case of a "problem during operation," such as a temporary shortage of operators, personnel may work up to 2,260 hours per year. That limit is 260 hours more than the standard of 2,000 hours per year and is equivalent to 32 additional 8-hour days or working Monday through Saturday for over 7 months of the year. Thus, even under the recommendation on hours of work, overtime can overshadow routine schedules, which reduces the importance and effect of an NRC policy on routine schedules.

Another difficulty in establishing a binding policy on routine schedules is that the line between a routine schedule and overtime is sometimes indistinct. For example, at some nuclear plants where staffing is short, whenever one group of operators goes on training for one or more weeks, other operators go on a 12-hour/day schedule to fill in for them in the control room. Is the 12-hour/day schedule then a "routine schedule," a "semi-routine schedule," or an "overtime schedule"? Such conditions make a strict definition of "routine schedule" complicated and would make NRC oversight cumbersome. 
3.3 ALTERNATIVE A: PANEL RECOMMENDATION--REQUIRE NRC APPROVAL TO DEVIATE FROM GUIDELINES

The recommendation of the Shift Scheduling Project panel is a set of guidelines for 8-hour/day routine schedules; if a plant wishes to exceed these guidelines (either with a variant of an 8-hour/day schedule or with a 12-hour/ day schedule), it must first obtain NRC's approval.

The panel's guidelines in essence recommend 8-hour/day schedules that average of 40 hours of work per week. Recognizing, however, that rotating shift schedules are inherently irregular, the panel made the following specific recommendations:

1. The schedules should be limited to a maximum of 6 consecutive days of work.

2. The schedule should not exceed 20 days (160 hours) of work in any 4-week period.

For a more complete description of the panel's recommendation, see Appendix A.

\subsection{ALTERNATIVE B: MAINTAIN THE STATUS QUO--PRESENT NRC POLICY}

Present NRC policy recommends a routine schedule with an 8-hour day and a 40-hour week: "The objective is to have operating personnel work a nomal 8-hour day, 40-hour week while the plant is operating" (see Appendix E). This is a recommendation only; if a plant wishes to deviate from the recommendation, it is obliged neither to inform NRC nor to obtain NRC approval to do so. Most plants deviate from this recommendation to some degree. A few plants have deviated to a considerable degree by adopting 12-hour/day routine schedules (with NRC's implicit approval).

\subsection{SUMMARY}

The main characteristics of the project staff's recommendations, the panel's recommendations, and present NRC policy are summarized in Table 3.2. The single most important difference is that both our recommendations and present NRC policy are nonbinding recommendations, whereas the panel recommends that utilities be required to obtain NRC approval to exceed the guidelines. 
IABLE 3.2. Comparison of Policies for Routine 8-Hour/Day Schedules

\begin{tabular}{|c|c|c|c|}
\hline & $\begin{array}{l}\text { Project Staff } \\
\text { Recommendation }\end{array}$ & $\begin{array}{c}\text { Panel } \\
\text { Recommendation }\end{array}$ & $\begin{array}{l}\text { Present } \\
\text { NRC Policy }\end{array}$ \\
\hline $\begin{array}{l}\text { Status of } \\
\text { guidelines }\end{array}$ & Nonbinding & $\begin{array}{l}\text { To exceed guide- } \\
\text { lines requires } \\
\text { NRC approval }\end{array}$ & Nonbinding \\
\hline $\begin{array}{l}\text { Guidelines } \\
\text { for about } \\
\text { one week }\end{array}$ & $\begin{array}{l}\text { Maximum of } 7 \\
\text { work days in } \\
9 \text {-day period }\end{array}$ & $\begin{array}{l}\text { Maximum of } 6 \\
\text { consecutive work } \\
\text { days }\end{array}$ & $\begin{array}{l}5 \text { work days in } 1 \\
\text { week }\end{array}$ \\
\hline $\begin{array}{l}\text { Guidelines } \\
\text { for } 4 \text { weeks }\end{array}$ & $\begin{array}{l}\text { Maximum of } 22 \\
\text { work days in } \\
4 \text { weeks }\end{array}$ & $\begin{array}{l}\text { Maximum of } 20 \\
\text { work days in } \\
4 \text { weeks }\end{array}$ & $\ldots(a)$ \\
\hline
\end{tabular}

(a) NRC does not have a policy for 4 weeks. 



\subsection{BASIS FOR RECOMMENDATION ON ROUTINE 12-HOUR/OAY SCHEDULES}

The project staff recommends that licensees be required to obtain NRC approval in order to adopt a 12-hour/day routine schedule and that NRC establish criteria for granting such approval.

Present NRC policy recommends a routine schedule of 8 hours of work per day. However, NRC has implicitly allowed several nuclear plants to adopt routine schedules with 12 hours of work per day. NRC officials are informally monitoring the effects of the schedules in those plants. Schedule No. 6 in Appendix $G$ is the 12-hour/day schedule for two of those plants.

Many nuclear power plants temporarily adopt 12-hour/day schedules when overtime is expected to continue for a period of time. These temporary 12-hour/day schedules, however, can be distinguished from routine 12-hour/day schedules by the fact that work hours greatly exceed an average of 40 per week. An even clearer distinguishing characteristic of routine 12-hour/day schedules is a renegotiation of the basic wage rate, so that base pay plus "overtime pay" (i.e., the legally required "overtime pay" for working in excess of 8 hours per day) yields the same total salary as did the previous routine 8-hour/day schedule.

The recommendation for an NRC policy statement on routine 12-hour/day shift schedules was presented in Section 1.1. In this chapter, Section 4.1 repeats the recommendation and explains it more fully; Section 4.2 presents the basis for the recommendation; and Section 4.3 summarizes criteria for approving a routine 12-hour/day schedule.

\subsection{RECOMMENDATION: REQUIRE NRC APPROVAL TO AOOPT ROUTINE 12-HOUR/DAY SCHEDULES}

The basic recommendation concerning routine 12-hour/day schedules is the same as that of the Shift Scheduling Project panel--that nuclear plants be required to obtain NRC approval in order to adopt a 12-hour/day routine schedule, and that NRC establish criteria for granting such approval. The Shift Scheduling Project panel recommended certain criteria (described in Appendix A) and suggested that the PNL project staff develop the criteria in greater detail. Following the panel's suggestion, we recommend the following primary criteria:

1. The schedule should contain a maximum of 4 consecutive 12-hour work days.

2. Four consecutive 12-hour work days should be followed by no fewer than 4 days of $f$.

3. The basic 12-hour/day schedule should be "2-on, 2-off," "3-on, 3-off," "4-on, 4-off," or a systematic combination of these such as the "every-other-weekend-off" schedule, which combines "2-on, 2-off" with "3-on, 3-off" (Schedule No. 10 in Appendix G). (To a certain 
extent this criterion repeats the first two criteria. The point is to provide adequate rest after a series of 12-hour work days before beginning another series.)

4. The general safety record of the plant should be satisfactory, based on criteria such as those used in NRC's Systematic Assessment of Licensee Performance (SALP) ratings.

5. The plant should have the ability to cover unexpected absences satisfactorily without having any individual work more than 12 hours per day.

6. The round-trip cormute times for the operators should not exceed $21 / 2$ hours.

The first three primary criteria are important and should be adhered to. However, if a plant's record on the other criteria (4-6) is strong, a minor deviation may be allowed. An example of a minor deviation occurs in Schedule No. 6 in Appendix $G$, which is basically a "4-on, 4-off" 12-hour/day schedule. That schedule, however, contains one sequence of "4-on, 3-off, 4-on." This deviation occurs only once in the 10-week cycle. Thus, it can be considered a minor deviation. In addition to the primary criteria listed above, NRC should also consider but give less emphasis to secondary criteria, which are discussed in Section 4.3 .

\subsection{BASIS FOR RECOMMENDATION}

Although routine 12-hour/day schedules are becoming more popular, the number of plants using them is still small compared to the number of plants using routine 8-hour/day schedules. Although increased recent experience with routine 12-hour/day schedules is providing additional evidence that personnel on 12-hour/day schedules can perform satisfactorily, a certain amount of evidence to the contrary also exists, so some controversy remains.

Both sides of this issue were argued forcefully at the meeting of the Shift Scheduling Project panel. One panelist stated that the operational data he collected in the petrochenical industry give no indication that a 12-hour/ day schedule degrades performance. Another panelist, however, stated that in a literature review by Kelly and Schneider (1982), it was estimated that the overall probability of human error for a 12-hour shift is twice that for an 8-hour shift. Kelly and Schneider therefore concluded that before deciding whether a particular plant should be allowed to adopt a 12-hour shift, the operators' safety records must be examined, and the consequences of an accident must be considered. However, the consensus of the entire panel was that if the criteria are satisfied, a nuclear power plant can adopt a routine 12-hour/day schedule and continue to operate the plant with an adequate margin of safety. Therefore, the pane? recommends that NRC consider each case individually and judge it by the criteria mentioned above, before granting it approval to adopt a routine 12-hour/day schedule. The panel's recommendation coincides with the 
recommendations of two of Europe's leading experts on shift scheduling, Knauth and Rutenfranz (in Kogi, Miura and Saito, eds. 1982, pp. 357-358), who state:

Systematic and long-term research is necessary before shift lengths of more than $8 \mathrm{hr}$ can be generally accepted. However, in exceptional cases when limitations concerning the work load ... and the sleep of shift workers have been included as criteria, $12 \mathrm{hr}$ shift systems have operated satisfactorily.

\subsubsection{Basis for a Maximum of 4 Consecutive 12-Hour Work Days}

The first three criteria for allowing a 12-hour shift schedule are related and are all based on the following evidence. Of the typical 12-hour/day schedules in use in the petrochemical industries in the United States (Northrup, Wilson and Rose 1979, pp. 315-316) and in Europe (Colquhoun and Rutenfranz 1980, pp. 407-413), some have as many as 4 consecutive 12-hour work days, and none have more than that. Three nuclear power plants that adopted "4-on, 4-off" 12-hour schedules are generally very satisfied with their schedules. Another nuclear power plant adopted a "4-on, 2-off" schedule, but later abandoned it because the operators became too fatigued.

\subsubsection{Basis for Considering the General Safety Record of the Plant}

Although every year more nuclear power plants are adopting routine 12-hour/day shift schedules and although the bulk of the evidence collected so far indicates that 12 -hour shifts not only are safe but also raise employee morale, 12-hour/day schedules are still relatively new and unusual compared to routine 8-hour/day schedules. Until NRC and the nuclear industry gain more experience with 12-hour shifts, we recommend that NRC exercise a certain degree of caution by considering the overall safety record of licensees that apply for NRC approval to adopt a routine 12-hour/day schedule.

We recommend that a plant's safety record be examined because if a 12-hour shift does in some way reduce the margin of safety of a plant, the remaining margin of safety would evidently be greater for those plants that initially have strong overall performance and safety ratings than for plants with lower ratings. For example, if NRC were to receive imnediately a large number of applications for approval to adopt a routine 12-hour/day schedule, we recommend that NRC proceed cautiously by first granting approval only to those plants with the best overall safety records.

The recommended criterion (the licensee's performance and safety record) is similar to the criterion used by a task group that was formed at Ontario Hydro in 1981. The objective of the task group was to evaluate the potential effects of changing from an 8-hour/day schedule to a 12-hour/day schedule at Ontario Hydro's nuclear power plants and at its Bruce Heavy Water Plant to recommend for or against 12-hour shift schedules at those facilities (Kelly and Schneider 1982, p. 369). At the time Ontario Hydro's task group was formed, the Bruce Heavy Water Plant had already been on a routine 12-hour/day shift schedule for over a year. 
The task group compared shift crew error data for the 12-hr and 8-hr shift periods at the Bruce Heavy Water Plant and was not able to identify any significant change in error frequency or magnitude. However, this was not accepted as convincing evidence of no impact because of the coarseness of the data (Kelly and Schneider 1982, p. 371). The task group then examined previous research conducted in non-nuclear industries. Based on that research, the task group predicted that by changing from an 8-hour/day to a 12-hour/day schedule, the error rate for safety-related shift workers at the Bruce Heavy Water Plant would increase by $80 \%$ to $180 \%$, and that the error rate for safety-related shift workers at its nuclear power plants would approximately double (p. 381).

The task group then considered the effect of doubling the human error rate on the risk to public health and safety. Ontario Hydro's task group reasoned that if the human error rate with a routine 8-hour/day schedule were very low at a particular plant, and if the plant's margin of safety were large, a doubling of the human error rate would still allow for a fully satisfactory margin of public safety for the plant. If, on the other hand, the margin of safety at a particular plant were already relatively small, then a doubling of the human error rate would not be acceptable, and the task group would recommend against that plant's adopting a routine 12-hour/day shift schedule.

As early as 1962, Ontario Hydro had adopted a "comprehensive, systematic and quantitative method for measuring, analyzing, and maintaining acceptable public safety risk during operation" (Kelly and Schneider 1982, p. 370). "Since the margin between the target and actual performance (as measured by the quantitative measures) was very small for some of the nuclear generating stations ... on an 8-hr shift schedule, the task group estimated the predicted increased error rates for 12-hr shifts would not be acceptable. Thus, the task group recommendation was not to support $12-\mathrm{hr}$ shifts for nuclear generating stations" ( $p .381)$.

Performance criteria for the Bruce Heavy Water Plant were not as well developed as the performance criteria for Ontario Hydro's nuclear power plants. The task group therefore restricted itself to public safety considerations and recommended against continuing the routine 12-hour/day schedule at Bruce Heavy Water Plant (Kelly and Schneider 1982, p. 381).

In the end, the task group's recommendations were not followed. Ontario Hydro and the Canadian Atomic Energy Control Board allowed the Bruce Heavy Water Plant to continue its 12-hour schedule and allowed its nuclear power plants to adopt 12-hour schedules in November, 1984. The Control Board did, however, exercise a certain degree of caution in requiring that Ontario Hydro set up a special program to monitor the effect of the 12-hour schedule on quantitative measures of plant safety during an initial trial period.

\subsubsection{Basis for Requiring a Demonstrated Ability to Cover Absences}

With an 8-hour shift, a common way to cover an unexpected absence is to have someone work a double shift, which is 16 consecutive hours of work. As was mentioned above, 16 consecutive hours of work should be considered a maximum and allowed only infrequently and only when the rest of the crew works a 
normal schedule and remains relatively "fresh." With a 12 -hour shift, a double shift would be 24 hours in length, which is too long. Thus, some other provision must be made for covering absences, such as 1) maintaining some people on call, and 2) staffing each crew with extra operators.

\subsubsection{Basis for Considering Commute Time}

The Shift Scheduling Project panel recommended that time available for sleep be considered an important criterion in judging an application for a 12-hour/day schedule. One important constraint mentioned by the panel is commute time. The following passage is taken from the report on the panel meeting (Appendix A, P. A.9).

Because many nuclear power plants are located in isolated areas, oneway commute times of 90 minutes are not uncommon. A 3-hour roundtrip drive could reduce time available for sleep. Thus, in considering the merits of an application, NRC should make a rough estimate of the daily schedules of operators having the longest commute times. In the following hypothetical example, a 3-hour round-trip commute leaves only 6 hours for sleep:

$\begin{array}{lc}\text { Work } & 12: 00 \text { hours } \\ \text { Shift turnover time } & 0: 30 \\ \text { Round-trip commute } & 3: 00 \\ \text { Before work shower \& breakfast } & 1: 00 \\ \text { After work dinner \& preparation for bed } & 1: 30 \\ \text { Sleep } & \underline{6: 00} \\ \quad \text { Total } & 24: 00 \text { hours }\end{array}$

In addition to the Shift Scheduling Project panel, European experts Knauth and Rutenfranz, in the passage quoted above, specifically include adequate sleep as a criterion for the acceptability of a 12-hour/day schedule. Operators and their families should understand that 12 hours of work leaves essentially no time for recreation on work days.

\subsubsection{Basis for Requiring NRC Approval}

Most authorities on shift scheduling agree that 12-hour/day shift schedules may be adopted if certain criteria are met. NRC has the responsibility to determine whether the criteria are met. Furthermore, by requiring approval, NRC can control the rate at which routine 12-hour/day schedules are adopted by the nuclear industry.

\subsection{CRITERIA FOR ALLOWING ROUTINE 12-HOUR/DAY SCHEDULE}

When considering an application to adopt a routine 12-hour/day schedule, NRC should consult the checklist of advantages and disadvantages of routine 
12-hour/day schedules presented below. The checklist includes some of the items recommended in Section 4.1 as primary criteria. It also contains other factors that can be considered to be secondary criteria. Some of the items on the checklist are fairly well documented, whereas others are speculative. The checklist is summarized in Table 4.1 and is discussed in greater detail below.

1. Most workers like the 12-hour schedule. Northrup, Wilson and Rose (1979) report that the American petrochemical plants that adopted 12-hour schedules did so in response to a request from employees. The 12-hour schedules in those plants are continued on the condition of support by a majority of their employees. All 50 plants that Northrup et al. contacted reported that the change to the 12-hour schedule generally improved employee morale. They also reported some evidence that, in general, the supply of job applicants increased and that turnover decreased. A reduction in turnover would tend to increase the level of experience in a crew. However, older workers are less supportive of the change, possibly because they have more difficulty adjusting to the longer hours; if so, turnover of older workers would tend to decrease the level of experience in a crew.

An investigation by Clarke Institute (1983) of Ontario Hydro employees indicates that employees on a 12-hour schedule are satisfied with their schedule. The report further indicates that employees on an 8-hour/day schedule resented not being allowed to have a 12-hour schedule. This, in turn, was a major source of stress. Before adopting a 12-hour shift, one utility reported that approximately $80 \%$ of the operators at its nuclear plants favored the adoption of a 12-hour schedule, and now, after adopting the 12-hour shift, $97 \%$ of its operators favor continuing the 12-hour shift.

2. More Days 0ff and More Consecutive Days Off. The increased number of days off and the increased number of consecutive days of $f$ appear to be the major reason that workers prefer the 12-hour schedule.

Whether a 12-hour schedule offers more consecutive days off than an 8-hour schedule depends on the particular schedules. The typical 12-hour schedule in the European petrochemical industry is 2 days of work followed by 2 days off, in which case the number of consecutive days off is only 2. However, most North American 12-hour schedules offer more consecutive days off.

The additional number of consecutive days off, however, has some disadvantages. Northrup et al. (1979) report that in petrochemical plants "during longer breaks, there was ... a greater 'forgetting factor' and, therefore, a need for some reorientation upon returning to work" ( $p .323$ ). As a result, these petrochemical plants had begun to rely more on written communications. In an interview with project staff, the Chief of Police of a municipal police force that adopted a 
TABLE 4.1. Potential Advantages and Disadvantages of 12-Hour Schedules Factor Advantaye Disadvantage

1. Most workers like it, which could result in

- Increased job satisfaction--less difficulty in recruiting new personnel

- Decreased attrition (decreased training cost, more experienced operators)

2. More days off and more consecutive days off

- Workers like days off

- More weekends off

$x$

- Workers lose touch with operations

- Workers might be tempted to moonlight, travel great distances, or engage in exhausting recreation on consecutive days off and return to work fatigued

3. Shift turnovers reduced from 3/day to 2/day

- Fewer opportunities to fail to comunicate during turnover

- More chance that the crew that begins a maintenance job, or begins an evolution, will be the same crew that ends it. This contributes to quality work and job satisfaction

- Reduce commute tíme and commute cost by about one-third

4. Within any one day, 12 hours of work is more fatiguing than 8 hours of work

- Alertness and safety might declíne

- Because the day is longer, workers might pace themselves by working slower

- Workers need more breaks

- Eight-hour night shifts are difficult; 12-hour night shifts are more difficult

- Twelve hours might be more difficult for older workers

5. Over several consecutive days, 12 hours of work per day is more fatiguing than 8 hours of work per day

- Less time for rest exists between consecutive work days, fatigue might accumulate

6. Fewer consecutive work days; more rest days dissipate fatigue 
12-hour schedule reported that his force is limiting the number of consecutive days off to 3 because in their experience, when an officer is away from duty for 4 or more days, it takes him too long to become reoriented to his duties.

3. Shift Turnovers Are Reduced From 3 per Day to 2 per Day. An 8-hour/day schedule requires 3 crews to cover 24 hours, so it requires 3 shift turnovers per day. A 12-hour/day schedule requires only 2 shift turnovers per day, so shift turnovers are reduced by one-third. During a shift turnover, the outgoing crew must communicate the status of the plant and activities in progress to the incoming crew. Failure to communicate properly can result in problems for the next crew. Reducing the number of turnovers can reduce the number of such communication errors (Northrup, Wilson and Rose 1979, p. 320).

The longer shift increases the chances that the crew that is on duty when a maintenance procedure begins, or when an evolution begins, will be the same crew that ends it. Thus, less need exists to communicate work in progress, and operators can take pride and responsibility for seeing a job through to its completion. This contributes to quality work and job satisfaction (Northrup, Wilson and Rose 1979, p. 323).

By reducing shift turnovers by one-third, commute time, comrnute distances and commute costs are also reduced by one-third for everyone on the crew. Also, if shift turnovers force the postponement of other tasks, then reducing turnovers allows crews to continue productive work that totals 7 extra "crew-hours" of work per week.

4. Within Any One Day, 12 Hours of Work is More Fatiguing Than 8 Hours of Work. Twelve hours of work in one day could lead to a decline in alertness and safety. This is the most important concern with 12-hour shifts, especially in the nuclear industry where public health and safety are major issues. Kelly and Schneider (1982) addressed this issue and estimated that the overall human error rate for working 12 consecutive hours is approximately twice as high as the rate for working 8 consecutive hours. This concern is also revealed in the federal limits on consecutive hours worked by Air Force airplane crew (single control), railroad operators, truck drivers and airline pilots and crew, which are 12, 12, 10, and 8 respectively (see Table 2.4 ).

The degree to which fatigue increases and performance declines during 12 consecutive hours of work varies among individuals and by type of work. Northrup et al. (1979, p. 312) state, "The drawbacks of ... (the 12-hour schedule) include the difficulty that some older workers have in adjusting to it; (and) the possibility that it might not be feasible in industries in which the work is more arduous...." 
5. Over Several Consecutive Days, 12 Hours of Work Per Day is Probably More Fatiguing Than 8 Hours of Work Per Day. Furthermore, if the worker has a long commute, he might have less time for rest before the next work day. This issue was discussed in Section 4.2.4.

A recent comparison of sleep habits between workers on 8-hour shifts and 12-hour shifts in West Germany showed little difference in sleep length between the two groups; both slept a little longer than 7 hours on days off, and both slept a little less than 7 hours on work days (Frese 1984, p. 563). The investigation, however, did not consider commute time.

6. Fewer Consecutive Work Days; More Rest Days Dissipate Fatigue. Even though a 12-hour schedule might be more fatiguing than an 8-hour schedule when compared over the same number of days worked, fewer consecutive days are worked on a 12-hour schedule. This is the only factor on which a 12-hour schedule might be less fatiguing than a comparable 8-hour schedule, but it could be an important factor.

In addition to the disadvantages with 12-hour shifts that were 1 isted in Table 4.1, Northrup et al. (1982, p. 319) mention an additional potential disadvantage with a 12-hour schedule--difficulty in covering unscheduled absences:

Employers switching to a twelve-hour shift ... encountered many probTems in manning. It is common practice, when necessary, to hold workers over after eight hours of work, but this is discouraged after twelve hours and is possible only up to a maximum of four additional hours.

Several systems for ensuring coverage have been established, but they have not been totally successful. Dne is the "spare hoard" system, which requires certain workers to remain at home on their days off for one hour prior to the beginning of a shift and one hour following its end so that they are available should they be needed for coverage. One plant issues "beepers" to workers assigned to the spareboard.... The disadvantage to this system, however, is that most employees feel that they do not actualiy have a day off if they must worry about. the possibility of being called into work.

To mitigate the problem of having to find people to cover for absentees, some utilities "overstaff" their crews; i.e., they assign to their crews more than the minimum number of people required by their technical specifications. This practice reduces or eliminates the need to cover absences.

One electric utility, in an unpublished report, stated that it initially had some difficulty obtaining people for off-schedule overtime, but later resolved the problem. The fact that the plant only had four crews might have been a factor in this problem. 
In addition to the advantages with 12-hour shifts that were listed in Table 4.1, finding people for scheduled overtime (in contrast to finding people for unscheduled overtime) also seems to be facilitated by a 12-hour shift. Because 12-hour schedules have many days off, overtime can simply be scheduled in advance for a day off. Even working 60 hours per week still leaves two days off. These advantages are undoubtediy important reasons why some nuclear plants switch temporarily to 12-hour schedules when overtime is required.

As was mentioned in Section 2.1, the recommendation on hours of work (including overtime) is intended to apply to all nuclear plants, whether their routine schedules are 8- or 12-hour/day schedules. 


\subsection{BASIS FOR RECOMMENDATION ON THE TOTAL NUMBER OF CONTROL ROOM OPERATORS AT A NUCLEAR PLANT}

The alternatives in Chapters 2 and 5 have the same ultimate objective, to reduce or eliminate excessive overtime. The alternatives in Chapter 2 deal with overtime directly, by limiting hours of work. The alternatives in Chapter 5 deal with overtime indirectly, by dealing with staffing levels, which are closely related to levels of overtime.

Available information indicates that most plants are striving to hire, train, and retain enough control room operators to staff six crews. Some utilities have raised salaries to attract and retain operators. Others have conducted nationwide recruiting campaigns. Still others have instituted educational and recruiting programs in local high schools on the theory that local high school graduates will be more likely to make a career at the plant and less likely to leave after a few years of expensive training.

Nonetheless, recruiting, training, retraining, and retaining operating staff can be difficult and expensive. Available evidence suggests that some plants have been understaffed to the point where overtime might have been routine. The successful recruiting campaigns of some plants might have contributed to the understaffing difficulties of other plants as operators left one plant to become employed at another. Possibly an NRC policy limiting hours of work should only be one part of a larger positive program to increase the pool of operators at particular plants or throughout the nation.

The project staff's recommendation for an NRC policy on the total number of control room operators at a nuclear plant is discussed in Section 5.1, and Section 5.2 briefly presents the basis for the reconmendation. Sections 5.3 and 5.4 discuss alternatives to the recommendation. Some of the implications of the logical relationship between Chapter 2 and 5 are described in Section 5.5.

\subsection{RECOMMENDATION: GATHER DATA}

Although available evidence suggests that some nuclear power plants may have problems with understaffing, this evidence is unofficial and unquantified. Two possible methods for collecting reliable data are as follows:

1. NRC could conduct an official survey of nuclear power plants to determine the number of auxiliary operators (AOS), and licensed control room operators in each plant. (A distinction must be made here between "licensed operators" and "licensed control room operators." A "1icensed operator" is a person who has a valid reactor operator license or senior reactor operator license. A "licensed control room operator" is a person with suck a license whose primary duty is to operate the plant from the control room. Some people with such licenses do not operate the plant from the control room, but rather are trainers or managers. Information on 
the number of "licensed operators" at each plant is available to the public; it is retained in the NRC Docket Room. However, information on the number of "licensed control room operators" is unavailable to the public. An official NRC survey would make such information publicly available.

2. Another method for collecting this information can be linked with the recommendation in Chapter 1 concerning limits on hours of work. The recommendation includes a provision that nuclear plants obtain NRC approval before exceeding specified limits on hours of work. The documents recording NRC's approval could then become an important source of data on overtime. If the data are important, NRC could require that licensees applying for this approval also report to NRC the number of $\mathrm{AOS}$ and licensed ROS and SROS whose primary duty is to operate the plant from the control room. $(a)$

These methods for collecting data will not be developed further in this section because 1) gathering data is not in itself a policy position, and 2) methods for gathering data are discussed further in Chapter 6.

\subsection{BASIS FOR RECOMMENDATION}

Understaffing leads to overtime, which could reduce the operating margin of safety at nuclear power plants. Estimating the extent of the problem, evaluating current policies to deal with the problem, developing a new policy, and simply monitoring the level of staffing all require data.

5.3 ALTERNATIVE A: REQUIRE THAT EACH PLANT HAVE A SPECIFIED NUMBER OF CONTROL ROOM OPERATORS

The term "control room operator," or simply "operator," here refers to AOS, and to licensed ROS and SROs whose primary duty is to operate the plant from the control room. Specifying a minimum number of operators at a plant is different from specifying a minimum number of operators on shift. The Tatter refers to the minimum number of operators required to be operating the plant at any one time. NRC has promulgated regulatjons on the minimum number of SR0s and ROs (but not AOs) required on shift. (D) This minimum depends on the number

(a) Another possible source of data on the number of control room operators at each plant is NRC Form 398, entitled "Personal Qualifications--Licensee." Form 398 must be submitted by all applicants for reactor operator's license and for a renewal of reactor operator's license. On Form 398, Section 10 asks for the applicant's current position and includes as two of the options "control room operator" and "senior control room operator."

(b) Although NRC has no requirements concerning the number of AOs on shift during normal operations, NRC does have a requirement concerning the number of A0s on shift during emergencies; these requirements are specified in NUREG-0737, Supplement 1 (1983), entitled Clarification of TMI Action Plan. Requirements for Emergency Response Capability. 
of units at a site, on the number of control rooms, and on the number of units operating. For a single operating unit (with one control room), the minimum number of ROS and SROs on shift is two each. [These regulations are contained in 10 CFR 50.54 (m) (1) and (m) (2).]

Alternative $A$ is to require that each plant have a specified minimum number of SROS, ROS, and AOs at the plant. The required minimum number of SROs and ROs at the plant would be some multiple of the minimum number required on shift. For example, the minimum required at the plant might be 4 (or 5 or 6 ) times the minimum required number on shift. An equivalent way to state the same idea is: nuclear plants must have enough SROs and ROs to staff 4 (or 5 or 6) crews. (Because there is no required minimum number of A0s on shift, a different method must be devised to specify a required minimum number of AOs at a plant.)

Alternative A has two advantages: 1) it is simple, and 2) it deals directly with one of the fundamental causes of overtime in the nuclear industry--understaffing. Nonetheless, Alternative $A$ is not recommended at this time, for the following reasons: 1) our primary recommendation, to set a policy on hours of work, is a more direct means to ensure that fatigue does not impair performance; this gives the licensee flexibility to employ the number of operators that is most appropriate for its circumstances, as long as the plant meets the conditions of NRC policy on hours of work; 2) An investigation into alternative NRC actions, and the consequences of alternative NRC actions if a licensee falls below the minimum required number of operators for his plant, is beyond the scope of work for this project.

The Shift Scheduling Project's panel recommends that NRC require that each plant have enough SROs and ROs to staff 6 crews.

\subsection{ALTERNATIVE B: MAINTAIN THE STATUS QUO--PRESENT NRC POLICY}

The present NRC policy statement considers the total number of operators to be the fundamental issue behind overtime: "Enough plant operating personnel should be employed to maintain adequate coverage without routine heavy use of overtime." Present NRC policy on overtime, however, does not specify a minimum number of ROs and SROs to be employed at a plant. According to the policy statement, when overtime is required, individuals may work up to the specified limits, "on a temporary basis" only. If the need for overtime persists, the utility is expected to hire and train more people. (a)

(a) As was mentioned in Section 5.3, NRC does have requirements concerning the number of SROS and ROS on shift during routine operations. NRC also has requirements concerning the number of SROS, ROS, and $A 0 S$ on shift during emergencies (NUREG-0737, Supplement 1, 1983, ค. 27). 


\subsection{RELATIONSHIP TO RECOMMENDATION ON HOURS OF WORK}

The recommendation discussed in this chapter (on the total number of control room operators at a plant) and the recommendation on hours of work have the same ultimate objective, which is to reduce or eliminate excessive overtime. It is recommended that NRC place primary emphasis on dealing with overtime directly, by adopting the recommendation on hours of work. However, if NRC decides against dealing with overtime directly, then we recommend that NRC consider dealing with overtime indirectly by requiring that each plant have at least a specified minimum number of operators (Section 5.3). One of the first steps in developing such a requirement would be to collect data on the number of control room operators presently employed in nuclear plants (Section 5.1). 


\subsection{METHODS FOR COLLECTING INFORMATION ON OVERTIME, NUMBER OF OPERATORS, FATIGUE, AND PERFORMANCE}

Collecting information could be the most important issue for NRC's policy on shift scheduling and overtime, depending on the quality of information NRC requires in order to decide on a policy. If the quality of information presently available is considered to be marginal, many methods for collecting additional information are available; five are described in this section.

The Federal Aviation Administration (FAA) presently employs at least two of the methods described in this section: 1) one member of an FAA team that investigates aircraft accidents routinely records the number of hours the pilot and crew had been flying before the accident, and 2) the FAA has established an anonymous, voluntary safety reporting system (the Aviation Safety Reporting System). The FAA also requires that the "black box" tape recorder be installed in commercial aircraft. The "black box," which records flight characteristics (for example, altitude, air speed, etc.) and aircraft radio communications, is routinely used in investigating aircraft accidents.

The Department of Transportation requires that a meter that records driving time be installed in trucks; the data on driving time are then routinely recorded on accident report forms for every truck accident. Air Force pilots and crews keep logs; the data on flying time is then routinely recorded from the logs by accident-investigation teams after every accident.

Our understanding of the present situation is that NRC generally keeps in touch with the status of work hours, fatigue, and performance in the nuclear industry through a variety of informal channels, mostly without requiring or producing written documents. NRC has received several letters from operators claiming that in some instances overtime has led to operator fatigue. Evidence indicates that many personnel in the nuclear industry would like to communicate more directly and more often with NRC (McGuire, Walsh and Boegel 1984). Also, according to NRC's policy statement, licensees should document each case in which the plant manager authorizes overtime in excess of the guidelines. These documents, however, need not be submitted to NRC, and so it would be very difficult to use these documents as a data base for research. If NRC were to use these documents as a data base to establish a correlation between hours of work and performance, the following steps would be necessary:

1. obtain authorization from NRC to inspect the utility documentation of plant manager approval for overtime (or obtain authorization from NRC to inspect complete utility records on hours of work for safetyrelated personnel)

2. obtain information on the performance of personnel who worked overtime (or at least on plant performance) 
3. attempt to correlate the data on overtime with the performance data by (a) comparing the performance of people who worked overtime with the performance of people who did not, (b) comparing the performance of people when they worked overtime with their performance when they did not, (c) comparing the performance of a plant when most of its people worked overtime with the performance of the plant when most of its people did not, or (d) comparing the performance of plants whose people work heavy overtime with the performance of plants whose people do not.

\subsection{COLLECT DATA FROM DOCUMENTS OF APPROVAL TO EXCEED GUIDELINES}

If adopted, the recommendation on hours of work (including overtime), presented in Chapter 1, would produce two types of documents that could be used as a data base for assessing the relationship between hours of work and performance:

1. documentation of plant manager approval to exceed the limits in Column $A$ of Table 1.1

2. documentation of NRC approval to exceed the limits in Column B of Table 1.1.

The first type of document is virtually identical to the documents available under present NRC policy. The primary difference is that under present policy, some plants may not have imposed upon themselves the requirement to document plant manager approval, whereas the recommendation is that all plants be required to document plant manager approval. The second type of document, documentation of NRC approval, would differ from documentation of plant manager approval in that they would be NRC documents; no special approval would be necessary to gain access to them.

\subsection{WHEN A LICENSEE EVENT REPORT INDICATES HUMAN ERROR, GATHER INFORMATION ON HOURS OF WORK}

After a Licensee Event Report (LER) that includes human error is submitted, the NRC inspector can gather additional data that would help provide a basis for NRC policy or modifications in NRC policy on shift scheduling and overtime. Because the workloads of NRC inspectors are heavy, both the importance of the data and the time required to collect it should be considered in designing the data collection effort. Important data include:

- the number of consecutive hours the operator had been working when the error occurred

- the number of hours the operator, or the entire crew, had been working over a period of one or more weeks. 
Both the U.S. Air Force and the FAA routinely collect and record data on flight time during the investigations that follow every airplane accident. However, project staff have not seen analyses of these data and suspect that such analyses, if they exist, are confidential.

\subsection{ESTABLISH A NUCLEAR SAFETY REPORTING SYSTEM}

NRC can establish a Nuclear Safety Reporting System modeled on the FAA's Aviation Safety Reporting System (ASRS). The FAA's system is described briefly in Appendix D. NRC has considered adopting such a system (see, for example, Finlayson and Ims 1983). Members of the Shift Scheduling Project panel stated that most experts believe that FAA's ASRS is the best source of information on human factors safety in the airline industry. They strongly recommend that a similar system be established for the nuclear industry.

\subsection{EXPAND THE ALLEGATION TRACKING SYSTEM}

NRC presently maintains an Allegation Tracking System. This system is not generally known to industry personnel as a way that they can report information concerning hours of work, fatigue, and performance. Also, the "Allegation Data Form" used by this system does not specifically encourage industry personnel to recommend a solution to the alleged problem. (Recommended solutions are considered to be an important part of the FAA's Aviation Safety Reporting System.) Thus, the Allegation Iracking System could be expanded by encouraging its use for providing information on hours of work, fatigue, and performance.

NRC's Allegation Tracking System is described in an NRC internal memorandum from James $H$. Sniezek, Deputy Director, Office of Inspection and Enforcement, dated December 2, 1982. According to that memorandum, the Allegation Tracking System went into effect on December 6, 1982. As stated in Mr. Sniezek's memorandum, the purpose of the Allegation Tracking System is "to track the receipt, disposition, and status of allegations involving NRC 1icensees ... and to provide periodic status reports on allegations to NRC management." The objectives of the system are:

1. to provide a record which demonstrates that allegations are reviewed, acted upon as appropriate, and receive proper NRC management attention

2. to provide periodic reports to management on the status of allegations and alert management of allegations that may affect pending major actions such as licensing decisions or escalated enforcement.

According to the memorandum, each office within NRC and each Regional Administrator is to designate a staff member to serve as office Coordinator for the system. When a member of the public makes an allegation to any NRC employee, the allegation is directed to the office Coordinator for that employee's Office or Region. That Office Coordinator then fills out an Allegation Data Form, which includes space for 1) the name of the facility involved 
(with instructions to write only the word "sensitive" if anonymity of the facility should be maintained), 2) a description of the allegation, and 3 ) the type of source of the information (i.e., "contractor employee," "licensee employee," etc.) Instructions emphasize, "Do not identify the name of the individual providing the allegation."

The Office Coordinator of the allegation "Receiving office" then sends the Allegation Data Form to the Office Coordinator in the appropriate NRC office for action on that particular allegation. That office is called the allegation "Action Office." The Action Office then informs NRC's Office of Inspection and Enforcement (IE) that it has received the Allegation Data Form, takes appropriate action, and informs IE of updates in the status of the allegation. IE then issues a monthly status report that includes all new allegations and all updates on old allegations.

A memorandum, dated September 10, 1984, from William J. Dircks, Executive Director for Operations, emphasizes that licensees, applicants, contractors, and subcontractors are prohibited from harassment, intimidation, or other forms of discrimination against people who make allegations.

Similarities exist between NRC's Allegation Tracking System (ATS) and FAA's Aviation Safety Reporting System (ASRS). Both provide a channel of communication between industry personnel and the regulating agency, and both maintain anonymity. However, important differences also exist. ASRS provides limited immunity from prosecution; ATS does not. ASRS is designed primarily to obtain information that can be used to improve FAA's general regulatory practice, whereas ATS is designed primarily to obtain information that can be used in regulatory actions for particular nuclear facilities. ASRS reports, using the words of the reporter (or modified slightly to maintain anonymity), are made available to the public; ATS reports are not.

Our understanding is that ATS also differs from ASRS in the following ways. The ASRS system is well publicized and well known to airline personnel, and ASRS report forms are made easily available to airline personnel at all airports, whereas ATS is not as well known and accessible in the nuclear industry. The FAA periodically analyzes the ASRS data base to estimate the prevalence of particular problems and these analyses are made public, whereas NRC does not make periodic scientific analyses of ATS data. Finally, the ASRS encourages reporters to suggest measures that will help prevent the recurrence of the problem, whereas ATS does not encourage reporters to make such suggestions. 


\subsection{SUMMARY COMPARISON OF NRC'S POLICIES AND PROJECT STAFF RECOMMENDATIONS}

The similarities and differences between NRC's present policies and the project staff's recommendations are summarized in this chapter.

\subsection{POLICY ON HOURS OF WORK (CHAPTER 2)}

The recommendation on hours of work expands upon NRC's present policy.

\subsubsection{Similarities}

- The objective of present NRC policy and the recommendation are the same: "to assure that, to the extent practicable, personnel are not assigned to shift duties while in a fatigued condition that could significantly reduce their mental alertness or their decision making capability" (Generic Letter 82-12).

- Present NRC policy and the recommendation use basically the same categorization of circumstances for which overtime is allowed: "problem during operation," "extended shutdown," and "unusual circumstances." (The recommendation, however, adds "very unusual circumstances.")

- In essence, the recommended guidelines adopt NRC's present guidelines. (We, however, recommends adding guidelines.)

\subsubsection{Differences}

- Present NRC policy is in one sense a nonbinding recommendation to licensees, and in another sense a legally enforceable requirement: NRC recommends that licensees incorporate into their technical specifications a statement concerning working hours and overtime. (NRC's recommended statements on hours of work are presented in Appendix E.) Once the licensee incorporates the statement into its technical specifications, its provisions become legally enforceable.

By contrast, we recommend that NRC require that all licensees incorporate the statement into their technical specifications.

- NRC's statements on hours of work include guidelines for 1, 2, and 7 days.

In addition to limits for 1, 2, and 7 days, we recommend that limits be added for 14 days, 28 days, and one year.

- NRC's statements on hours of work allow the limits to be exceeded, under certain conditions, if the plant manager approves. 
By contrast, we recommend that the plant manager be authorized to approve additional overtime only up to certain limits. If the plant manager anticipates that he or she might wish to have plant personnel exceed the higher set of limits, approval must first be obtained from NRC.

\subsection{POLICY ON ROUTINE 8-HOUR/DAY SHIFT SCHEDULES (CHAPTER 3)}

The recommendation on routine 8 -hour/day shift schedules is not a major change from present NRC policy.

\subsubsection{Similarities}

Present NRC policy concerning routine 8-hour/day schedules is a recommendation to licensees, not a requirement. We recommend that NRC policy on this subject continue to be a recommendation.

\subsubsection{Differences}

Present NRC policy recommends a standard 8-hour day and 40-hour week. By contrast, we recommend (that NRC recommend) that routine 8 -hour/day schedules meet a set of criteria that includes the following:

1. The schedule should be limited to a maximum of 7 consecutive days of work.

2. The schedule should not exceed 21 days of work in any 4-week period.

\subsection{POLICY ON ROUTINE 12-HOUR/DAY SHIFT SCHEDULES (CHAPTER 4)}

NRC's written policy statements make no explicit mention of routine 12-hour/day schedules. However, NRC has, by implication, allowed several licensees to adopt such schedules. By contrast, we recomend that NRC issue a written policy statement on routine 12-hour/day shifts stating that 1 icensees must obtain NRC approval before adopting such schedules, and that NRC will evaluate the licensee's application based on certain criteria, including the following:

1. The basic 12-hour/day schedule should be "2-on, 2-off," "3-on, 3-off," or "4-on, 4-off."

2. The plant should have the capability to cover unexpected absences satisfactorily without having individuals work more than 12 hours per day.

3. The general safety record of the plant should be satisfactory, as judged by general criteria such as those used in NRC's Systematic Assessment of Licensee Performance (SALP) ratings. 


\subsection{POLICY ON NUMBER OF CONTROL ROOM OPERATORS AT A PLANT (CHAPTER 5)}

NRC presently has very well-defined regulations concerning the number of licensed control room operators on shift (10 CFR 50.54). NRC also has a policy concerning the total number of licensed control room operators at a plant (Generic Letter 82-12). Whereas the former states explicitly the number of reactor operators (ROS) and senior reactor operators (SROS) required, the latter states a general objective: "Enough plant operating personnel should be employed to maintain adequate shift coverage without routine heavy use of overtime" (Generic Letter 82-12, p. 7).

The recommendation both on hours of work (Chapter 2) and on the total number of control room operators at a plant (Chapter 5) have the same objective: to reduce or eliminate excessive overtime. In order to meet this objective, we recommend that NRC give priority to the recommendation on hours of work, while at the same time, gather data on the number of operators at each plant. If, however, NRC decides against adopting the recommendation on hours of work, we recommend that NRC, rather than simply gather data on the number of operators at each plant, adopt an explicit, quantified requirement for the total number of control room operators at nuclear power plants. 

APPENDIX A

PANEL MEETING ON SHIFT SCHEDULING IN THE NUCLEAR POWER INDUSTRY HELD MAY 15-16, 1984, IN WASHINGTON, D.C. 


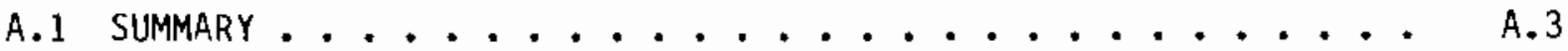

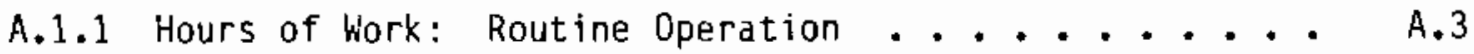

A.1.2 Hours of Work: Overtime .................. A

A.1.3 Additional Panel Recommendations........ A.4

A.1.4 Project Staff Comments on Panel Recormendations. . . A.5

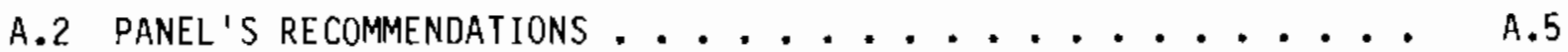

A.2.1 Hours of Work: Routine Operations ....... A.8

Maximum of 9 Hours Per Day (Including Shift Turnover

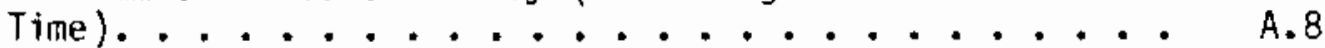

Maximum of 54 Hours in an 8-Day Period............ A.8

Maximum of 18D Hours in a Month................ A

Application to NRC to Exceed These Guidelines. . . A. A.9

A.2.2 Hours of Work: Overtime ................. A.

Overtime Disallowed for 1 SRO, 1 Ro, and 1 A0 Per Unit . A.10

Eliminate Distinction Between "Problem During Operation"

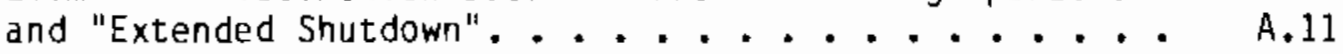

Maximum of 13 Hours Per Day ( 9 Hours For Night Shift). A.11

Maximum of 22. Hours in a 48-Hour Period. ....... A.13

Maximum of 66 Hours in a 7-Day Period......... A.13

Maximum of 123 Hours in a 14-Day Period. ....... A.13

Maximum of 213 Hours in a Month........... A.14

Maximum of 2400 Hours in a Year............... A.14

Exceeding the Overtime Guidelines in Emergencies.... A.14

No Need to Regulate Hours of Rest......... A.15

A.2.3 Enough 0perators to Staff 6 Crews................. A5 
A.2.4 Recommendation Against Setting Guidance on Speed and

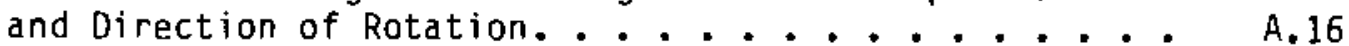

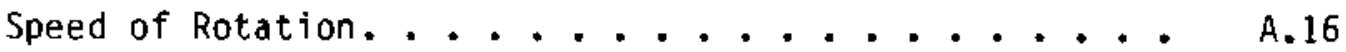

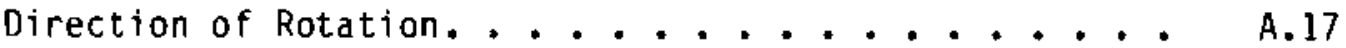

A.2.5 Other Recommendations. . . . . . . . . A.17 Proposal to Develop a Fatique Index is Inadequate. . . A.17 NRC Should Collect More Information......... A.18 Establish an Anonymous Safety Reporting System ..... A.18 Provide Information to Utilities on the Effects of

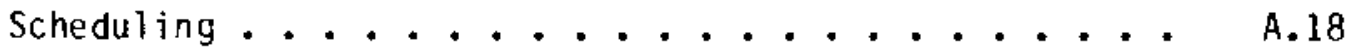
Suggested Training Solutions to Operator Error . . . . A.18 A.3 COMPARISON OF PANEL RECOMMENDATIONS WITH CURRENT SHIFT SCHEDULES ........................ A.19

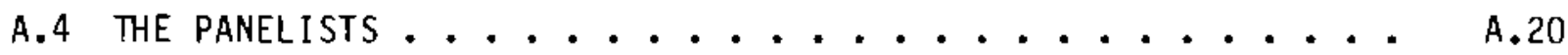


APPENDIX A

PANEL MEETING ON SHIFT SCHEDULING IN THE NUCLEAR POHER INDUSTRY

\section{A.1 SUMMARY}

Nine we11-known and respected administrators, researchers, and medical doctors concerned with fatigue in various industries and organizations in the United States and Canada participated in the panel meeting, held May 15-16, 1984, in Washington, D.C. This appendix summarizes that meeting's discussion. The resumes of the panelists are presented in Section A.4 of this report. The nine panel members were:

Robert A. Alkov, Ph.D., Naval Safety Center

R. Curt is Graeber, Ph.D., NASA Anes Research Center

Robert Henderson, Bureau of Motor Vehicle Safety

Gary R. Krieger, M.D., Boulder Medical Center

Carlton E. Melton, Ph.D., Federal Aviation Administration Medical Center

Timothy H. Monk, Ph.D., New York Hospital--Cornell Medical Center

Richard Moore, M.D., U.S. Coast Guard

M. Franz Schneider, Mantech

William F. Storm, Ph.D., U.S. Air Force School of Aerospace Medicine

In making recommendations, the panel members considered the interest of the NRC, the nuclear industry, and the public. Although the panel members felt free to voice minority opinions, there was a consensus for all of their most important recommendations. The panel's most important recommendations are presented in the subsections below.

\section{A.1.1 Hours of Work: Routine Operation}

1. Whereas present NRC policy recomnends a maximum of an 8-hour day, excluding shift turnover time, the panel recomends a maximum of a 9hour day including shift turnover time.

2. Present NRC policy recommends a routine schedule of a standard 8-hour day and 40-hour week. The panel essentially endorses this policy. However, the panel recognizes that the routine shift schedules for rotating shift work rarely conforms exactly to a 40-hour week. Although the average over an entire cycle (cycles range from 5 to 10 weeks in length) is usually very close to 40 hours per week, work hours in individual 7-day periods can range from 16 to 56 . The pane 1 recommends revising present policy to recognize the existing complexity in scheduling and to offer more realistic guidance. Specifically, the panel recommends a 1 imit of 6 days of work in an 8-day period. The panel further recomends explicit guidance that the schedule average 40 hour/week (excluding shift turnover time) within a period of one month. 
3. Whereas NRC presently implicitly permits some nuclear plants to have 12-hour/day shift schedules, the panel recommends that nuclear plants be required to formally apply for written permission from the NRC to exceed guidelines for routine shift schedules. The panel further recommends that the NRC establish criteria for judging whether a plant should be allowed to adopt a 12-hour/day schedule.

\section{A.1.2 Hours of Work: Overtime}

The panel recommends significant reductions in the maximum allowable number of hours of work when overtime is required.

4. Whereas present NRC policy allows individuals to work up to 16 hours per day (excluding shift turnover time), the panel recommends 13 hours (including shift turnover time) for workers on morning and afternoon shifts, and 9 hours (including shift turnover time, i.e., no overtime) for workers on the night shift. The numbers in present NRC policy shown below exclude shift turnover time, and the numbers in the panel recommendations include shift turnover time.

5. Whereas present NRC policy allows individuals to work up to 24 hours in 2 days, the panel recommends a maximum of 22 hours (e.g., 13 hours one day and 9 hours the next, including shift turnover time).

6. Whereas present NRC policy has no set limits for time periods longer than one week, the panel recommends maximums of 123 hours in 2 weeks, 213 hours in one month, and 2400 hours in one year.

7. Present NRC policy distinguishes between "problem during operation" and "extended outage". In the case of a "problem during operation," overtime is limited to individuals only; during an "extended outage," the entire crew may work overtime. The panel recommends eliminating the distinction, so that during a "problem during operation" and during an "extended outage," overtime would be limited to individuals only.

8. Under present NRC policy, during "very unusual situations" plant personnel may exceed the overtime limits if the plant manager approves. The panel recommends additional administrative requirements: after the plant manager approves, the utility must inform NRC and state its reason for exceeding the guidelines.

\section{A.1.3 Additional Panel Recommendations}

9. The panel recommends that utilities be required to have enough licensed control room operators to staff six crews. This policy in itself could forestall most overtime problems.

10. The panel recommends against making a policy statement concerning speed or direction of rotation because evidence does not justify such a policy. 
11. The panel recomends that the Shift Scheduling Project staff and the NRC obtain more information on routine shift schedules and overtime practices in the nuclear industry.

\section{A.1.4 PNL's Comments On Panel Recommendations}

The panel members have a great deal of professional experience with the issues of work hours, fatigue, and performance. They conscientiously attempted to apply their experience to the nuclear industry in an even-handed way, recognizing the legitimate interests of all parties. PNL considers the counsel of the panel members to be valuable information that deserves full and serious consideration, especially with respect to limits on hours of work. Even when PNL's recommendations and those of the panel differ to some degree, PNL feels that the panel's point of view should be considered seriously.

In one case, however, PNL feels that the panel's recomendation would probably lead to administrative complications that are not justified by the potential gain in safety. The panel recommended that NRC limits include shift turnover time. The panel's reason for including shift turnover time is that work during shift turnover adds to fatigue and should be dealt with directly and explicitly. Thus, the panel's recommended limit on hours of work in a normal day is 9, instead of the usual 8. This addition of one hour per day carries through all of the panel's limits on hours of work, for both routine operation and for overtime, and for all periods of time ranging from one day to one year. If utility records are based on an 8-hour work day, adding shift turnover time to determine the number of hours personnel worked in a week, month and year would create an unreasonable burden. Nonetheless, the panel's main point is still valid: shift turnover time does add to fatigue, and that fact should be considered when setting limits on hours of work. For example, a limit of 72 hours of work in a week, excluding shift turnover time, is a limit of about 75 hours of real work. The panel's main point should be extended: comnute time also adds to fatigue, and many nuclear power plants located in isolated rural settings require long comutes. If, for example, the one-way commute time for an employee is 90 minutes, then a limit of 72 hours of work in a week, excluding shift turnover time, is a limit of about 93 hours of workrelated activity.

\section{A.2 PANEL RECOMMENDATIONS}

In making recommendations, the panel members considered the interests of NRC, the nuclear industry, and the public. Although panel members freely expressed minority opinions, there was consensus on all the most important recommendations.

The panel's recommendations concerning hours of work (both routine operations and overtime) are summarized in Table A.1. Some of the panel's calculations leading to the recomendations are included in Table A.2. 
TABLE A.1. Panel Recomnendations on Hours of Work (all hourly limits include shift turnover time)

A

Routine

Operation

1 day

2 days

1 week

14 days

1 month

1 year
9 hrs

$$
\text { (8-day period) * }
$$

To exceed these guidelines, e.g., for a 13-hr/day schedule, NRC approval is required in advance.
B

Overtime (For all but 1 SRO and 1 RO in each unit)

13 hrs for morning and afternoon shifts;

9 hrs (i.e., no overtime) for night shift.

22

66

123

213

2400
1. In non-emergency situations, exceeding these guidelines is not permitted. 2. In emergency situations, exceeding these guidelines is permitted if the plant manager approves; the utility must subsequently inform NRC and state the reasons.

*Although this recommendation is listed in the row for "one week," the time period is 8 days, not 7 . The maximum of 54 hours is derived by multiplying 6 working days (in an 8 -day period) by 9 hours per day. 
TABLE A.2. Panel Recommendations on Hours of Work Including Some of the Panel's Calculations (all hourly limits include shift turnover time)

A

\section{Routine \\ Operation}

1 day

2 days

1 week

14 days

1 month

1 year
$9 \mathrm{hrs}$

(8-day period)

6 days work $\times 9 \mathrm{hrs} /$ day
$54 \mathrm{hrs}$
$9 \mathrm{hrs} /$ day

$\times 5$ days/wk

$\times 4$ wks
$180 \mathrm{hrs}$

\section{B}

Overtime

(For all but 1 SRO and 1 RO in each unit)

13 hrs for morning and afternoon shifts;

9 hrs (i.e., no overtime) for night shift.

$$
\begin{array}{r}
13 \mathrm{hrs} \\
+\frac{9}{22 h r s}
\end{array}
$$

$66 \mathrm{hrs}$

(see below)

( 2 days rest)

$\begin{array}{rc}13 & 13 \mathrm{hrs} \\ 9 & 9 \\ 13 & 13 \\ 9 & 9 \\ 13 & 13 \\ 9 & 0 \\ +\quad 0 & +\frac{0}{57}=123 \mathrm{hrs}\end{array}$

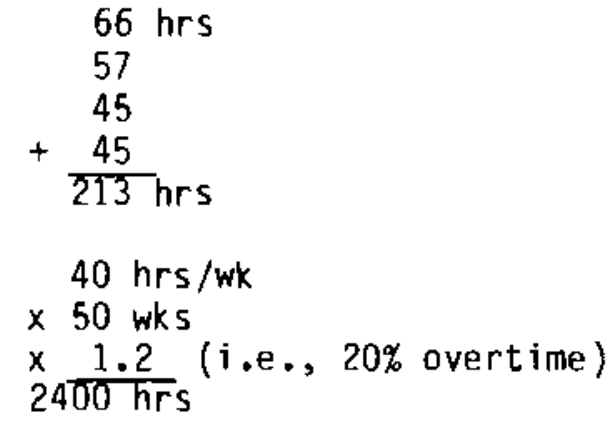

1. In non-emergency situations, exceeding these guidelines is not permitted. 2. In emergency situations, exceeding these guidelines is permitted if the plant manager approves; the utility must subsequently inform NRC and state the reasons. 
A.2.1 Hours of Work: Routine Operations

The panel recommends relatively minor changes from present NRC policy regarding shift schedules for routine operation.

Maximum of 9 Hours Per Day (Including Shift Turnover Time)

Whereas present NRC policy recomends a maximum of an 8-hour day excluding shift turnover time, the panel recommends a maximum of a 9-hour day including shift turnover time. The panel's reasoning is that work during shift turnover adds to fatigue, and should be dealt with directly and explicitly.

As a result of the panel's decision to set hourly limits that include shift turnover time, all of the hourly limits in Tables A.1 and A.2 include shift turnover time.

The panel originally discussed setting limits on hours of work including commute time. If operators typically commuted to work in company-owned buses, the panel's recommendations might have explicitly included commute time. But because nuclear plant personne? generally drive to work in their own automobiles, the panel decided that NRC guidance dealing with commute time would be infeasible. Thus the panel decided to deal explicitly with shift turnover time, but not with commute time.

The panel discussed at length whether NRC should raise the maximum number of hours of work in one day to 13 . Some panelists favored the proposal, saying that many process control industries have changed to a 12-hour day without significant declines in safety and production. One panelist opposed the proposal, saying that data from several industries indicate that error rates are lowest in the 1st 4-hour period of work, are higher in the 2nd 4-hour period of work, and either remain the same or are still higher in the 3rd 4hour period. Even assuming that the error rates in the 2nd and 3rd 4-hour periods are equal (a conservative assumption), the total error rate over a 24hour period will be higher with 2 twelve-hour shifts than with 3 eight-hour shifts, because 2 twelve-hour shifts contain 4 four-hour periods with higher error rates, whereas 3 eight-hour shifts contain only 3 four-hour periods with higher error rates.

\section{Maximum of 54 Hours in an 8-Day Period}

Present policy recommends a routine schedule of an 8-hour day and a 40-hour week. By contrast, the panel recommends that routine schedules be limited to 54 hours in an 8-day period. As is indicated in Table A.2, the 54-hour maximum was derived as follows:

$$
(9 \mathrm{hrs} / \text { day }) \times(6 \text { days })=54 \mathrm{hrs} \text {. }
$$

The factor $9 \mathrm{hrs} / \mathrm{day}$ is the panel's recommended maximum number of hours of work per day, including shift turnover time. The factor 6 days was chosen instead of 5 because rotating shift schedules commonly have 6 consecutive work 
days, and because the panel judged 6 consecutive days of work to be a reasonable upper limit if the 6 days of work are followed by 2 days of rest and if the worker works an average of only 5 days per week over the period of a month, as is specified below.

\section{Maximum of 180 Hours in a Month}

The panel recommends that routine schedules be limited to a maximum of 180 hours of work in a month. The figure 180 is derived as follows:

$$
(9 \mathrm{hrs} / \text { day }) \times(5 \text { days } / \mathrm{wk}) \times(4 \mathrm{wks})=180 \mathrm{hrs} \text {. }
$$

Working an average of 5 days a week over the period of a month is consistent with present NRC policy of working a standard 8-hour day and a $40-$ hour week.

\section{Application to NRC to Exceed These Guidelines}

Present NRC policy recommends a routine schedule of 8-hour days and a 40 hour week. However, NRC has implicitly permitted several nuclear plants to operate with a 12-hour/day schedule (generaliy with 4 days on and 4 days off).

The panel recommends that NRC policy concerning routine operation be formalized, so that if a nuclear plant wishes to exceed the guidelines for routine operation, it would be required to apply for permission to do so. The NRC then would grant or withhold permission based on the merits of the individual case.

Some of the criteria the panel suggests that NRC use in determining the merits of each case are as follows:

1. The potential for increased fatigue toward the end of 12 hours of work, and toward the end of several consecutive days of 12 hours of work.

2. The commute time of plant personnel. Because many nuclear plants are located in isolated areas, one-way commute times of 90 minutes are not uncommon. A 3-hour round-trip drive could reduce time available for sleep. Thus, in considering the merits of an application, NRC might make a rough estimate of what the daily schedules would be with a 12-hour working day. In the following hypothetical example, a 3-hour commute leaves only 6 hours for sleep:

Work

Shift turnover time

Round-trip commute

Before work shower \& breakfast

After work dinner \& preparation for bed Sleep
12:00 hours

$0: 30$

$3: 00$

$1: 00$

$1: 30$

$6: 00$

Total $24: 00$ hours 
3. Whether the plant can cover absences without having anyone work more than 12 hours a day. Several methods exist for providing such assurance: (1) each crew could be large enough so that absentees need not be replaced; (2) the plant could have enough crews 50 that an absentee could be replaced by members of a crew that is off-duty or in training, or (3) the plant could place certain members of off-duty crews "on call" so that a replacement for an absentee would be assured.

4. The characteristics of the proposed schedule. For example, the panel recommends a maximum of four consecutive 12-hour night shifts.

5. The safety record of the plant.

6. Potential benefits of a 12-hour day schedule such as: (a) the reduction in shift turnovers from 3 to 2 in a 24 -hour period; (b) the increased likelihood that the crew that starts a maintenance task will also be able to finish the task; (c) the reduction in commute time over the course of a week, and (d) potential improvement in the morale of workers who prefer the 12-hour shift.

\section{A.2.2 Hours of Work: Overtime}

The panel recommended significant reductions in the maximum allowable number of hours of work when overtime is required. Overtime is indicated in Column B of Tables A.l and A.2.

Overtime Disallowed for One Senior Reactor Operator (SRO), One Reactor operator (RO) and One Auxiliary Operator (AO) Per Unit

Present NRC policy distinguishes between overtime "on an individual basis" and overtime "for the entire staff on shift" (see Section 2.4). As can be seen in the statement of present NRC policy, however, these terms are not defined. The panelists preferred that the terms be defined and asked Paul Lewis, who organized the panel meeting, to propose a definition. Paul Lewis first explained that the minimum number of operators required by NRC in sites with multiple units is not necessarily the minimum number at one unit multiplied by the number of units. He then offered the following definition of "overtime on an individual basis," which the panelists accepted.

"Overtime on an individual basis" means that overtime may be worked by some nembers of a crew as long as there are at least 3 people in each unit who have worked no overtime, and those 3 people are qualified to perform, and are at the time performing, the duties of an SRO, an RO and an $A O$, respectively.

Although this definition takes a step toward greater precision, it still leaves some issues undefined, such as (1) the length of time during which the 3 operators have worked no overtime, and (2) the definition of "on an individual basis" for personnel other than operators. 
Eliminate the Distinction Between "Problem During Operation" and "Extended Shutdown"

Present NRC policy distinguishes between "problem during operation" and "an extended shutdown." In the former case, overtime is allowed "on an individual basis only." In the latter, overtime is allowed for the entire staff on shift.

The panel recommends that this distinction be eliminated. Specifically, it recommends that overtime be allowed "on an individual basis," during both "problem during operations" and "extended outages." The panel recommends that overtime not be allowed for an entire crew.

The panel's main reason for this recommendation is that extended outages have safety implications that are fully as important as those of operations, especially because errors made during extended outages can compromise safe operations after the outage. Furthermore, crews that have worked long hours during extended outages might not have adequate time to rest before beginning the critical tasks of startup and operation.

\section{Maximum of 13 Hours Per Day (9 Hours for Night Shift)}

Whereas present NRC policy allows a maximum of 16 hours of work per day (excluding shift turnover time) when overtime is required, the panel recommends a maximum of 13 hours of work per day (including shift turnover time) for workers on the morning and afternoon shifts, and 9 hours (including shift turnover time) for workers on the night shift.

The panelists are aware of the importance of this issue, because we emphasized its importance during the meeting, and because a statement on the issue was included on page 3 of "Ten Alternative Recommendations..." in the packet of material sent to the panelists prior to the meeting. That statement reads as follows:

"[The former NRC policy on hours of work] ... set a maximum of 12 hours of continuous work in the case of unforeseen problems during operations. The present NRC policy allows 16 hours. One of the reasons for the change was as follows: if an operator is unexpectedly absent during the night shift, it is sometimes difficult to replace him. One way to replace him is to have an operator on the afternoon shift stay on to work the first four hours of the night shift (for a total of 12 hours of work), and then have an operator on the morning shift come in early to work the second four hours of the night shift plus his regular 8-hour morning shift (for a total of 12 hours of work). However, it is often difficult to awaken an operator at 2 AM and to have him arrive at the plant on time and alert. Based on the assumption that it might be easier and safer to have the operator on the afternoon shift work the entire night shift (for a total of 16 hours of work), the limit was raised." 
Some of the reasons the panelists recommend reducing the maximum number of hours of work from 16 to 13 are:

1. Working 16 consecutive hours is too fatiguing. It puts personnel at the limits of their endurance with insufficient reserves to handle an emergency.

2. The argument is sometimes made that adrenalin causes people to become alert once an emergency is detected. However, some potentially dangerous situations require an operator to be alert simply in order to detect, recognize, and analyze the seriousness of a situation. Panelists cited examples of airline pilots who made major errors and failed to recognize them until it was too late for adrenalin to help, such as pilots who forgot to lower their landing gear. Panelists also noted that big accidents often result from a combination of small errors. One example is the accident that occurred when the pilot of a $D C-10$ landed on the left runway instead of the right runway of two parallel runways in Mexico City. That error in itself was insignificant. But a dump truck happened to be on the ieft runway, and a major accident occurred before adrenalin could help.

3. In most cases the worker plans his energy expenditure for 8 hours of work; if he is later told to work an additional 8 hours, he will be unprepared and will thus have inadequate reserves of energy.

4. No other industry (regulated by the federal government) is allowed a maximum of 16 hours of work in a day.

5. Work in a nuclear power plant is not always "hours of boredom punctuated by moments of sheer terror." Work at nuclear plants can also include long periods of routine work, such as signing off for maintenance work, and conducting tests, and people get tired doing that type of work.

The reasons the panelists recommend that personnel on $\mathrm{night}$ shift not work more than 9 hours in a 24-hour period are: (1) a worker's circadian rhythms (a) will decrease alertness and increase the error rate after a $n i g h t$ shift, (2) night workers often have difficulty getting adequate sleep during the day, and (3) when a night worker is held over so that he is unable to get to sleep by 8 or $g$ AM, he often has difficulty falling asleep at all during the day.

(a) Circadian rhythms are bodily rhythms that oscillate within a period of approximately 1 day (circa = approximately, dian = day). The sleep/wake cycle is the most obvious circadian rhythm. Body temperature, gastric secretions, and many other bodily functions also have circadian rhythms. 


\section{Maximum of 22 Mours in a 48 -Hour Period}

Present NRC policy allows an individual to work a maximum of 16 hours one day and 8 hours the next day, for a total of 24 hours in 2 days. The panel recommends that a person be allowed to work a maximum of 13 hours one day (including shift turnover time) and 9 hours the next day, for a total of 22 hours in 2 days.

$$
\begin{array}{r}
13 \mathrm{hrs} \\
+\frac{9}{22 \mathrm{hrs}} .
\end{array}
$$

\section{Maximum of 66 Hours in a 7-Day Perjod}

Present NRC policy allows an individual to work a maximum of 72 hours in one week. The panel recommends a maximum of 66 hours (including shift turnover time). As is shown in Table A.2, 66 hours in 7 days can be achieved by working alternating 13- and 9-hour days for 6 days, followed by a day off:

$$
\begin{array}{r}
13 \mathrm{hrs} \\
9 \\
13 \\
9 \\
13 \\
9 \\
+\frac{0}{66 \mathrm{hrs}}
\end{array}
$$

\section{Maximum of 123 Hours in a 14-Day Period}

Present NRC policy does not quantify overtime limits for periods longer than one week. However, present policy does clearly rule out working at the weekly maximum for an unlimited number of weeks. The NRC policy statement allows personnel to work overtime only "on a temporary basis." The panel concurs with present NRC policy on this point, and further recommends establishing quantified limits on hours worked for periods of 2 weeks, 1 month and 1 year.

For the period of 2 weeks, the panel recommends a maximum of 123 hours. In 14 days 123 hours can be worked by combining 2 work weeks such as:

$$
\begin{array}{rr}
13 & 13 \mathrm{hrs} \\
9 & 9 \\
13 & 13 \\
9 & 9 \\
13 & 13 \\
9 & 0 \\
+\frac{0}{66}+\frac{0}{57}=123 \mathrm{hrs}
\end{array}
$$


Maximum of 213 Hours in a Month

The panel recommends a maximum of 213 hours in one month. In one month 123 hours can be worked by combining the two overtime weeks shown above, plus 2 weeks without overtime (a week without overtime is 45 hours per week, including shift turnover time).

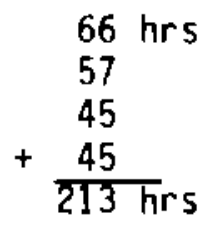

Maximum of 2400 Hours in a Year

The panel recommends a maximum of 2400 hours of work (including shift turnover time) per year. The panel derived this figure by multiplying the standard number of hours of work in a year and adding a maximum of $20 \%$ for overtime:

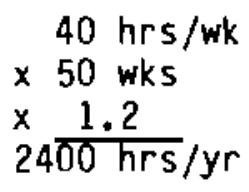

Based on its knowledge of overtime in other industries, the panel considered $10 \%$ overtime to be reasonable and $20 \%$ overtime in a year to be a maximum. This calculation is slightly different from the panel's other calculations: the number of hours in the base-period multiplier (40 hours) excludes shift turnover time, but the resulting maximum (2400 hours)

includes shift turnover time. This difference is deliberate: the panel feels that workers should work no more than 2400 hours in one year, including shift turnover time.

\section{Exceeding the Overtime Guidelines in Emergencies}

Present NRC policy states: "Recognizing that very unusual circumstances may arise requiring deviation from the above guidelines, such deviation shall be authorized by the plant manager ...."

The panel recommends that NRC continue its policy of not limiting hours of wark during an emergency. However, the panel recommends adding the following administrative requirements (see Note 2 in Tables A.1 and A.2): after the plant manager approves, the utility must (1) inform NRC, and (2) state the reason.

The panel further recommends that the term "very unusual circumstances" be replaced by "emergency situation," because the former term can be interpreted too broadly. For example, during an extended outage that clearly is not an emergency, a plant manager might approve exceeding 72 hours of work per week because "very unusual circumstances" required it. 
The panel recommends that the terms "non-emergency" and "emergency" (see Notes 1 and 2 in Tables A.I and A.2) be defined so that the hourly limits cannot be exceeded unless a true emergency exists. The panel realizes that a proper definition of "emergency" would depend on a detailed knowledge of the industry, but suggests, as examples, the following components of a definition:

o a breakdown of a safety system

o a potential threat to public safety

o a rapid and unexpected onset of such a situation.

Examples of "non-emergency" situations are:

o the desire to return the plant on-line as soon as possible

o the lack of a sufficient number of operators to operate the plant without excessive overtime.

The panel feels that if the utility is unable to run the plant in a nonemergency situation without exceeding the guidelines on the maximum number of hours worked, then the plant should be shut down until the situation can be corrected.

No Need to Regulate Hours of Rest

Present NRC policy includes both maximum hours of work and minimum hours of rest. The policy on minimum hours of rest is as follows:

"A break of at least eight hours should be allowed between work periods (including shift turnover time)."

The majority of panel members recommended 1 imits on hours of work but made no recommendations on hours of rest. One panel member, however, recommended establishing a policy on hours of rest, rather than hours of work. In particular, he felt that one 16-hour day would not be too fatiguing if the worker was assured adequate rest afterwards. Other panel members st $\overline{r o n g l y}$ emphasized the importance of job satisfaction and of days off, especialiy weekends and blocks of 3 to 7 consecutive days off.

\section{A.2.3 Enough 0perators to Staff 6 Crews}

Present NRC policy on the total number of operators is contained in the NRC policy statement on shift scheduling: "Enough plant operating personnel should be employed to maintain adequate shift coverage without routine heavy use of overtime."

When the panelists were informed that operators often work 12 hours/day and 72 hours/week for 2 or 3 consecutive months during outages, they concluded that NRC should attempt to deal with the root of the overtime problem, which is an 
insufficient number of operators. The panel recommends that present NRC policy concerning the number of operators be quantified: nuclear plants should be required to have enough licensed ROS and SROs to staff 6 crews.

Even if a plant has enough operators to staff 6 crews, it might still prefer 5 crews, with more operators per crew. It is the number of operators, not the number of crews, that reduces overtime per operator. Thus, the panel's recommendation specifies the number of operators, not the number of crews.

\section{A.2.4 Recommendation Against Setting Guidance on Speed and Direction of Rotation}

The panel recommends against making a regulation or policy statement concerning speed or direction of rotation because evidence does not justify making such a policy.

\section{Speed of Rotation}

"Rapid rotation" means that a crew changes to a different shift (i.e., rotates) every 1-3 days. "Weekly rotation" means that a crew rotates about every week. "Slow rotation" means that a crew rotates every 3-5 weeks.

One panelist stated that rapid rotation and slow rotation are both better than weekly rotation. It usually takes about a week of working night shift before one's circadian rhythms adjust to it. With slow rotation, one's circadian rhythms are given enough time to adjust to the night shift, and enough time to benefit from the adjustment. With rapid rotation, one's circadian rhythms are not given enough time to adjust, so they remain fixed at the normal daily cycle, which means that one's circadian rhythms are appropriate for the morning shift, the day shift and days off, which comprise most of the week. With weekly rotation, however, a worker's circadian rhythms barely adjust to night shift before he rotates to the next shift. Because this same process occurs every week, his circadian rhythms are always out of synchrony with his work schedule.

Another panelist stated that slowly rotating shift schedules do not exist in practice, because as soon as a worker gets a day off, which is approximately once per week, he immediately reverts to the normal daytime schedule.

Dr. Cariton Melton reported that his studies (e.g., Melton et al. 1973) produced no evidence of increased fatigue among air traffic controliers on a rapidiy rotating shift schedule. That schedule, called the 2-2-1 schedule or "the rattler", makes a complete cycle, rotating backwards (2 afternoon shifts, 2 morning shifts, one night shift) in $8 \mathrm{~B}$ hours, leaving an 80-hour ( 3 days plus 8 hours) "weekend." (It should be noted that the 2-2-1 schedule could not be used by nuclear plant operators because it includes only half as many night shifts as morning and afternoon shifts. This is due to the lighter nighttime workload for air traffic controllers.) 


\section{Direction of Rotation}

"Forward rotation" means that a crew rotates in the direction the clock moves, i.e., from morning shift to afternoon shift to night shift, back to day shift, and so forth. "Backward rotation" is the opposite direction.

Although the panel recommended against making a policy statement on direction of rotation at this time, individual panel members did make statements on the subject that indicate the complexity of the issue. Severa? of these statements are summarized below.

Dr. Carlton Melton cited his study of the air traffic controllers' 2-2-1 schedule. On this schedule, a controller works two afternoon shifts, two morning shifts, and one night shift; i.e., it is a backward rotating shift schedule. Dr. Melton's study indicated that the 2-2-1 schedule is at least no worse than the "straight 5" schedule. (The "straight 5 " schedule is a schedule with weekly rotation, i.e., with 5 days of work followed by 2 days off. Straight 5 schedules can rotate either forward or backward.) Most controllers preferred the 2-2-1 schedule over the straight five. To the controllers, one of the primary advantages of the 2-2-1 schedule is the long weekend between work periods.

Another panelist stated that the argument for forward rotation applies only to schedules in which the period of rotation is one week or longer because the argument only applies when one's "body clock" attempts to adapt to the changed work/rest schedule. In a rapidly rotating schedule, such as the 2-2-1 schedule of the air traffic controllers, rotation is so rapid that the "body clock" essentially makes no attempt to adjust, and thus remains on its normal day/night rhythm. This panelist, however, did state his belief that if the period of rotation is one week or longer, then backward rotation would produce more fatigue. This panelist admitted that no study has yet provided adequate evidence for this belief. (The Great Salt Lake experiment by Czeisler, MooreEde, and Coleman (1982) attempted to provide evidence for this belief, and an increase in productivity was recorded at the plant after one-third of the employees switched to a forward rotating shift schedule. However, the increase in productivity could plausibiy be attributed to several factors other than forward rotation, so this evidence is not strong.)

A third panelist stated that most experts favor forward rotation.

\section{A.2.5 Other Recommendations}

Individual panelists offered the following recommendations and comments. The panel as a whole did not vote on them.

Proposal to Develop a Fatigue Index is Inadequate

PNL's proposal to develop a fatigue index was stated in the report entitled "Plan for the Development of a Fatigue Index for Nuclear Power Plants," which was included in the packet of material sent to the panelists before the meeting. A fatigue index is a quantification of relationships among hours of work, fatigue, and performance. 
One panelist stated that PNL's proposal to develop a fatigue index for the nuclear power industry is unacceptable, primarily because it proposed to use retrospective data on fatigue levels and performance, both of which would be unreliable, and indeed "completely meaningless." The panelist recommended instead the use of sleep logs. He also stated, however, that collecting the data properly would be "incredibly expensive."

To develop the index, one panelist recommended the Stanford Sleepiness Scale, another panelist recommended against it, and two other panelists suggested alternatives.

One panelist noted that existing fatigue indexes for airline pilots are based on very limited data, and fatigue indexes are used primarily to resolve differences between employees who regularly pilot or fly airplanes and their employers. Although the International Civil Aviation Organization has continued to use its fatigue index for about ten years, panelists indicated that in the airline industry, fatigue indexes are used infrequently, if at all. Existing fatigue indexes have not been used to develop federal regulations.

\section{NRC Should Collect More Information}

The panel recommends that NRC and PNL collect more information on routine shift schedules and overtime practices in the nuclear industry. According to one panelist, trying to recommend a policy without such basic information is like "trying to perform Hamlet without the Prince."

\section{Establish an Anonymous Safety Reporting System}

Panelists strongly recommend that NRC establish an anonymous safety reporting system similar to the Aviation Safety Reporting System (ASRS) in the airline industry. ASRS, an anonymous safety reporting system operated by NASA and Battelle for the Federal Aviation Administration, is considered by most experts to be the best source of information on human error in the airline industry. A similar system could collect equally important information for NRC and the nuclear industry.

\section{Provide Information to Utilities on the Effects of Shift Scheduling}

Panel members recomend that NRC and PNL provide information to utilities on the effects of various shift schedules and overtime practices--particularly if the NRC wishes to change its present policy.

\section{Suggested Training Solutions to Operator Error}

Dr. Graeber is currently a member of a team of research scientists who are conducting an extensive study of fatigue among commercial airline pilots. As a result of that study effort, Dr. Graeber recommends that in addition to setting limits on hours of work, the NRC and the nuclear industry also pursue positive approaches to reducing shiftwork errors. In particular, Dr. Graeber and other panel members recommend the training practices that are currently popular in 
the airline industry: full-mission simulation training for entire crews (where subtle malfunctions are introduced and problem solving is observed and taped for subsequent crew debriefing), emphasizing improved crew combnunication, and extensive cross-training. The use of "full-mission" simulations may be a way to gather some useful data on performance, by comparing the performance of crews working different schedules.

\section{A.3 COMPARISON OF PANEL RECOMMENDATIONS WITH CURRENT SHIFT SCHEDULES}

The panel urged that PNL compare the panel's recommendations with shift schedules currently in use at nuclear plants. Recognizing that a wide variety of shift schedules exist in the nuclear industry, the panelists want to avoid disallowing unusual but reasonable schedules, and want to ensure that their recommendations give nuclear power plants reasonable means to adapt to problems.

The schedules of 7 nuclear plants are presented in Appendix $G$ of this report. The panel recommendations were compared with these 7 schedules; the results of the comparison are presented below.

Although most of the plant schedules come close to meeting the panel's recommended guidelines, strictly speaking none of them do, for the following reasons:

o Whereas the panel recommended a maximum of 54 hours (6 days) of work in a period of 8 consecutive days, Plants No. 2 - 5 all have 7 consecutive days of work, and Plant No, 1 has 8 consecut ive days of work.

o Whereas the panel recommended a maximum of 180 hours (20 days) of work in a 4-week period, Plants No. 1 - 5 have 21-23 days of work in a period of 28 consecutive days.

o Plant No. 6 would have to apply for special permission to continue its 12hour/day shift schedule. In deciding whether to grant permission, NRC would have to take into account the fact that it is not quite a "4 on - 4 of $f$ " schedule, because at one point 4 days on is followed by only 3 days off. 


\section{A.4 THE PANELISTS(a)}

Robert A. Alkov, Ph.D. Head, Behavioral Science Branch, Aeromedical Division, Aviation Safety, U.S. Naval Safety Center, NAS, Norfolk, Virginia. Dr. Alkov's responsibilities include recomending federal regulations based upon research results.

R. Curtis Graeber, Ph.D. Dr. Graeber is a Research Psychologist in the Aerospace Human Factors Research Division, NASA-Ames Research Center, California. He is the principal investigator for a Congressionally mandated multi-million dollar study of the effect of hours of work and time zone changes on airline pilot performance.

Robert Henderson. Mr. Henderson works for the Bureau of Motor Vehicle Safety, which is responsible for government regulations concerning the operation of motor vehicles.

Gary Krieger, M.D. Dr. Krieger is Director, Occupational Medicine Department and Urgent Care Clinic, Boulder Medical Center. Dr. Krieger has gathered data on the effect of various types of shift schedules on the performance of operators at refineries of Exxon Chemical Anericas. He has also worked with Dr. Charles Czeisler and Dr. Martin Moore-Ede at the Center for Design of Industrial Schedules in Boston, Massachusetts.

Carlton Melton, Ph.D. Dr. Melton is Supervisor, Aviation Physiology Laboratory, FAA Civil Aeromedical Institute, Mike Monroney Aeronautical Center, Oklahoma City. Dr. Melton has done work on subjective measures of fatigue, circadian effects, and shift rotation.

Timothy Monk, Ph.D. Dr. Monk led several studies concerning the effect of shift work on performance in the United Kingdom. He is now working at the Institute of Chronobiology at the New York Hospital--Cornell Medical Center, White Plains, New York. He is presently conducting research on the effect of time zone changes on pilot performance under a contract to NASA Ames.

Richard Moore, M.D. Chief, Special Medical Operations at the U.S. Coast Guard headquarters in washington, D.C. His responsibilities include determining whether fatigue is a contributing cause of errors by Coast Guard rescue pilots.

Franz Schneider. Mr. Schneider is a founding member of Mantech, a human factors consulting firm. He is also the Supervising Safety Specialist, Health and Safety Division, Ontario Hydro. He was on the task force that evaluated the 12-hour shifts at the Bruce Heavy Water Plant.

William Storm, Ph.D. Dr. Storm is a researcher in the USAF School of Aerospace Medicine at Brooks Air Force Base, Texas. He has led several simulator and field experiments to determine the effect of extended hours of flight on subjective fatigue, physiological measures, and performance among Air Force pilots.

(a) The views expressed by the panelists at this meeting are their own, and are in no way intended to represent those of their organizations or employers. More detailed resumes of the panelists are presented in the following pages. 
ROBERT A. ALKOV, Ph.D.

Dr. Alkov is the head of the Behavioral Science Branch, Aeromedical

Division, Aviation Safety, U.S. Naval Safety Center, NAS, Norfolk, Virginia.

\section{EDUCATION}

M.S. General Experimental Psychology. The Florida State University. 1962

Ph.D. Experimental Psychology. The FTorida State University. 1965

\section{PROFESSIONAL EXPERIENCE}

Research Psychologist, U.S. Naval Safety Center, since 1 August, 1966. Served as project director for Human Error Research and Analys is Program contracted by Navy to Douglas Aircraft Company (1966-1970). Responsible for project definition, planning, technical guidance, etc. Project required collection of data from various Naval sources and commands. Since then he has planned, coordinated, directed, and performed numerous studies into the causes of human error in aviation mishaps. He has analyzed accident reports and Medical Officers' Reports of accidents for pertinant human factors problems. He has acted as consultant in aviation safety and human factors to various Navy agencies and other Department of Defense and government offices involved in aviation safety.

Dr. Alkov served as a Research Associate at George Washington University's Human Resources Research Office, Division 6 (Aviation), Fort Rucker, Alabama, $1965-1966$.

He served on active duty in the U.S. Navy from 1953 to 1957 . He went through Navy flight training and was designated Nava? Aviator in 1955.

\section{PROFESSIONAL STANDING}

Past President, Association of Aviation Psychologists

Past Chairman, Safety Technical Interest Group of the Human Factors Society

Past President, Tidewater Chapter, Human Factors Society

Associate Fellow, Aerospace Medical Association

\section{SELECTEO PUBLICATIONS}

"The Human Error Research and Analys is Program." Journal of Aircraft Vol. 5, No. 5, 1968, pp. 497-501 (with Mastropaolo, Burrows and Luehrs).

"A Questionnaire Study of Psychological Background Factors in U.S. Navy Aircraft Accidents." Aviation, Space and Environmental Medicine.Vol. 51, No. 9, Section 1, pp. 860-863, Sept. 1980, (with Borowsky). 
(Dr. Alkov, cont.)

"Psychological Stress, Health and Human Error." Professional Safety. Vol. 26, No. 8, pp. 12-14, August 1981.

"Stress Coping and the U.S. Navy Aircrew Factor Mishap." Aviation, Space and Environmental Medicine. Vol. 53, No. 11, pp. 1112-1115 (with Borosky and Gaynor).

"Human Factors in Aircraft Accidents" Parts I and II, APPROACH. Vo1. 25, Nos. 6, 7. 1980 (with Shannon).

"Am I Too Tired?" APPROACH. Vo1. 26, No. 8, 1381, pp. 24-25.

\section{SELECTED PRESENTATIONS}

"Crew Performance as a Function of Flight Duration (Fatigue) in an Operational Simulator." Aerospace Medical Association Convention, San Francisco, California, 1969.

"Pilot Error Accidents Aboard Aircraft Carriers and Ashore... A Comparison of Day and Night Rates." Forty-second Annual Scientific Meeting of the Aerospace Medica1 Association, Houston, Texas, 1971,

"Life Stresses, Biorhythms and Aircraft Accidents." Third Annual Seminar of the Society of Air Safety Investigators, Washington, D.C., 1972.

"Life Changes and PiTot Error Accidents." The Fourth Symposium on Psychology in the Air Force, 1974.

\section{OUTSIDE CONSULTANT SERVICES}

Served as a consultant to the FAA in the writing of a student pilot's training manual on judgment (wrote the chapter on stress).

Served as Technical Advisor on film "Accident on the Way to Happening" MN11375.

\section{AERONAUTICAL RATINGS}

Dr. Alkov holds a commercial pilot's license with multi and single engine glider and instrument ratings. 


\section{R. CURTIS GRAEBER, Ph.D.}

Dr. Graeber is a Research Psychologist in the Aero-space Human Factors Research Division, NASA-Ames Research Center, Moffet Field, California.

\section{EDUCATIDN}

M.A. Experimental Psychology, University of Virginia, Charlottesville, 1970

Ph.D. Physiological Psychology, Univ. of Virginia, Charlottesville, 1972

\section{MILITARY SERV ICE}

U.S. ARMY. Active duty, Medical Service Corps, 1969 - present. Current rank: Major. (selected for Lieutenant Colonel)

\section{SELECTED PROFESSIONAL EXPERIENCE}

Research Psychologist: Department of Military Medical Psychophysiology, Division of Neuropsychiatry, Walter Reed Army Institute of Research, Washington, D.C., 1977-1981 (Deputy Chief, 1981).

\section{PARTICIPATION IN PROFESSIONAL SOCIETY ACTIVITIES}

Aerospace Medical Association: member, 1981-present; Board of Directors, 1983 -present.

International Society for Chronobiology: member, 1975-present.

American Association for the Advancement of Science: member, 1972-75, 1980present.

\section{AERONAUTICAL RATINGS}

Private pilot: airplane single engine land.

\section{SELECTED HONORS AND AWARDS}

Commander's Award in Science, U.S. Army Natick Research and Development Command, 1974.

U.S. Army Commendation Medal, 1976, with oak leaf cluster, 1983. 
(Dr. Graeber, cont.)

SELECTED PUBLICATIONS

Brown, F.M. and R.C. Graeber. 1982. Rhythmic Aspects of Behavior. Erlboum Associates, Hillsdale, N.J.

Levine, Jacobs, Graeber, Thompson and Halberg. 1975. "Timing Circadian Group Rhythm Characteristics for Physiologic, Physical and Mental

Performance of Subjects on a Limited Free-Choice Diet." Chronobiologia. 2(Supp 1. 1): 24, (abstract).

Levine, Halberg, Halberg, Thompson, Graeber, Thompson and Jacobs. "Changes in the Internal Timing of Heart Rate, Diastolic Blood Pressure and Certain Aspects of Physical and Mental Performance in Presumably Healthy Subjects on Different Mea 1 Schedules." XII International Conf. Proc. of Internationa? Soc. Chronobiology. Milan: "I I Ponte", 139-148, 1977.

Graeber, Cuthbert, Sing, Schneider, and Sessions. "Rapid Transmeridinal Deployment: I. Use of Chronobiologica Countermeasures to Hasten Time Zone Adjustment in Soldiers." XIV International Conf. Proc. of International Soc. Chronobiology, Milan: "Il Ponte." in press. (Also Chronobiologia, $6: 102,1979$, Abstract.)

Cuthbert, Graeber, Sing, and Schneider. "Rapid Transmeridial Deployment: II. Effects of Age and Countermeasures Under Field Conditions." XIV International Conf. Proc. of International Soc. Chronobiology, Milan: "Il Ponte." in press. (Also Chronobiologia, 6:91, 1979, Abstract.)

Graeber. "Alterations in Performance Following Rapid Transmeridian Flight." Chronobiologia, 6:101-102, 1979 (Abstract).

Graeber. "Recent Studies Relative to the Airlifting of Military Units Across Time Zones." In L. Scheving and F. Halberg (eds.) Chronobiology: Principles and Applications to Shifts in Schedules. Alphen aan den Rijn, Sitjhoff \& Noordhoof, 1980, pp. 353-369.

Graeher, Foushee and Lauber. "Dimensions of Flight Crew Performance Decrements: Methodological Implications for Field Research." In Cullen, Siegrist, and Wegmann (eds.) Breakdown in Human Adaptation to 'Stress'

Vo1. 1. The Haque, M. Nijhjoff Pub7., 1984, pp. 584-605.

\section{SELECTED PRESENTATIONS}

Graeber. "Circadian Rhythms in Cognitive Performance." Presented at an invited symposium on "Biological Rhythms and Behavior: Theoretical and Practical Aspects," Annual Meeting at the Western Psychological Association, San Francisco, CA, 1983.

Conne 11, Gander, and Graeber. "Chronobiology in the Cockpit." Presented at 3rd Gordon Research Conference on Chronobiology, Colby-Sawyer College, NH, 1983. 


\section{GARY R. KRIEGER, M.D.}

Dr. Krieger is the Director of the Occupational Medicine Department and Urgent Care Clinic, Boulder Medical Center, P.C., Boulder, Colorado. He is responsible for the development of full-service occupational medicine programs for area businesses.

\section{PROFESSIONAL EXPERIENCE}

Consultant; Circadian Physiology Laboratory, Harvard Medical School. He produced studies on the effects of shift work on vigilance, performnce, productivity and safety.

Medical Director; Exxon Chemical Americas, Houston Area. He was responsible for the development of full-service occupational medicine programs at five facilities with combined population of 1,800 .

Board Eliqible; American Board of Occupational Medicine

Board Certified; American Board of Internal Medicine

\section{EDUCATION}

1981-82 Johns Hopkins School of Hygiene and Public Health, Departments of Occupational Medicine and International Health - Masters Public Health (M.P.H.)

1978-81 Mayo Clinic, Department of Medicine - Internship, Residency

1973-78 University of North Carolina, M.D. Degree

Selected Honors and Awards:

Faculty Award for Student Research

Honors: Medicine, Surgery, Ob-Gyn

Overall Honors: Senior Medical Student

\section{SELECTED PUBLICATIONS AND PRESENTATIONS}

1984 American Occupational Medicine Association Meeting: Abstract "A Program of Chronohygiene for the Shift Worker" Moderator - Panel Discussion "Alternate Shift Schedules"

1984 Presentation: "Plant Safety and Productivity as a Function of Shift Schedule."

Texas Chemical Council Occupational Safety Committee 
(Dr. Krieger, cont.)

1983- Multiple presentations to Fortune 500 corporations on effects of shift work on vigilance, performance, and productivity

1983 Invited participant: Gordon Research Conference on "Chronobiology"

1983 Testimony before the Investigations and Oversight Subcommittee on Science and Technology, U.S. House of Representatives "Shiftwork and the Petrochemical Industry: Defining Concerns Formulating Solutions" 
CARLTON E. MELTON, Ph.D.

At the time of the panel meeting, Dr. Melton was the Chief, Aviation Physiology Laboratory, GS-15, Civil Aeromedical Institute, Federal Aviation Administration, Oklahoma City. Dr. Melton is now retired from government service and is a private consultant.

\section{EDUCATION}

M.S. Zoology, University of Illinois, Urbana, 1950

Ph.D. Physiology, University of Illinois, Urbana, 1953

\section{AWARDS}

Arnold D. Tuttle Memorial Award of the Aerospace Medical Association 1979, for outstanding research achievements in Aviation Medicine.

\section{SELECTED PROFESSIONAL EXPERIENCE}

Chief, Electrophysiology Section, Neurophysiology Branch, Civil Aeromedical Research Institute, 1961-65.

Associate Professor of Research Physiology, Member of the Graduate Faculty, University of Oklahoma School of Medicine, 1961-66.

Professor of Research Physiology at the Oklahoma University Health Sciences Center, 1966-present.

Chief, Stress Physiology Unit, Aviation Physiology Laboratory, Aeromedical Research Branch, Civit Aeromedical Institute, 1965-75.

Chief, Aviation Physiology Laboratory, Aeromedical Research Branch, GS-15, Civil Aeromedical Institute, 1975-84.

\section{PARTICIPATION IN PROFESSIONAL SOCIETY ACTIVITIES}

American Physiological Society, the American Association of Anatomists, the Aerospace Medical Association, and the Society of the Sigma $X i$.

\section{AERONAUTICAL RATINGS}

Conmercial Pilot with instrument and flight instructor ratings. 
(Dr. Melton, cont.)

\section{SELECTED PUBLICATIONS}

Balke and Melton. "Physiological Stress and Fatigue in Aerial Missions for the Control of Forest Fires." Aerospace Medicine 37:221-227, 1966.

Hale, Williams, Smith, and Melton. "Excretion Patterns of Air Traffic Controllers." Aerospace Medicine 42:128-138, 1971.

Hale, Williams, Smith, and Melton. "Neuroendocrine and Metabolic Responses to Intermittent Night Shift Work." Aerospace Medicine 42:156-162, 1971.

Smith, Melton, and McKenzie. "Affect Adjective Check List Assessment of Mood Variation in Air Traffic Controllers." Aerospace Medicine 42:1060 $1064,1971$.

Smith, Melton. "Susceptibility to Anxiety and Shift Difficulty as Determinants of State Anxiety in Air Traffic Controllers." Aerospace Medicine 45:549-601, 1974. Also reprinted in The Journal of Air Traffic Control. 16:5-7, 1974.

Melton, McKenzie, Kelln, Hoffmann, and Saldivar. "Effect of a General Aviation Trainer on the Stress of Flight Training." Aviation, Space and Environmental Medicine 46:1-5, 1975.

Melton. "Comparison of U.S. Air Traffic Control Facilities By Means of a Stress Index." The Controller 14:28-31, 1975.

Melton, McKenzie, Saldivar, and Hoffmann. "Studies on Stress in Aviation Personnel: Analys is and Presentation of Data Derived From a Battery of Measurements." AGARD CPP 180:A9-1 - A9-6, 1975.

Melton. "Biochemical and Physiological Estimate of Stress in U.S. Air Traffic Controllers." Proceedings of the Symposium on Stresses of the Air Traffic Control Officer (Latest Developments). University of Manchester, Department of Postgraduate Medical Studies and the Guild of Air Traffic Control Officers (U.K.), 1976.

Melton, Smith, McKenzie, Hoffman, and Saldivar. "Stress in Air Traffic Controllers: Effects of ARTS-III," Aviation, Space and Environmental Medicine 47:925-930, 1976.

Melton and Smith. "Shedding Some Light on Stress." FAA World 8:14-16, 1978.

Melton, Smith, McKenzie, Wicks, and Saldivar. "Stress in Air Traffic Personnel: Low Density Towers and Flight Service Stations." Aviation Space and Environmental Medicine 49:724-728, 1978. 
(Or. Melton, cont.)

Melton. "Workload and Stress in Air Traffic Controllers." AGARDograph No. 246:137-144, 1979.

\section{SELECTED TECHNICAL REPORTS}

Melton. "Physiological Recordings From Pilots Operating an Aircraft Simulator." OAM Report AM-64-18, September 1964.

Melton and Wicks. "Effect of Age on Binocular Fusion Time." OAM Report 6635 , October 1966.

Salvidar, Hoffman, and Melton. "Sleep in Air Traffic Controllers." OAM Report AM-77-5, 1977.

Melton, Mckenzie, Wicks, and Saldivar. "Fatigue in Flight Inspection Field Office (FIF0) Flight Crews." OAM Report FAA-AM-81-13, 1981.

\section{SELECTED RELATIONSHIPS WITH OTHER GOVERNMENT AGENCIES}

Collaborative research related to objective determination of flight and duty time limits. U.S. Forest Service, Department of Agriculture, Aerial Fire Depot, Missoula, Montana, 1964-1968.

Collaborative research on biochemical indicators of human operator stress. U.S. Air Force School of Aviation Medicine, 1968-1970, and U. S. Naval Air Development Center, Johnsville, Warminster, Pennsylvania, 1968-1974. 
TIMOTHY H. MONK, Ph.D.

Dr. Monk is an Assistant Professor of Psychology in Psychiatry, Cornell University Medical College. His office is located in the Institute of Chronobiology, New York Hospital--Cornell Medical Center, White Plains, New York.

\section{EDUCATION}

BSc (1st Class Joint Honours) Mathematics and Psychology, University of Nottingham, Nottingham, England

Ph.D. Psychology, University of Nottingham, Nottingham, England

\section{MAJOR RESEARCH INTEREST AND SUPPORT}

Circadian rhythms in human cognitive performance and affective state, their relationship to physiological circadian rhythms and sleep; and the effect on them of a change in, or removal of, the factors serving to symchronize them.

Principal Investigator of NASA-Ames research, "Effectiveness of Circadian Countermeasures in Simulated Transmeridian Flight Schedules."

Supported by grants: "Psychoneuroendocrine Rhythms, Aging, and Sleep."

\section{ADVISORY BOARDS}

Scientific Committee on Shiftwork (PCIAOH)

International Scientific Advisory Board of the Center for the Design of Industrial Schedules

\section{SELECTED PUBLICATIONS}

"The Effect of Memory Load on the Circadian Variation in Performance Efficiency Under a Rapidly Rotating Shift System." By Folkard, Knauth, Monk, and Rutenfranz. Ergonomics. 1976, 19, 479-488.

"Concealed Inefficiency of Late Night Study." By Monk and Folkard. Nature 1978, 273, 296-297.

"Short and Long-Term Adjustment of Circadian Rhythms in 'Permanent' Night Nurses." By Folkard, Monk, and Lobban. Ergonomics, 1978, 21, 785-799.

"Towards a Predictive Test of Adjustment to Shiftwork." By Folkard, Monk, and Lobban. Ergonomics, 1979, 22, 79-91. 
(Dr. Monk, cont.)

"Shiftwork and Performance." By Folkard and Monk. Human Factors, 1979, $21,483-492$.

"Time of Day and Processing Strategy in Free Recall." By Folkard and Monk. Quarterly Journal of Experimental Psychology, 1979, 31, 461-475.

"Circadian Rhythms in Human Memory." By Folkard and Monk. British Journal of Psychology, 1980, 71, 295-307.

"Traffic Accident Increases as an Indicant of Desynchronosis." By Monk. Chronobiologia, 1980, 7, 527-529.

"A Field Study of Circadian Rhythms in Actual and Interpolated Task Performance." By Monk and Embrey. In Reinberg, Vieux, and Andlauer (eds.) Night and Shift Work: Biological and Social Aspects. Pergamon Press, 0xford, $1981,427-480$.

"Individual Differences in the Circadian Response to a Weekly Rotating Shift System." By Folkard and Monk. In Reinberg, Vieux, and Andlauer (eds.) Night and Shift Work: Biological and Social Aspects. Pergamon Press, 0xford, 1981, 365-374.

"Research Methods on Chronobiology." T.H. Monk. In Webb (ed.) Biological Rhythms, Sleep, and Performance. John Wiley and Sons, Chichester, 1982, 27-57.

"The Arousal Model of Time of Day Effects in Human Performance Efficiency." T.H. Monk. Chronobiologia, 1982, 9, 49-54.

"Time of Day Effects in Simple Repetitive Tasks: Some Possible Mechanisms." By Monk and Leng. Acta Psychologica, 1982, 51, 207-221.

"Circadian Rhythms and Shiftwork." By Monk and Folkard. In Hockey (ed.) Stress and Fatigue in Human Performance, John Wiley and Sons, Chichester, 1983, 97-121.

"Circadian Rhythms in Subjective Alertness and Core Body Temperature." By Monk, Leng, Folkard and Weitzman. Chronobiologia, 1983, 10, 49-55.

"Chronopsychology: Circadian Rhythms and Human Performance." By Folkard and Monk. In Gale and Edwards (eds.) Physiological Correlates of Human Behavior Volume 2. Academic Press, London, 1983, 57-78.

"Task Variables Determine Which Biological Clock Controls Circadian Rhythms in Human Performance." By Monk, Weitzman, Fookson, Moline, Kronauer, and Gander. Nature, 1983, 304, 543-545.

"Search." T.H. Monk. In Warm (ed.) Sustained Attention in Human

Performance, John Wiley and Sons, Chichester. In press.(Dr. Monk, cont.) 
(Dr. Monk, cont.)

"Subjective Sleepiness--The Underlying Circadian Mechanisms." By Monk, Weitzman, Fookson, and Moline. Submitted to Nature.

\section{GOVERNMENT REPORTS}

Individual Differences and Adjustment to Shiftwork. By Folkard, Monk, and Lewis. Final Report to the European Foundation for the Improvement of Working and Living Conditions.

European Shiftwork Research. T.H. Monk. Hearings before the Subcomittee on Investigations and 0versight of the Committee on Science and Technology, House of Representatives, 98th Congress. U.S. Government Printing Office, Washington, D.C., 1983, 389-407.

BOOK

Hours of Work. Folkard and Monk (eds). Commissioned by John Wiley and Sons, Chichester (currently in preparation). 
RICHARD C. MOORE, USPHS

Dr. Moore is the Chief, Special Medical Operations at the U.S. Coast Guard headquarters in Washington, D.C. His responsibilities include determining whether fatigue is a contributing cause of errors by Coast Guard rescue pilots. His current rank: Commander.

\section{EDUCATION}

University of California, Los Angeles, M.D. 1972

South Baltimore General Hospital Rotating 0 1972-1973

Johns Hopkins University MPH 1981

\section{PROFESSIONAL ORGANIZATIONS}

Diplomate, American Board of Family Practice, 1978

Sigma Phi Epsilon, Alpha Phi Omega, Alpha Omega Alpha

Society of U.S. Nava? Flight Surgeons

Association of Naval Aviation

Med-Chi Faculty of Maryland

Aerospace Medical Association

Southern Medical Association

\section{MIL ITARY AWARDS}

Humanitarian Service Medal, National Defense Service Medal, U.S, Navy Meritorious Unit, U.S. Coast Guard Meritorious Unit, USCG Unit Commendation with "0", USCG Achievement Meda?.

\section{PROFESSIONAL EXPERIENCE}

1973 Emergency room physician, SBGH

1973-76 Medical Corps, U.S. Navy, U.S. Navy Flight Surgeon Class 74-1; VQ4, NATC Patuxent River, MD. Highest rank: LCDR.

1976- Commissioned Officer, USPHS detailed to Coast Guard. Senior present Medical Officer, USCG Aviation Training Center, Mobile AL. Chief, Special Medical Operations, USCG HQ, Washington, D.C. 


\section{FRANZ SCHNEIDER}

$\mathrm{Mr}$. Schneider is the director of an ergonomic research laboratory at Ontario Hydro. He is also the senior principal at MANTECH, a human factors consulting firm.

\section{EDUCATION}

M.S. Erqonomics, Department of Human Biology, University of Guelph

D.S1. Industrial Engineering, Cologne, West Germany

B.S. Psychology, State University of New York

B.S. Physiology, State University of New York

\section{SELECTED PROFESSIONAL EXPERIENCE}

Director of ergonomic research laboratory at Ontario Hydro. Projects included standards development on hours of work and ambient environment, development of accident investigation techniques, development of management training program in systems safety and safe management, productivity enhancement, analyses of video display terminal work station requirements, measurement and prediction of human reliability coefficients for nuclear applications, shiftwork, back injury prevention, research and evaluation of tradesman work methods, product designs, development of eronomic reference base for engineers and designers, and procedural content and formatting.

MANTECH Consultant (Toronto and New York), Senior Principal. Consulted on productivity and safety enhancement for Nissan, General Motors, Dupont, Sony, among others.

Published monthly bulletin covering key developments in areas of human factors, management of productivity, and labour-relations issues of new technologies specifically designed to meet the needs of each subscriber. Presently, services 15 different client profiles.

\section{SELECTED PUBLICATIONS}

Schneider, M. F. 1983. "Human Factors in Nuclear Power Plant Operation." Joint Meeting of the H.U.F.A.C, and the C.N.A., Toronto, Canada.

Kelley, R., and M. F. Schneider. 1983. "The 12 Hour Shift Revisited Implications for Human Reliability." 12th Annual Conference on Night and Shiftwork, Kyoto, Japan.

Schneider, M. F., J. Brooke and N. Morey. 1983. "A Method for the Quantification of Human Performance in Low Probability/High Consequence Events." 13th Annual Meeting of the Human Factors Association of Canada, Hamilton, Ontario. 
(M. Franz Schneider, cont.)

Schneider, M. F. 1983. "The Application of Ergonomics to the Utility." In Press.

Schneider, M. F. 1983. "The Role of Human Factors in the Reduction of Occupational Electrical Contact Accidents." 12th Annual Meeting of the International Labour Office, Congress on Occupational Risk Due to Electricity, Cologne, West Germany.

Lueder, and M. F. Schneider. 1983. "The Ergonomic Requirements of Keyboard Design." Computing Now. In Press.

\section{IN-HOUSE PUBLICATIONS}

Schneider, M. F., and Jackson. 1983. The Design of Procedures.

Schneider, M. F., J. Martin and Walsh. 1983. A Review of Video Display Ergonomics.

Schneider, M. F., and Donne11y. 1983. What is System Safety?

Schneider, M. F. 1983. The Requirements for Effective Safety Propaganda.

Schneider, M. F. 1983. A Human Error Analysis Method for Accident Investigations.

Schneider, M. F. 1984. The Application of Ergonomics to Productivity Enhancement in General Motors.

Schneider, M. F. 1984. Applications of Human Factor Enhancements for the Nissan "Kan Ban" Program.

Schneider, M. F. 1984. An Analys is of Human Factor Implications from

"Pursuit of Excellence".

Schneider, M. F., Lueder and Vanderhoef, 1984. An Ergonomics and Productivity Enhancement Program for Hewlett Packard. 


\section{WILLIAM F. STORM, Ph.D.}

Or. Storm is a Supervisory Research Psychologist, GM-14. Chief, Psychophysiology Function, Aerospace Research Branch, Crew Technology Division, USAF School of Aerospace Medicine, Aerospace Medical Division (AFSC), Brooks Air Force Base, Texas, 78235.

\section{EDUCATION}

M.A. Experimental Psychology, San Diego State College, 1965

Ph.D. Experimental Psychology, University of Missouri, 1970

MIL ITARY SERV ICE

USAिF Reserve Program, 1962-1968

\section{SELECTED HONORS AND AWARDS}

USAF School of Aerospace Medicine Outstanding Professional Civilian, 1980 Sustained Superior Performance Award, 1982, 1983

\section{PROFESSIONAL EXPERIENCE}

National Research Council Research Associate: 1969-1971, Psychophysiology of Sleep in Primates; Work/Rest Schedules. 6571st Aeromedical Research Laboratory. USAF Fellowship Program, GS-12 equivalent.

Research Psychologist: 1971-1975, Effects of Work/Rest Schedules, Time Zone Changes, and Environmental Stresses on Psychomotor Performance.

Directed a series of four field evaluations of aircrew fatigue and workload associated with 2 -week sortie surge exercises involving $A-7, A-10$, and $F-4$ operations. (TAC) 1976-1979.

Director, field test and evaluation of $\mathrm{C} 5-\mathrm{A}$ crew fatigue in aerial refueling missions employing the double crew (Blue/Gold) concept of operation. (MAC) 1977-1981.

Consultant to HQ MAC/OCS Plans for Operational Test and Evaluation 15-19-79 "C-141 Inflight Crew Rest." (MAC) 1978-1979.

Directed field evaluations on operational impact of 24- and 48-hour duty periods on Minuteman missile crew performance and fatigue. (SAC) 1978-1980.

Responsible for biomedical evaluation of crew capabilities during extended missions of the E4-B National Emergency Airborne Command Post. (AFOTEC) 1979-1980. 
(Dr. Storm, cont.)

Advisor, National Research Council Research Associateship Program on Effects of Work load, Stress, and Fatigue on Human Performance. 1979-1984.

Consultant to NASA/Ames Research Center on methods for collection of behavioral and physiological data on the effects of sleep loss, irregular schedules, and circadian desynchronization on aircrew fatigue and performance. (NASA) 1980-1984.

Consultant on crew scheduling for the Mobile Ground Terminal of the Mobile Ground System segment of the Defense Support Program. (AFOTEC) 1981-1982.

Consultant to North American Air Defense Command, Cheyenne Mountain Complex, Colorado, on work/rest schedules for rotational shift work in continuous operations. (NORAD) 1981-1984.

\section{SELECTED PUBLICATIONS AND REPORTS}

Storm, Hartman, and Bollinger. A Retrospective Study of the 1973 Mid-East Resupply Effort: Crew Factors and Fatigue. USAFSAM-TR-75-19, 1975.

Storm and Hapenny. Mission-crew Fatigue During USAF Security Service RIVET JOINT Operations. USAFSAM-TR-76-36, 1976.

Storm, Hartman, and Makalous. Aircrew Fatigue in Nonstop, Transoceanic Tactical Deployments. AGARD CP-217 in Studies on Pilot Workload. 1977.

Storm and Gray. Minuteman Missile Crew Fatigue and 24-Hour Alerts. USAFSAM-TR-78-19, 1978.

Storm and Merrifield. Fatigue and Workload in Fourman C-5A Cockpit Crews. (VOLANT GALAXY). USAFSAM-TR-80-23, 1980.

Storm. E-4B Crew Fatigue Associated With 30-Hour IOT\&E Mission. USAFSAMTR $-80-40,1980$.

Storm. Mission Crew Fatigue During RIVET JOINT Block II Demonstration/ Evaluation. USAFSAM-TR-80-37, 1980.

Storm. "Aircrew Fatigue During Extended Transport, Tactical, and Command Post 0perations." AGARD-CP-338 in Sustained Intensive Air Operations: Physiological and Performance Aspects. 1983. 
APPENDIX B

SOURCES OF EVIDENCE ON ROUTINE 12-HOUR/DAY SHIFT SCHEDULES 
APPENDIX B

\section{SOURCES OF EVIDENCE ON ROUTINE 12-HOUR/DAY SHIFT SCHEDULES}

This appendix briefly summarizes some of the principal sources of evidence that were used by the project staff in making the recommendations on routine 12-hour/day schedules.

\section{B.1 TWELVE-HOUR/DAY SCHEDULLE IN EUROPE}

Twelve-hour shifts were typical for supervision and control activities in German heavy chemica? industries as early as 1970. In contrast to the American "four on, four off" schedule, the European 12-hour schedule is "two on, two off." Furthermore, in contrast to the American schedule where the four consecutive work days are all on the same shift, the two consecutive work days in the European schedule are different shifts--a day shift followed immediately by a night shift. The European four-day cycle is as follows: day 1 - day shift, day 2 - night shift; day 3 - off; and day 4 - off.

This schedule, which is presented as Schedule No. 10 in Appendix G, has been constructed according to principles often observed in European schedulers: fatigue is reduced by minimizing the number of consecutive night shifts, and by scheduling days off after night shifts (Colquhoun and Rutenfranz 1980 , pp. 403, 407).

\section{B.2 NORTHRUP, WILSON AND ROSE (1979)}

Northrup, Wilson, and Rose (1979) have described the adoption of 12-hour shift schedules by petroleum and chemical industries in North America. Imperial 0 il (Exxon controlled) in winnipeg, Canada, first adopted a 12-hour shift schedule in 1970. As a result of an article describing Imperial's schedule, one petroleum plant in the Gulf Coast area adopted it, and within 3 years about 20 other nearby plants had adopted it. Since then, the 12-hour schedule has been adopted by petroleum and chemical plants in other parts of the United States.

Adoption of the 12-hour shift schedule in the petrochemical industries has generally followed the pattern first seen at Imperial 0il: employee request after discussion with management, study, trial period, and continuation "with employees" enthusiastic support" (p. 314).

Employers in the plants with 12 -hour schedules have generally supported the 12-hour schedule, subject to four basic requirements (p. 314):

1. continued employee support (all plants underwent at least one trial period, after which employees voted to determine acceptance-majority support was needed to continue the schedule) 
2. no increased difficulty in administration (such as in covering overtime, etc.)

3. no decrease in productivity and efficiency

4. no increase in accident frequency and no violation of Occupational Safety and Health Administration (OSHA) standards.

According to Northrup, Wilson and Rose (p. 315), most petrochemical plants on 12-hour schedules follow one of three schedules: "every-other-weekend-off," "three-on, three-off," or "four-on, four-off." These three schedules are shown as Schedules 10, 11 , and 12 in Appendix $G$. The most popular of the three is the "every-other-weekend-of $f$ " schedule. This schedule assures each worker of having every other Friday, Saturday, and Sunday off. This schedule yields more desirable time off (i.e., the weekends), and "might aid in communication because workers are away from work no more than two consecutive days between Monday and Friday" (p. 315).

Because Northrup, wilson and Rose collected most of their information through interviews with managers, most of that information is the reported judgment of managers. The authors recognize that a manager might be reluctant to admit that his shift schedule is unsafe or unsuccessful. Only in a few cases were the authors able to collect objective data.

\section{B.3 PANEL COMMENTS}

The Shift Scheduling Project's panel discussed routine 12-hour/day schedules at length. The statements of panelist Franz Schneider were similar to those expressed in his published work (Kelly and Schneider 1982), which is suminarized in section 4.2. Another panel member had interviewed operators in the petrochemical industry and had gathered data on their performance. Although he has not yet fully analyzed the data, he stated that the analysis performed so far provides strong evidence that performance does not decline in the last 4 hours of the 12-hour working days in petrochemical plants.

\section{B.4 CLARKE INSTITUTE STUDY OF STRESS AMONG NUCLEAR OPERATORS AT ONTARIO HYDRO}

Ontario Hydro commissioned the Clarke Institute to conduct a study of stress among operators at their nuclear plants. The clarke Institute report (1983) states that "Shiftwork was the leading source of job dissatisfaction by far among .... the Nuclear first Operators and Level 1 0perators" (p. 122). Furthermore, "those who worked twelve hour shifts were significantly more satisfied with their shift schedule ... and viewed shiftwork as significantly less stressful ( $p$. 94) ...." Those who worked 12-hour shifts were quick to point out the benefits of their schedule, and some of the operators working eight-hour shifts expressed considerable resentment about not being allowed to switch over to 12-hour shifts. Several operators complained in quite colorful 
language about the people at head office "who never worked a day of shiftwork in their lives and yet were dictating what sort of shift schedules the operators should work" (p. 96).

These conclusions are based on a quantitative investigation of 0ntario Hydro employees. The results indicate that on the average operators on a 12-hour shift schedule have higher satisfaction with the shift schedule and less stress with shiftwork, as determined by a health questionnaire administered to the operators (p. 95).

\section{B.5 TWELVE-HOUR SHIFT SCHEDULES AT A NUCLEAR UTILITY}

According to an unpublished report, one nuclear utility's experience with the 12-hour schedule has been a success. For the former 8-hour schedule and the 12-hour schedule, the report compares data on sickness allowances, overtime off-schedule, medical-only injuries, disabling injuries, resignations, requests to transfer, absenteeism, number of reportable occurrences committed by operating personnel, capacity factor, availability, forced outages, and forced load reductions. No change or an improvement is shown on almost all of these indicators. The report also provides subjective evaluations of job satisfaction and productivity. Ninety-seven per cent of the operators favor continuing the program. When discussing the 12-hour shift program, operators mentioned the increased number of days off per year as the major advantage. 

APPENDIX C

FATIGUE INDEXES 


\section{FATIGUE INDEXES}

A "fatigue index" is an algorithm that estimates the level of employee fatigue (or determines schedule characteristics that are related to fatigue, such as maximum allowable flight time and minimum allowable rest time) based on factors that can induce fatigue such as time of departure, flight duration, number of time zones crossed, and arrival time.

Four fatigue indexes have been developed for airline crew and passengers. The project staff adapted these four fatigue indexes to calculate corresponding maximum allowable hours of work and minimum hours of rest for rotating shift workers. The airline fatigue indexes are applicable to rotating shift work because 1) like airline pilots and passengers, rotating shift workers suffer from the jet-lag effect of rotating shifts, 2) like airline pilots and passengers, rotating shift workers sometimes have their sleep disrupted by night work, 3) like airline pilots, nuclear power plant operators are highly skilled operators of expensive and complex machinery and bear a responsibility for public health and safety.

The results of the calculations are presented in Section C.1. The four fatigue indexes are summarized in Section C.2.

\section{C.1 LIMITS ON HOURS DF WORK IMPLIED BY FOUR FATIGUE INDEXES}

The results of the adaptation of the four fatigue indexes to rotating shift work are presented in Table C.1. In order to adapt the indexes to correspond to a morning shift, the calculations were made using the index numbers for a flight departure at 8 a.m., a flight duration of 8 hours, and an arrival at $4 \mathrm{p.m}$. In order to adapt the indexes to correspond to an afternoon shift, the calculations were made using the index numbers for a flight departure at 4 p.m., etc. It was assumed that no time zones were crossed in order to understate the effect of disrupting circadian rhythms due to rotating shift work. If the index included a coefficient for the number of take-offs and landings, one take-off and landing every four hours was assumed; the workload for pilots implied by this assumption is undoubtedly lower than the workload of operators during outages. Thus, we believe that the assumptions used tend to overestimate the maximums for hours of work.

\section{C.2 DESCRIPTION OF THE FOUR FATIGUE INDEXES}

The four fatigue indexes are sumarized below. The heading for each index includes the following information: author's name type of index (rest-hours index or work-hours index), author's affiliation, (a) and date of publication.

(a) Affiliation abbreviations are as follows: ICAO = International Civil Aviation Organization; FAA = Federal Aviation Administration; RAF = Royal Air Force. 
TABLE C.1. Application of Four Airline Fatigue Indexes to the Nuclear Power Industry

\begin{tabular}{|c|c|c|c|c|}
\hline \multirow[b]{2}{*}{$\begin{array}{c}\text { Time } \\
\text { Periods } \\
\end{array}$} & \multicolumn{4}{|c|}{ Four Fatigue Indexes } \\
\hline & $\begin{array}{c}\text { Buley's } \\
\text { Rest-Hours } \\
\text { Index } \\
\end{array}$ & $\begin{array}{c}\text { Gerathewohl's } \\
\text { Rest-Hours } \\
\text { Index } \\
\end{array}$ & $\begin{array}{l}\text { Nicholson's } \\
\text { Work-Hours } \\
\text { Index } \\
\end{array}$ & $\begin{array}{l}\text { Mohler's } \\
\text { Work-Hours } \\
\text { Index }\end{array}$ \\
\hline 1 day & NA & NA & NA & $\begin{array}{l}\text { For morning and } \\
\text { afternoon shifts, } \\
12 \text { hours is ok. } \\
\text { For night shift, } \\
6 \text { hours is a high } \\
\text { load. }\end{array}$ \\
\hline 2 days & $\begin{array}{l}24 \text { hours } \\
\text { of work is } \\
\text { Ok if work } \\
\text { begins at } \\
8: 00 \text { a.m. }\end{array}$ & $\begin{array}{l}24 \text { hours } \\
\text { is too many. }\end{array}$ & $\begin{array}{l}\text { Upper limit } \\
\text { is } 30 \text { hours. }\end{array}$ & $\begin{array}{l}\text { For morning and } \\
\text { afternoon shifts, } \\
24 \text { hours is a high } \\
\text { load. For night } \\
\text { shift, } 16 \text { hours is } \\
\text { too many. }\end{array}$ \\
\hline 7 days & NA & NA & $\begin{array}{l}\text { Upper limit } \\
\text { is } 55 \text { hours. }\end{array}$ & $\begin{array}{l}56 \text { hours is high } \\
\text { load. } 84 \text { hours } \\
\text { is (much) too } \\
\text { many. }\end{array}$ \\
\hline 14 days & NA & NA & $\begin{array}{l}\text { Upper limit } \\
\text { is } 77 \text { hours. }\end{array}$ & $\begin{array}{l}112 \text { hours is high } \\
\text { load. } 168 \text { hours } \\
\text { is (much) too } \\
\text { many. }\end{array}$ \\
\hline 1 month & NA & NA & NA & NA \\
\hline
\end{tabular}

$N A=$ Not applicable 
1. Buley's Rest-Hour Index, ICA0, 1970

Rest period (in tenths of days) = flight duration (in hours)/2

+ Number of time zones crossed in excess of four

+ Departure time coefficient + Arrival time coefficient.

2. Gerathewoh1's Rest-Hour Index, FAA, 1974 (this FAA index improves on the ICAO index)

Rest period (in hours) $=$ Flight duration (in hours)

+ Departure time coefficient + Arrival time coefficient

+ Geodirectional (east versus west) coefficient

+ Age coefficient.

3. Nicholson's Work-Hour Index, RAF, 1972

Nicholson developed his algorithm by gathering data on flight schedules that resulted in subnormal amounts of sleep for the pilots. The final algorithm is a table of numbers in which the maximum recommended number of duty hours depends on the number of days on route:

$$
\begin{aligned}
& \begin{array}{lllllllllll}
\text { Days on Route } & 2 & 3 & 4 & 5 & 6 & 7 & 8 & 9 & \ldots
\end{array} \\
& \text { Maximum Duty hours } 30 \quad 36 \quad 42 \quad 47 \quad 51 \quad 55 \quad 59 \quad 62 \quad \ldots \text {. }
\end{aligned}
$$

4. Mohler's Work-Hour Index, FAA, 1976 (this FAA index improves on the RAF index)

Mohler developed his algorithm by having a researcher fly in the cockpit with pilots of Pan American international flights. His algorithm consists of five tables of numbers (for departure time, number of days in the flight pattern, number of takeoffs and landings, etc.) that determine five factors to be multiplied together. Ideally, the product of the five numbers should be close to 1. A product over 1.75 indicates a high work load. A product over 2.3 indicates that the work load could "dangerously deplete physiological reserves." 

APPENDIX D

REPORTS OF FATIGUE AMONG AIRPLANE CREW AND CONTROLLERS 
APPENDIX D

REPORTS OF FATIGUE AMONG AIRPLANE CREW AND CONTROLLERS

To the project staff's knowledge, no office within NRC systematically collects information on the potential contribution of hours of work and fatigue to off-normal events. The Federal Aviation Administration (FAA) and the air forces of the military services have collected and reported such information. These reports provide insight into the sorts of errors that can be influenced by fatigue for skills that are similar to those required by nuclear power plant operators.

Section 0.1 contains sample reports from FAA's Aviation Safety Reporting System, Section D.2 is an excerpt from the U.S. Naval Flight Surgeon's Manual, (a) which describes the Navy's unsuccessful attempt to reduce fatigue to a few measurable variables, and describes the effects of fatiguing, peacetime exercises in Naval aircraft.

\subsection{REPORTS FROM FAA'S AVIATION SAFETY REPORTING SYSTEM}

The Aviation Safety Reporting System (ASRS) is a way for airline pilots and crews to voluntarily and anonymously report unsafe situations to the FAA. The system also provides a limited waiver of disciplinary action to reporters who may have inadvertently violated a Federal Air Regulation. In order to preserve anonymity, the reporters do not send their reports directly to the FAA, but send them instead to an independent agency (the National Aeronautics and Space Agency (NASA), which in turn subcontracts to Battelle). The independent agency may telephone the reporter to obtain any additional information needed about the incident. The agency then removes all identifying information before forwarding the report to the FAA.

In 1981 NASA published an analysis of ASRS reports (Lyman and Orlady 1981), which conctuded as follows (p. 21):

1. Fatigue-associated performance decrements occur, and they can produce potentially hazardous conditions.

2. Long duty periods, large numbers of flight segments, and disturbed sleep are frequently reported as the reasons for fatigue associated with performance decrements.

The project staff obtained the text of all ASRS reports related to fatigue that were collected after the 1981 analysis. Since the 1981 analysis, 381 such reports have been filed, which is an average of 1 report every 3 days. Fifteen

(a) U.S. Department of Defense. Department of the Navy. 1978. U.S. Naval Flight Surgeon's Manual. Chapter 20, "Fatigue," pp. 20-2 to 20-4 (not publicly avaitable). 
of the 381 reports are summarized below. These reports mention relatively minor errors (more serious errors would have been investigated by an investigating team), but they are still important because the accumulation of minor errors can become precursors to a major event. Several of the reports indicate that the pilot had been on duty more than 12 hours. FAA regulates flight time, not duty time (duty time = flight time + ground duty time).

- A pilot and/or traffic controllers became confused about the position of a second aircraft. That confusion almost lead to a mid-air collision. The pilot said that he must have missed a change-ina)titude assignment. He felt that the main factor in the incident was fatigue. He had been on duty nine hours and this was his third flight. He thought he was performing well when he was not. The pilot acknowledged that his schedule was within regulations but nonetheless fatiguing and potentially hazardous.

- During a prelanding check, a pilot forgot to put the landing gear in full down position. Just before landing, he mistook the landing gear warning horn for the stall warning horn and landed on the belly of the aircraft. He attributed fatigue from being on duty for 12 hours and distractions as reasons for not rechecking the gear.

- On an intermediate stop, a pilot responded during the check that the fuel was okay, but didn't check the gauge. His flight papers indicated that he had 20,000 pounds of fuel when he only had 13,700 pounds. Once airborne, he realized his mistake and had to make an unscheduled landing to refuel. The pilot felt that fatigue from the 3 days of early morning departures, 13 hours on duty, and the many landings were causes of the incident.

- On takeoff, the first officer exceeded the airport's 5,000 feet restriction by 2,500 feet. The crew had been given several instructions and were very fatigued from a typical 16-18 hour day. The pilot noted that his company was trying to extend their maximum duty time from 14 to $16-18$ hours, which he felt was impossible for effective and safe aircraft performance.

- A pilot who was cleared to climb and maintain at 10,000 feet began to exceed the clearance. Air control warned him to maintain at 10,000 feet because of traffic at 11,000 feet. The pilot started to descend and was at 10,500 feet when a small aircraft passed directly over at 11,000 feet--a near miss. The pilot and crew were not alert because of fatigue from their typical flying schedule. They had been called early in the morning for a nfght flight and had trouble sleeping again before the day flight.

- Departure control cleared a pilot to climb to 10,000 feet. At 8,500 feet the controller questioned the pilot's altitude, saying that the plane had been cleared only to 7,000 feet. When the pilot told him that the plane had been cleared and confirmed at the time, the controller admitted that he was wrong. It was near the end of his shift and he was tired. 
- After takeoff, a crew received clearance to 31,000 . The First 0fficer mistakenly set the altitude for 33,000 feet. At 31,500 feet, the controller pointed out the error. The crewman noted that fatigue could have been a factor as it was the third day of a three-day trip and all three days were early wakeups combined with 10 hours of duty each day.

- Because of bad weather, a pilot received approval to deviate slightly from the flight course. When he landed a few minutes later, he was at the wrong airport. He attributes similarity in airports, proximity of airports (10 miles), bad weather and crew fatigue from a 13-hour day as causes for the incident.

- A First officer contacted ground control to get clearance to taxi to the ramp. Both the First officer and the pilot thought they had been cleared and began taxiing. The crew heard several broken and blocked communications on ground frequency, but because the ramp looked uncongested, they continued. Upon arrival, the tower informed them that they had not been cleared and had tried to contact them. The pilot attributes the incident to mechanical failure and crew fatigue, stating that they heard what they wanted to hear.

- On takeoff, the control tower gave the pilot his headings and frequency for departure control. The departure controller made no changes until the pilot had to turn to avoid another aircraft. The controller thought he had given him a heading change to avoid the second aircraft but realized afterwards that he hadn't. The pilot noted the the controller sounded very tired.

- An aircraft crew was given instructions from approach for landing but forgot to call the tower to get landing clearance and landed. The pilot contributed their error to the delayed departure that morning, many hours of flying that day, several intermediate stops, and some booking and baggage problems that caused disruptions and stress.

- While climbing from 10,000 to 23,000 feet, as instructed, center control instructed a pilot to stop the climb at 12,000 feet. At that moment, the aircraft was at 12,300 feet and in attempting to reverse the climb, came within $1 \mathrm{mile}$ of another aircraft. It was determined that the controller had erred; the pilot attributes the controller's mistake to fatigue from 75-hour work weeks and newness to the job. (The incident occurred after the air controlter strike and layoff.)

- A controller reported that several air traffic controllers had been working even though they were $i 11$, and other controllers had worked while in a state of extreme exhaustion. One controller even worked the day of his father's funeral. No incidents had occurred yet because of these conditions, but the controller was reporting them because he felt that the FAA thought the controllers could work under those conditions forever, and he was worried about the consequences. 
- A pilot either didn't receive or forgot about receiving clearance to descend to 4,000 feet before landing. Because some of his departures had been moved on short notice to earlier hours, he was tired and may have missed the clearance.

- A plot began taxiing around another aircraft and going through his checklist for takeoff without having called ground control to get clearance. The pilot attributed his error to fatigue from an extra long day of work.

\section{D.2 EFFECTS OF FATIGUING, PEACETIME EXERCISES IN NAVAL AIRCRAFT}

The following excerpts from the U.S. Naval Flight Surgeon's Manual (a) summarize the Navy's unsuccessful attempt to reduce fatigue to a few measurable variables, and summarize the effect of fatigue in peacetime exercises in one type of aircraft. Even though a nuclear power plant is not a Naval airplane, similarities to the nuclear power industry can be seen in the long hours of urgent work, and in the various effects of fatigue on basic skills and performance.

Literally millions of dollars have been spent studying fatigue, yet its essential nature remains more unknown than known .... The varying interpretations of fatigue .... are due to the fact that the word has no specific scientific meaning. It does not represent a distinct clinical entity ....

A Flight Surgeon must be sensitive to the problem of operational fatigue and the variables which are instrumental in producing this condition. Although operational fatigue is difficult to measure with precision, there is no doubt that it is rea! ....

A good example of aviation missions in which fatigue-inducing factors should be prominent is in antisubmarine warfare (ASW) exercises. During a typical ASW exercise, aircrewmen may log as many as 150 hours in a 40-day period. Flights during such exercises can last as long as 12 to 16 hours .... In the P-3 aircraft, for example, as many as 16 individuals can be on a single fiight with only two bunks available for (rest) ....

A survey of accidents to P-3 aircraft ... between 1962 and 1969 [recorded] ... 16 major accidents, excluding those from hostile action .... In eight of the eleven accidents that involved personnel factors, fatigue was listed as contributing to the errors made by pilots and crewmen. .... In some of those situations, fatigue may have led to the precipitation of the emergency; in others, fatigued

(a) U.S. Department of Defense. Department of the Navy. 1978. U.S. Naval Flight Surgeon's Manual. Chapter 20, "Fatigue," pp. 20-2 to $\overrightarrow{20-4}$ (not pubticty avaitable). 
personnel were unable to react appropriately to emergency conditions created by factors beyond their control.

A review of comments concerning one of the $P-3$ accidents shows a typical form of operational fatigue:

The operational tempo of flying for this period had been close to the limit possible for continuous operation. This particular crew averaged over 100 hours of flight time per month for the last three months .... The stage was set for discontent. It is a known fact that crews resent training flights when they are already working 12 out of every 14 days and in many cases they go for weeks without a true day off. Thus, a possible poor attitude on the part of some or all of the crewmembers may have been established .... Playback of the Ground Control Tape revealed a sleepy or groggy inflection in the copilot's voice .... The aircraft descended from a seated 650 feet into the water in an apparent G-1 maneuver. How the aircraft descended 650 feet without the pilot, copilot, or engineer noting the descent or radar altimeter red warning light is the primary question .... The aircraft flew into the water with eight fatalities and four major injuries. 

APPENDIX E

PAST AND PRESENT NRC POLICIES

ON SHIFT SCHEDIJLING AND HOURS OF WORK 
PAST ANO PRESENT NRC POLICIES

ON SHIFT SCHEDULING ANO HOURS OF WORK

This appendix contains three sections. All three sections are direct quotations from NRC documents. Section E.1 contains NRC's previous policy on shift scheduling and hours of work, from NUREG-0737 (1980, pp. 3-6 and 3-7). Section E.2 contains NRC's present policy on shift scheduling and hours of work, from Generic Letter $82-12$ (1982, p. 7). Section E.3 also contains what may be considered NRC's present policy on shift scheduling and hours of work, from Generic Letter 82-16 (1982). Sections E.1, E.2, and E.3 are all direct quotes.

Whereas Generic Letter 82-12 is addressed "to All Licensees of Operating Plants, Applicants for an 0perating License, and Holders of Construction Permits," Generic Letter $82-16$ is addressed "to All Pressurized Power Reactor Licensees." Although many of the passages in Generic Letters 82-12 and 82-16 are identical, some passages differ. An example of a sentence that appears in Generic Letter $82-16$ but not Generic Letter 82-12 is "... individual overtime shall be reviewed monthly by (Plant Superintendent) ...." Most significantly, however, both of these Generic Letters request, but do not require, that licensees incorporate the respective policy statements into their technical specifications.

\section{E.1 PAST NRC POLICY: NUREG-0737 (1980)}

Licensees of operating plants and applicants for operating licenses shall include in their administrative procedures (required by license conditions) provisions governing required shift staffing and movement of key individuals about the plant. These provisions are required to assure that qualified plant personnel to man the operational shifts are readily availahle in the event of an abnormal or emergency situation.

These administrative procedures shall also set forth a policy, the objective of which is to operate the plant with the required staff and develop working schedules such that use of overtime is avoided, to the extent practicable, for the plant staff who perform safety-related functions (e.g., senior reactor operators, reactor operators, health physicists, auxiliary operators, I\&C technicians, and key maintenance personnel).

The staff recognizes that there are diverse opinions on the amount of overtime that would be considered permissible and that there is a lack of hard data on the effects of overtime beyond the generally recognized normal eight-hour working day, the effects of shift rotation, and other factors. NRC has initiated studies in this area. Until a firmer basis is developed on working hours, the 
administrative procedures shall include as an interim measure the following guidance, which generally follows that of IE Circular No. 80-02.

In the event that overtime must be used (excluding extended periods of shutdown for refueling, major maintenance, or major plant modifications), the following overtime restrictions should be followed:

1. An individual should not be permitted to work more than 12 hours straight (not including shift turnover time).

2. There should be a break of at least 12 hours (which can include shift turnover time) between all work periods.

3. An individual should not work more than 72 hours in any sevenday period.

4. An individual should not be required to work more than

14 consecutive days without having two consecutive days off.

However, recognizing that circumstances may arise requiring deviation from the above restrictions, such deviation shall be authorized by the plant manager or his deputy, or higher levels of management, in accordance with published procedures and with appropriate documentation of the cause.

If a reactor operator or senior reactor operator has been working more than 12 hours during periods of extended shutdown (e.g., at duties away from the control board), such individuals shall not be assigned shift duty in the control room without at least a 12-hour break preceding such an assignment.

NRC encourages the development of a staffing policy that would permit the licensed reactor operators and senior reactor operators to be periodically assigned to other duties away from the control board during their normal tours of duty.

If a reactor operator is required to work in excess of eight continuous hours, he shall be periodically relieved of prinary duties at the control board, such that periods of duty at the board do not exceed about four hours at a time.

The guidelines on overtime do not apply to the shift technical advisor provided he or she is provided sleeping accommodations and a ten-minute availability is assured. 
Operating license applicants shall complete these administrative procedures before fuel loading. Development and implementation of the administrative procedures at operating plants will be reviewed by the Office of Inspection and Enforcement beginning 90 days after JuTy 31, 1980 .

(NUREG-0737, pp. 3-6 and 3-7)

\section{E.2 PRESENT NRC PDLICY: GENERIC LETTER 82-12 (1982)}

Licensees of operating plants and applicants for operating licenses shall establish controls to prevent situations where fatigue could reduce the ability of operating personnel to keep the reactor in a safe condition. The controls should focus on shift staffing and the use of overtime--key job-related factors that influence fatigue.

The objective of the controls would be to assure that, to the extent practicable, personnel are not assigned to shift duties while in a fatigued condition that could significantly reduce their mental alertness or their decision making capability. The controls shall apply to the plant staff who perform safety-related functions (e.g., senior reactor operators, reactor operators, health physicists, auxiliary operators, and key maintenance personnel).

Enough plant operating personnel should be employed to maintain adequate shift coverage without routine heavy use of overtime. The objective is to have operating personnel work a normal eight-hour day, 40-hour week while the plant is operating. However, in the event that unforeseen problems require substantial amounts of overtime to be used, or during extended periods of shutdown or refueling, major maintenance or major plant modifications, on a temporary basis, the following guidelines shall be followed:

a. An individual should not be permitted to work more than 16 hours straight (excluding shift turnover time).

b. An individual should not be permitted to work more than 16 hours in any 24-hour period, nor more than 24 hours in any 48-hour period, nor more than 72 hours in any seven-day period (a11 excluding shift turnover time).

c. A break of at least eight hours should be allowed between work periods (including shift turnover time).

d. Except during extended shutdown periods, the use of overtime should be considered on an individual basis and not for the entire staff on a shift. 
Recognizing that very unusual circumstances may arise requiring deviation from the above guidelines, such deviation shall be authorized by the plant manager or his deputy, or higher levels of management. The paramount consideration in such authorization shall be that significant reductions in the effectiveness of operating personnel would be highly unlikely.

In addition, procedures are encouraged that would allow licensed operators at the controls to be periodically relieved and assigned to other duties away from the control board during their tour of duty.

(U. S. Nuclear Regulatory Comission Generic Letter 82-12, p. 7)

\section{E.3 PRESENT NRC POLICY: GENERIC LETTER 82-16 (1982)}

Administrative procedures shall be developed and implemented to limit the working hours of unit staff who perform safety-related functions; e.g., senior reactor operators, reactor operators, health physicists, auxiliary operators, and key maintenance personnel.

Adequate shift coverage shall be maintained without routine heavy use of overtime. The objective shall be to have operating personnel work a normal 8-hour day, 40-hour week while the plant is operating. However, in the event that unforeseen problems require substantial amounts of overtime to be used, or during extended periods of shutdown for refueling, major maintenance or major plant modifications, on a temporary basis, the following guidelines shall be followed:

a. An individual should not be permitted to work more than 16 hours straight, excluding shift turnover time.

b. An individual should not be permitted to work more than 16 hours in any 24-hour period, nor more than 24 hours in any 48-hour period, nor more than 72 hours in any seven-day period, al1 excluding shift turnover time.

c. A break of at least eight hours should be allowed between work periods, including shift turnover time.

d. Except during extended shutdown periods, the use of overtime should be considered on an individual basis and not for the entire staff on a shift.

Any deviation from the above guidelines shall be authorized by the (Plant Superintendent) or his deputy, or higher levels of management, in accordance with established procedures and with documentation of the basis for granting the deviation. Controls 
shall be included in the procedures such that individual overtime shall be reviewed monthly by the (Plant Superintendent) or his designee to assure that excessive hours have not been assigned. Routine deviation from the above guidelines is is not authorized.

(U. S. Nuclear Regulatory Commission Generic Letter 82-16, Section 6.2.2) 



\section{APPENDIX $F$}

FEDERAL REGULATIONS ON HOURS OF WORK

FOR NON-NUCLEAR INDUSTRIES AND FOR THE ARMED FORCES 
FEDERAL REGULATIONS ON HOURS OF WORK

FOR NON-NUCLEAR INOUSTRIES AND FOR THE ARMED FORCES

Although non-nuclear industries and the armed forces present work situations different in some degree from those found in the nuclear industry, similarities also exist. Thus, a summary of those regulations provides perspective. NRC guidelines on hours of work are higher for every time period than are the limits on hours of work in three other industries and the limits on flight time in the U.S. Air Force and Coast Guard.

\section{F.1 FEDERAL REGULATIONS ON HOURS OF WORK IN PRIVATE INDUSTRIES}

The federal government sets guidelines for hours of work for the nuclear industry and for three transportation industries, which are regulated by the Department of Transportation (Lewis 1985, Pp. 2-5). The transportation regulations are more detailed than the nuclear regulations and contain a variety of rules and exceptions for special situations (e.g., for Alaskan bush pilots). All of the regulations provide that work-hour limits may be exceeded in emergencies or unusual situations.

On two important measures, NRC policy is more lenient than other federal agency regulations on hours of work:

1. Nuclear plant staff are permitted 16 consecutive hours of work, whereas pilots, seamen, truck drivers, and railroad operators are permitted only $8,8,10$, and 12 hours, respectively.

2. Nuclear plant staff are permitted 72 hours of work within a 7 -day period, whereas pilots and truck drivers are permitted only 30 and 60 , respectively.

These federal limits are summarized in Table F.1. NRC limits for the nuclear industry do not include shift turnover time, which averages about 30 minutes per day. If 30 minutes per day were added to the NRC 1 imits, the effective limits would be higher, as follows:

$\begin{array}{ll}\text { Hours Worked in } & 16+1 / 2=16 \mathrm{l} / 2 \mathrm{hr} \\ \text { a } 24-\mathrm{hr} \text { Period } & \\ \text { Hours Worked in } & 24+1=25 \mathrm{hr} \\ \text { a } 48-\mathrm{hr} \text { Period } & \\ \text { Hours Worked in } & 72+3=75 \mathrm{hr} \\ \text { a } 7 \text {-day Period } & \end{array}$


TABLE F.1. Summary of Federal Limits on Hours of Work in Four Industries

\begin{tabular}{|c|c|c|c|c|}
\hline & \multicolumn{4}{|c|}{ Industry } \\
\hline & $\begin{array}{l}\text { Nuclear Power } \\
\text { Industry } \\
\end{array}$ & $\begin{array}{l}\text { Airline Pilots } \\
\text { and Crew }\end{array}$ & $\begin{array}{l}\text { Railroad } \\
\text { Operators }\end{array}$ & $\begin{array}{l}\text { Truck } \\
\text { Drivers }\end{array}$ \\
\hline $\begin{array}{l}\text { Hours Worked in } \\
\text { a } 24 \text {-hour period }\end{array}$ & 16 & 8 & 12 & 10 \\
\hline Length of Break & \begin{tabular}{l}
\multicolumn{1}{c}{8} \\
(after up to \\
16 hours \\
worked)
\end{tabular} & $\begin{array}{l}\text { (after } \\
\text { (a hours } \\
\text { aloft) }\end{array}$ & $\begin{array}{l}\qquad 10 \\
\text { (after } 12 \\
\text { consecut ive } \\
\text { hours worked) }\end{array}$ & - (a) \\
\hline $\begin{array}{l}\text { Hours Worked in } \\
\text { a 48-hour Period }\end{array}$ & 24 & -- & $\begin{array}{l}8 \\
\text { (after } 12 \text { hours } \\
\text { of broken duty) }\end{array}$ & -- \\
\hline $\begin{array}{l}\text { Hours Worked in } \\
\text { a } 7 \text {-day Period }\end{array}$ & 72 & 30 & -- & 60 \\
\hline $\begin{array}{l}\text { Hours Worked in } \\
\text { a } 30 \text {-day Period }\end{array}$ & $\cdots$ & 100 & -- &.- \\
\hline $\begin{array}{l}\text { Hours Worked } \\
\text { in a Year }\end{array}$ & -- & 1000 & -- & -- \\
\hline
\end{tabular}

(a) Dashes indicate that no guideline is specified.

Based on these figures, a nuclear plant operator is allowed to work 100 hours in 10 days, whereas a commercial airline pilot is allowed 100 hours of flying time in 30 days.

\section{F.2 U.S. AIR FORCE LIMITS ON FLIGHT TIME}

Table F.2 summarizes U.S. Air Force regulations of aircraft crew rest and flight duty time limits $(a)$ that are most relevant to the nuclear industry. The first row in the table shows the maximum allowable number of hours in a single flight duty period. A flight duty period begins when crew members report for a mission or briefing, and ends when engines are stopped at the end of a mission or series of missions. The maximum al lowable number of hours in a single

(a) U.S. Department of Defense, Department of Air Force, January 2, 1975, AFR 60-1, PF. 7-1 to 7-3. This document is not available to the public. 
TABLE F.2. U.S. Air Force Regulations on Crew Rest and Flight Duty Time

$\begin{array}{lc}\text { Maximum flight duty period for } & \begin{array}{c}\text { Number of } \\ \text { Hours }\end{array} \\ \text { single control (one pilot) } & 12 \\ \text { aircraft } & 12 \\ \text { Crew rest period before a flight } & 125 \\ \text { Maximum flight time in } 30 \text { consecutive days } & 330 \\ \text { Maximum flight time in } 1 \text { calendar quarter } & \end{array}$

flight duty period is 12 for a single control (one pilot) aircraft. (Incidentally, if the aircraft has no autopilot, or if the autopilot is inoperative, the maximum crew duty time is 12 nours for all types of aircraft whether or not there is an augmented crew.)

The second row in Table F.2 shows that the minimum crew rest period before a mission is 12 hours. Crew rest time begins at the termination of the previous flight duty period. It includes free time and time for meals, transportation, and 8 hours of uninterrupted rest. The third and fourth rows show that maximum flying time in 30 consecutive days is 125 hours, and maximum flying time in a calendar quarter is 330 hours of logged flight time.

Table F.2 summarizes Air Force regulations that are most relevant to the nuclear industry. The complete statement of Air Force regulations is more complex. For example, Air Force regulations provide for different maximum flight duty periods depending on the type of aircraft, whether the aircraft has single control or dual control, whether the aircraft has sleeping provisions, whether the crew is a basic crew or an augmented crew (facilities for an augmented crew would allow one crew to sleep), and other considerations. For example, if a jet fighter has dual controls and two pilots, the maximum flight duty time is 16 hours. With a few exceptions, the maximum for aircraft with a single crew and no sleeping provisions is 12 hours; the maximum for aircraft with a single crew and with sleeping provisions is 16 hours.

The regulations described above are general Air Force regulations. In addition to these general regulations, each Command within the Air Force establishes its own specific regulations, which must at least meet the minimum safety standards of the general Air Force standards, and may set higher safety standards. The U.S. Air Force Material Air Command (MAC), for example, is very explicit and strict in requiring an adequate rest period before flight duty. If a MAC crew is scheduled for a mission that will take them away from their home station for more than one duty day, the crew rest period begins 24 hours 
before reporting for the mission. "During the first 12 hours of this period, a crew member may accomplish limited nonflying duties. The second 12-hour period is inviolate; no duties may be performed (emphasis ours). Infringement of the inviolate crew rest period wjl] necessitate the start of another 12-hour inviolate crew rest period." (a)

This information from the U.S. Air Force might be applicable to NRC and the nuclear industry in the following ways:

1. The range in Air Force limits on hours of work in one day generally corresponds to the range that NRC has considered in its past and present policies on hours of work, i.e., 12 to 16 hours per day.

2. The Air Force strictly enforces a 12-hour rest period before a mission. This corresponds to previous NRC policy, which required a 12-hour rest period between work periods.

3. The Air Force sets limits for a 30-day period and for a calendar quarter. These limits for longer periods indicate that the Air Force recognizes the importance of cumulative fatigue, and considers that the benefits of increased safety outweigh the costs of formal regulations, paperwork, and enforcement. These Air Force regulations for longer perjods of time correspond to FAA regulations and to the recommendation of the Shift Scheduling Project panel.

The Air Force limit on flight time is 125 hours in 30 days. The FAA limit for commercial airline pilots is 100 hours in 30 days. By contrast, the Shift Scheduling Project panel's recommended limit for nuclear power plant operators is much higher--192 hours in 28 days. of course, no direct comparison can be made among the three occupations because conditions differ. Also, flight time is less than total duty time.

4. The Air Force issues very detailed regulations, with separate limits for many separate types of circumstance.

5. The Air force has conducted a wide variety of experiments, which provided some basis for these regulations. PNL has read many of the Air Force research reports on fatigue. Although the reports generally indicate that fatigue is a problem and although they might help set limits within a wide range, they do not define the effects of fatigue within such narrow bounds that they could have been used by themselves to set the wide variety of specific limits that the Air Force has adopted. Although the details of how the Air Force established its regulations on crew duty time and rest periods are not

(a) U.S. Department of Defense. Department of Air Force. January 15, 1975. Material Air Command Regulations 55-1, Vol. 1, page 2-2 (not readily available to the public). 
known, these facts suggest that the Air Force has been willing to combine scientific experiments with experienced judgment in setting its regulations.

\section{F.3 U.S. COAST GUARD LIMITS ON FLIGHT TIME}

U.S. Coast Guard regulations on flight time and rest time for rescue crews are summarized in Tables F.3 through F.5.

TABLEF.3. Limits for Coast Guard Aircrew in a 24-Hour Period(a)

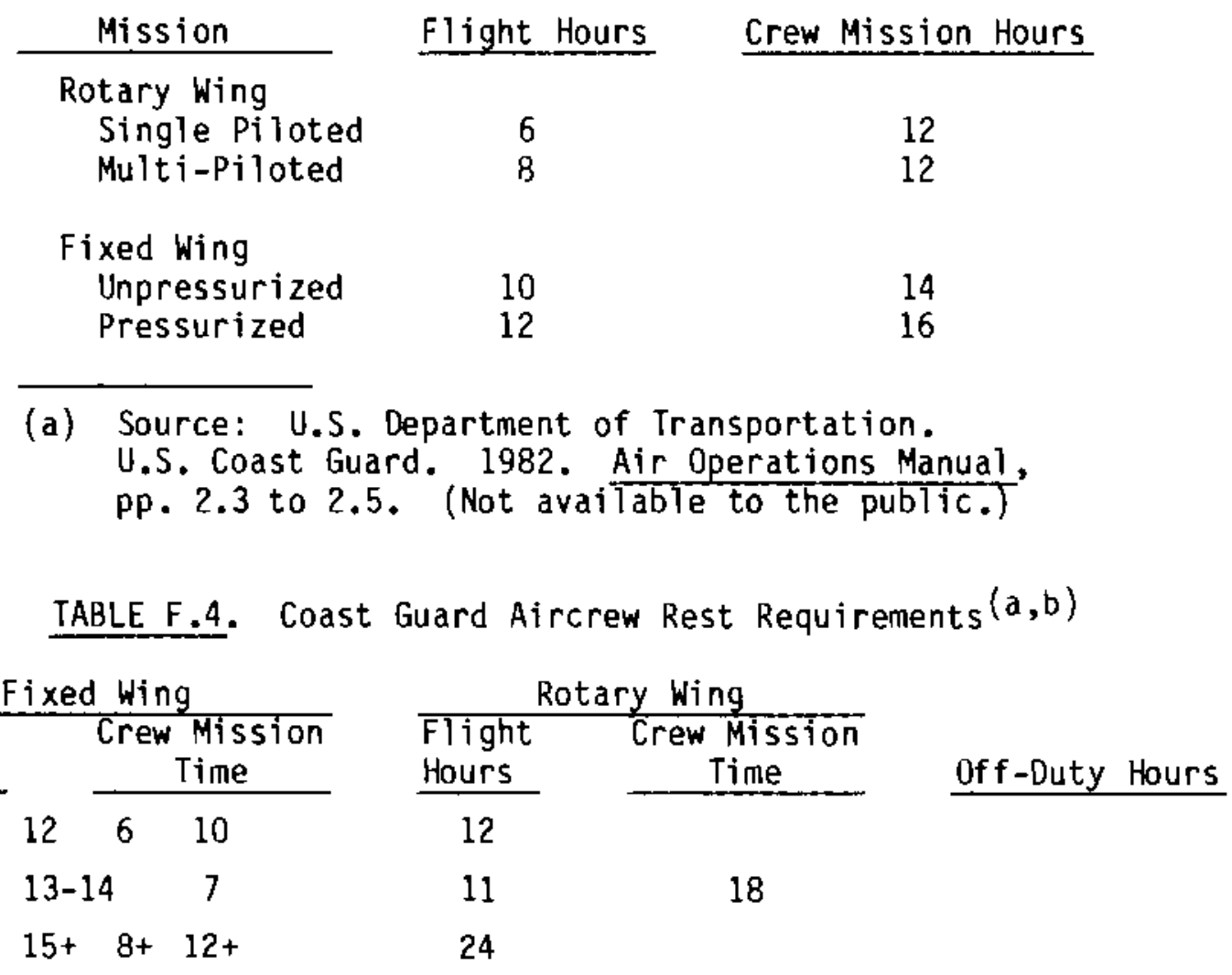

(a) Source: U.S. Coast Guard. 1982. (Not available to the public.)

(b) Table F.4 specifies the minimum required number of off-duty hours after a flight, before being assigned to any further Coast Guard duty, either on the ground or in flight. The minimum required of $f$-duty hours, specified in the right-most column of Table F.4, depends on the type of aircraft and the number of flight hours or crew mission time. 
TABLE F.5. Limits on Flight Time For Coast Guard Crew Members for Time Periods up to One Year (a)

\begin{tabular}{lr} 
Time Period & Limit on Flight Time \\
\hline Calendar week & 50 hours \\
Calendar month & 125 hours \\
Calendar year & 800 hours
\end{tabular}

(a) Source: U.S. Coast Guard. 1982. (Not available to the public.) 
APPENDIX G

SAMPLE SHIFT SCHEDULES 


\section{SAMPLE SHIFT SCHEDULES}

This appendix contains sample shift schedules from the nuclear industry and the petrochemical industry. Schedules 1-8 are from the nuclear industry; Schedule No. 6 is a routine 12-hour/day schedule. Schedules 9-12 are routine 12-hour/day schedules from the petrochemical industry.

Some of these schedules have been constructed from incomplete information and a few reasonable assumptions. For most schedules PNL lacks information on whether a night shift that is listed in the schedule for Thursday begins at $11 \mathrm{p} . \mathrm{m}$. Wednesday or $11 \mathrm{p} . \mathrm{m}$. Thursday. This lack of information makes uncertain the calculations of the number of hours in rest period between night shift and the day shifts. For this appendix, PNL has adopted the convention that a night shift that is listed in the schedule for Thursday begins at $11 \mathrm{p} . \mathrm{m}$. Thursday. 


\section{SCHEDULE NO. 1}

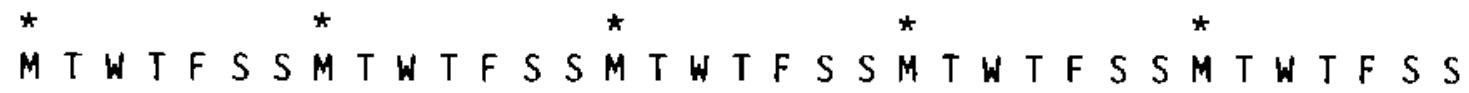

Crew A - A A A A A A - - D D D D D D D - D D D - N N N N N N -

"B AA- - DDDDDDDD- - DDD- N N N NNN- - - AAAAA

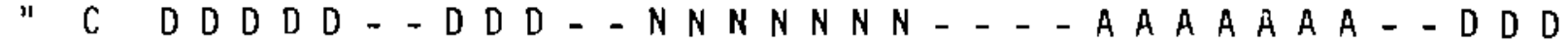

"D DDD- - N N N N N - - - A A A A A A A - D D D D D D D D -

$"$ ENNNNN- - A A A A A A - D D D D D D D - DDD- N N

\section{LEGEND}

$D=$ Day shift (about 8AM to 4PM)

$A=$ Afternoon shift (about 4PM to midnight)

$N=$ Night shift (about midnight to $8 A M$ )

$T=$ Training

$R=$ Relief/support crew

- = Day off

\section{CHARACTERISTICS OF SCHEDULE}

Hours per day $=8$

Number of crews $=5$

Length of cycle $=5$ wks.

Total work hours in cycle $=(25$ days $\times 8 \mathrm{hrs})=200 \mathrm{hrs}$

Average hours of work per week $=(200 \mathrm{hrs} / 5$ wks $\Rightarrow 40 \mathrm{hrs}$

Scheduled training hours as percent of total $=0 \%$

Scheduled relief hours as percent of total $=0 \%$

Greatest no. of consecutive days worked $=8$

Greatest no. of days worked in 28 consecutive days $=22$

Direction of rotation = backward

Speed of rotation $=(3$ shifts in 35 days $)=11.1$ days 


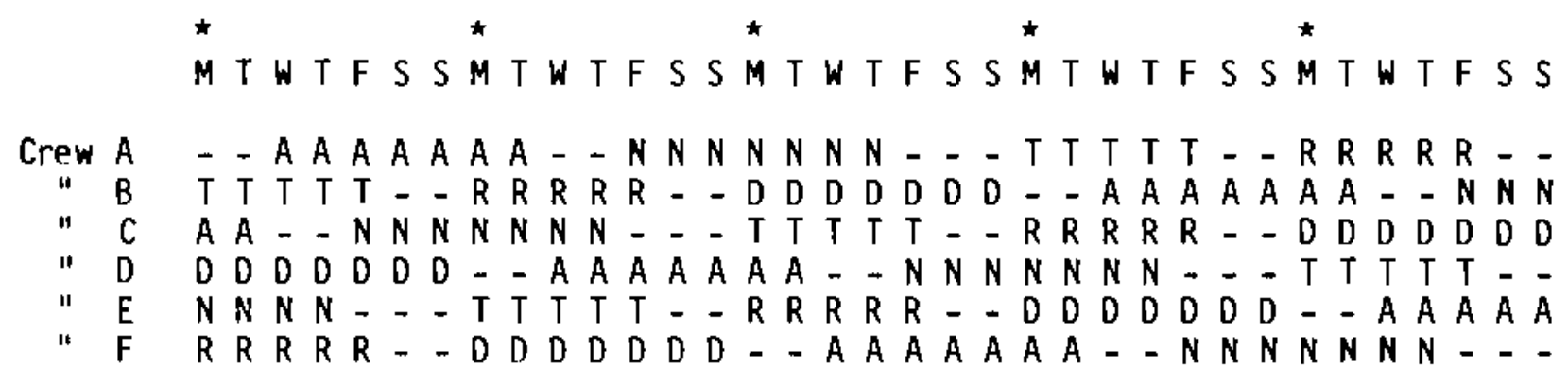

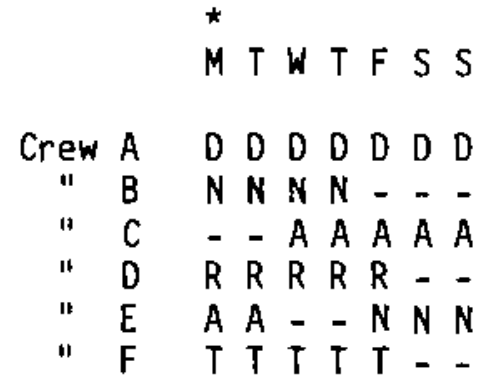

\section{LEGEND}

$D=$ Day shift (about 8AM to 4 PM)

$A=$ Afternoon shift (about 4PM to midnight)

$N=$ Night shift (about midnight to $8 A M$ )

$T=$ Training

$R=$ Relief/support crew

- = Day of $f$

\section{CHARACTERISTICS OF SCHEDULE}

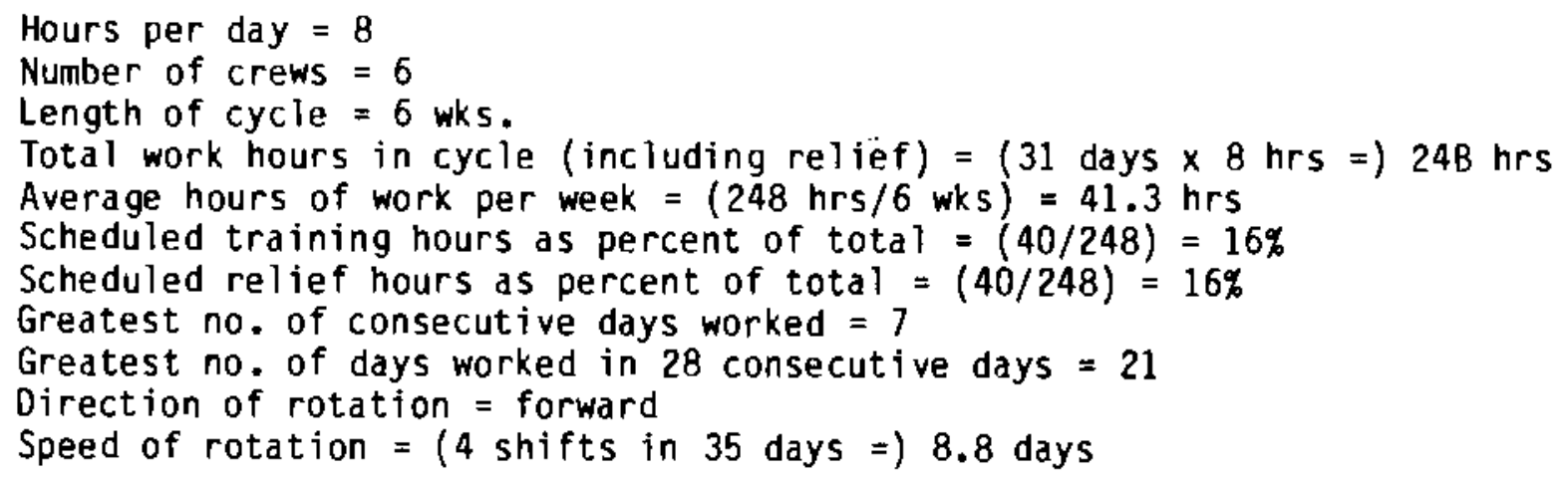


SCHEDULE NO. $3^{*}$

MTWTFSS

Crew A NNNNN- - T T T T T- - RRRRR-- - D D D D D D D - A A A A

"B TTTTT- $R R R R R-\cdots$ - D D D D D D D A A A A A A A - N N

"C RRRRR- - - D D D D D D - A A A A A A - - N N N N N N- -

"D - D D D D D D D - A A A A A A A - N N N N N N- - T T T T T-

"E DD - A A A A A A - N N N N N - - T T T T T - RRRRR- -

"F AAA- $N N N N N N N-$ T T T T T - RRRRR- - D D D D D

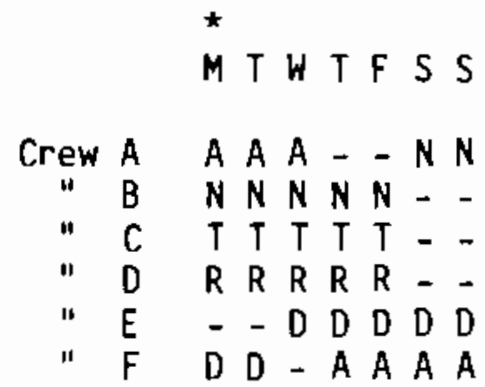

* This schedule has been constructed from incomplete information (only one week of the schedule was provided) and certain reasonable assumptions. This schedule is a minor variation of Schedule No. 2 .

LEGEND

$D=$ Day shift (about 8AM to 4PM)

$A=$ Afternoon shift (about $4 P M$ to midnight)

$N=$ Night shift (about midnight to 8AM)

$T=$ Training

$R=$ Relief/support crew

- = Day off

\section{CHARACTERISTICS OF SCHEDULE}

Hours per day $=8$

Number of crews $=6$

Length of cycle $=6 \mathrm{wks}$.

Total work hours in cycle (excluding relief) $=(31$ days $\times 8 \mathrm{hrs}=248 \mathrm{hrs}$

Average hours of work per week $=(248 \mathrm{hrs} / 6 \mathrm{wks})=41.3 \mathrm{hrs}$

Scheduled training hours as percent of total $=(40 / 248)=16 \%$

Scheduled relief hours as percent of total $=(40 / 248)=16 \%$

Greatest no. of consecutive days worked $=7$

Greatest no. of days worked in 28 consecutive days $=23$ (but the last 2 days in the 28-day period are for training)

Direction of rotation = forward

Speed of rotation $=(4$ shifts in 35 days $)=8.8$ days 
SCHEDULE NO. 4

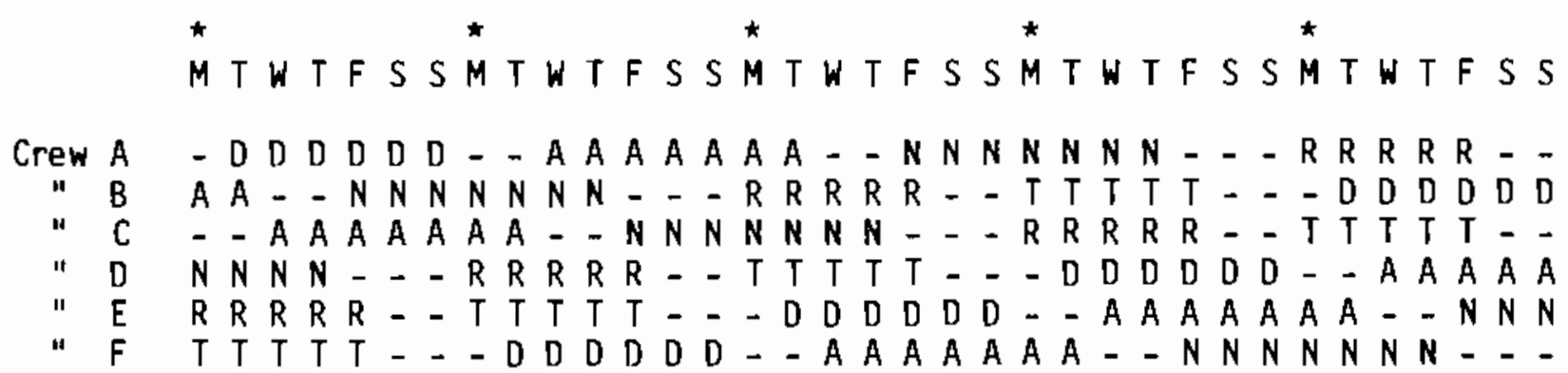

$+$

M T W T F S S

Crew A T T T T T - -

"B - A A A A

"C $-D D D D D D$

"D A A - N N N

"E N N N N - -

" F R R R R - -

$\underline{\text { LEGEND }}$

$D=$ Day shift (about 8AM to 4PM)

$A=$ Afternoon shift (about 4PM to midnight)

$N=$ Night shift (about midnight to $8 A M$ )

$T=$ Training

$R=$ Relief/support crew

- = Day off

\section{CHARACTERISTICS OF SCHEDULE}

Hours per day $=8$

Number of crews $=6$

Length of cycle $=6 \mathrm{wks}$

Total work hours in cycle (including relief) $=(30$ days $\times 8$ hrs $\Rightarrow 240 \mathrm{hrs}$

Average hours of work per week $=(240 \mathrm{hrs} / 6$ wks $)=40 \mathrm{hrs}$

Scheduled training hours as percent of total $=(40 / 240)=17 \%$

Scheduled relief hours as percent of total $=(40 / 240)=17 \%$

Greatest no. of consecutive days worked $=7$

Greatest no. of days worked in 28 consecutive days $=21$

Direction of rotation = forward

Speed of rotation $=(4$ shifts in 34 days $)=8.5$ days 
SCHEDULE NO. 5

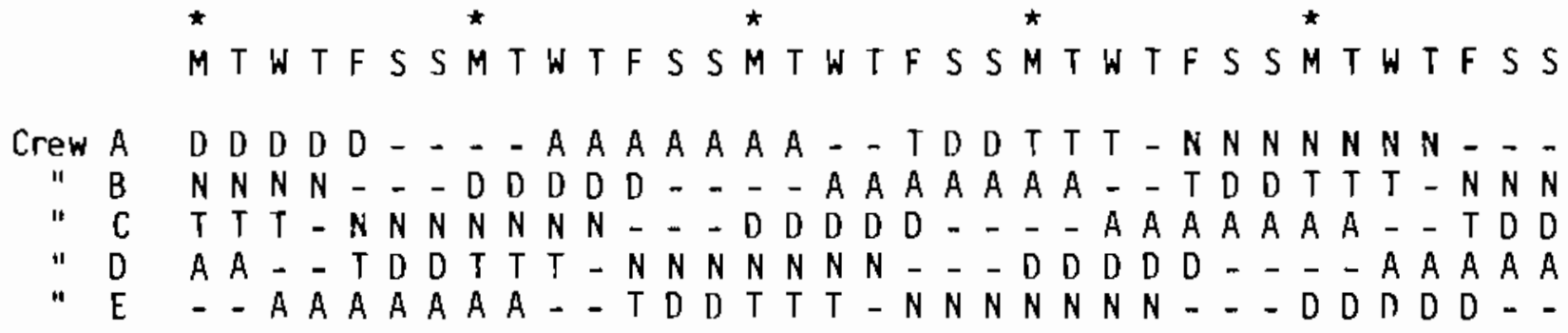

\section{LEGEND}

$D=$ Day shift (about 8AM to $4 \mathrm{PM}$ )

$A=$ Afternoon shift (about $4 P M$ to midnight)

$N=$ Night shift (about midnight to $8 \mathrm{AM}$ )

$T=$ Training/support

- = Day off

\section{CHARACTERISTICS OF SCHEDULE}

Hours per day $=8$

Number of crews $=5$

Length of cycle $=5 \mathrm{wks}$.

Total work hours in cycle $=(25$ days $\times 8 \mathrm{hrs}=) 200 \mathrm{hrs}$

Average hours of work per week $=(200 \mathrm{hrs} / 5 \mathrm{wks})=40 \mathrm{hrs}$

Scheduled training/support hours as percent of total $=(16 / 200)=8 \%$

Greatest no. of consecutive days worked $=$ ?

Greatest no. of days worked in 28 consecutive days $=22$

Direction of rotation = Day to afternoon to day to night

Speed of rotation $=(4$ shifts in 35 days $)=8.8$ days 
SCHEDULE NO. 6

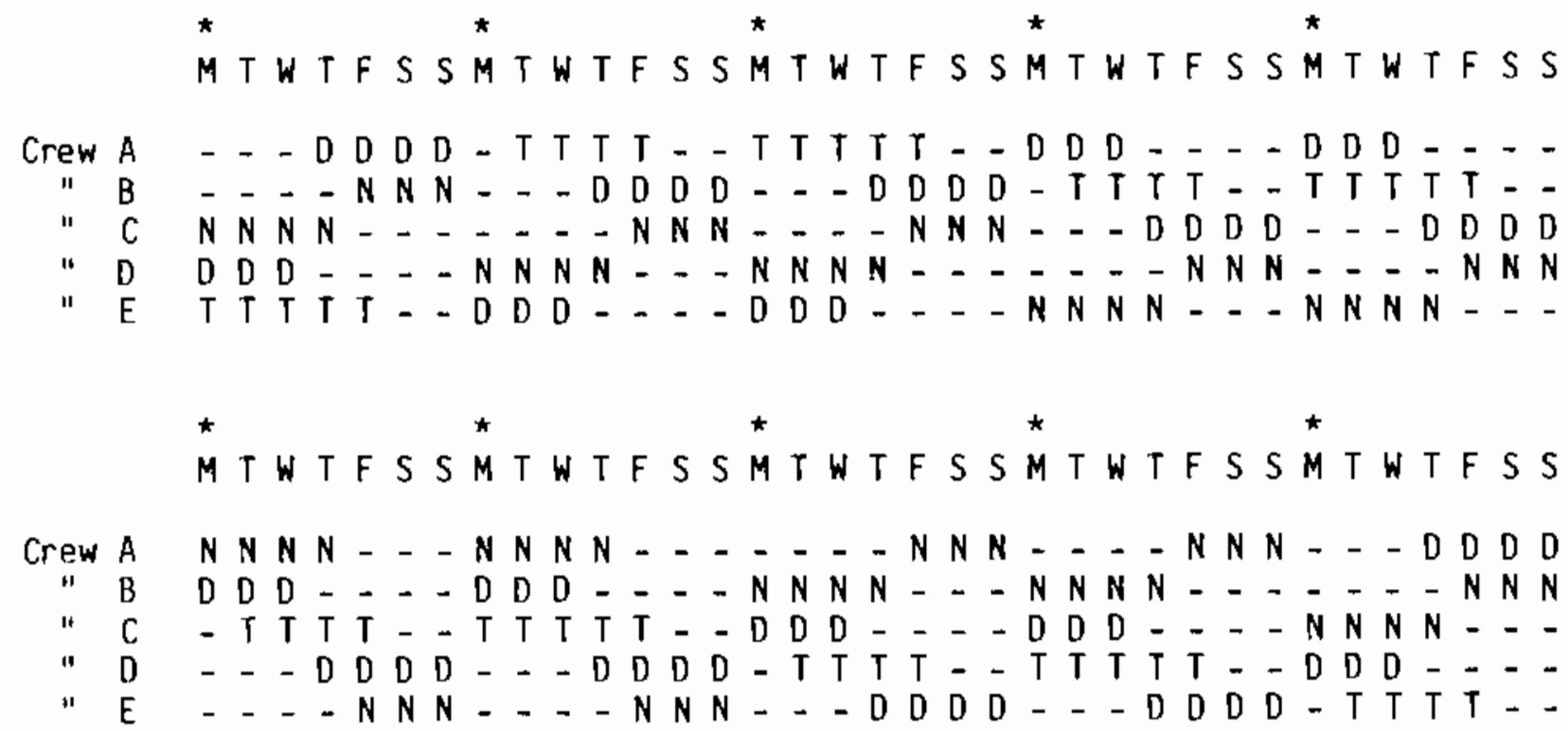

\section{$\underline{\text { LEGEND }}$}

$D=$ Day shift (7AM - 7PM)

$N=$ Night shift (7PM - 7AM)

$\mathrm{T}=$ Training

- = Day off

\section{CHARACTERISTI ICS OF SCHEDULE}

Hours per day in control room $=12$

Hours per day in training $=8$

Number of crews $=5$

Length of cycle $=10 \mathrm{wks}$

Total work hours in cycle $=(28$ days $\times 12 \mathrm{hrs}+9$ days $\times 8 \mathrm{hrs})=408 \mathrm{hrs}$

Average hours of work per week $=(408 \mathrm{hrs} / 10 \mathrm{wks})=40.8 \mathrm{hrs}$

Scheduled training hours as percent of total $=(72 / 408)=18 \%$

Greatest no. of consecutive $12-\mathrm{hr}$. days worked $\# 4$

Speed of rotation $=(2$ shifts in 70 days $)=35$ days 
SCHEDULE ND. $7^{*}$

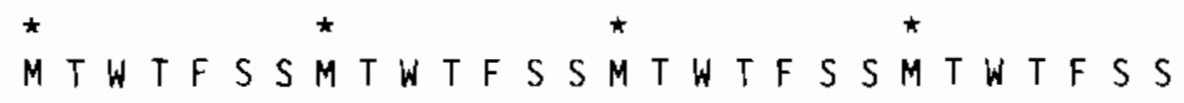

Crew A DDDDD- - - A A A A A A A - N N N N N N - D

"B NNNN- - DDDDDD- - - A A A A A A - N N N

"C A A - N N N N N - D DDDDD- - - A A A A A

$" D-$ - A A A A A A A - N N N N N N- - D D D D D D - -

$" E-R R R R D--R R R R D--R R R R D--R R R R D-$

“F T T T T T - T T T T T - T T T T T - T T T T T -

*This schedule has been constructed from incomplete information.

\section{LEGEND}

$D=$ Day shift (about 8AM to 4PM)

$A=$ Afternoon shift (about 4PM to midnight)

$N=$ Night shift (about midnight to BAM)

$T$ = Training. (Crew $F$ is a training crew. It also fills in for others who are in training.)

$R=$ Relief. (Crew $E$ is a relief crew. It also works Saturdays.)

- = Day off

\section{CHARACTERISTICS DF SCHEDULE}

Hours per day $=8$

Number of crews $=6$

Length of cycle $=4$ wks.

Total work hours in cycle (including relief) $=(20$ days $\times 8$ hrs $\Rightarrow 160 \mathrm{hrs}$

Average hours of work per week $=(160 \mathrm{hrs} / 4 \mathrm{wks})=40 \mathrm{hrs}$

Scheduled training hours as percent of total = (Unknown. It depends in part the number of people in Crew $F$, the training crew.)

Scheduled relief hours as percent of total = (Unkrown)

Greatest no. of consecutive days worked $=7$

Direction of rotation = (Unknown. PNL arbitrarily chose forward rotation in constructing this tab?e.)

Speed of rotation $=(3$ shifts in 28 days $)=9.3$ days 
SCHEDULE N0. $8^{*}$

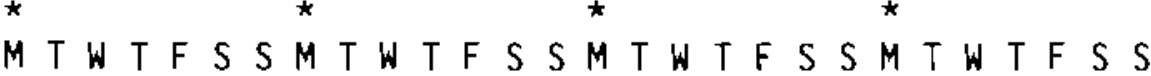

Crew A D D D D D - D D - - - N N N N N - N N - -

"B N N N N - - N N - - D D D D D - D D - . -

$" C \quad-N$ N - - D D D D D - D D - - - N N N N N

$" D-D D \ldots N$ N N N N - N N . . - D D D D D

* This schedule has been constructed from an incomplete verbal report. PNL has not been able to construct a complete schedule and are not certain that the portion of the schedule PNL has completed is entirely correct. The verbal report PNL received is as follows. It is a 12-hour/day work schedule: five days on days; two days off; two days on days; five days off; five nights; two off; two nights; five off. The schedule applies to SROs only. ROs reportedly would like to adopt this schedule, but must first resolve certain issues with their union.

\section{LEGEND}

$D=$ Day shift

$N=$ Night shift

- = Day off

\section{CHARACTERISTICS OF SCHEDULE}

Hours per day $=12$

Number of crews $=4$ or more?

Length of cycle $=4$ weeks

Total work hours in cycle $=$ (14 days $\times 12 \mathrm{hrs} \Rightarrow 168 \mathrm{hrs}$

Average hours of work per week $=(168 \mathrm{hrs} / 4 \mathrm{wks})=42 \mathrm{hrs}$

Scheduled training hours as percent of total $=0 \%$

Scheduled relief hours as percent of total $=0 \%$

Greatest no. of consecutive days worked $=5$

Speed of rotation $=(2$ shifts in 28 days $)=14$ days 
SCHEDULE NO. 9

TWELVE-HOUR/DAY SCHEDULE FOR PETROCHEMICAL PLANTS IN EUROPE "TWO ON, TWO OFF"

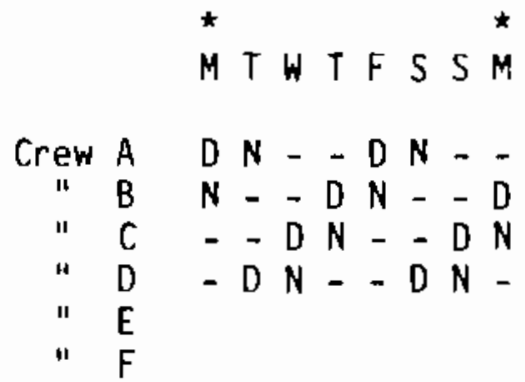

\section{$\underline{\text { LEGEND }}$}

$D=$ Day shift

$N=$ Night shift

- = Day off

\section{CHARACTERISTICS OF SCHEDULE}

Hours per day $=12$

Number of crews $=4$

Length of cycle $=4$ days.

Total work hours in cycle $=(2$ days $\times 12 \mathrm{hrs})=24 \mathrm{hrs}$

Average hours of work per week $=(24 \mathrm{hrs} \times 7 / 4)=42 \mathrm{hrs} / \mathrm{wk}$.

*Source: Colquhoun and Rutenfranz, 198D, P. 4D7. 
SCHEDULE NO. 10

TWELVE-HOUR/DAY SCHEDULE FOR PETROCHEMICAL PLANTS IN UNITED STATES "EVERY OTHER WEEKEND OFF"`

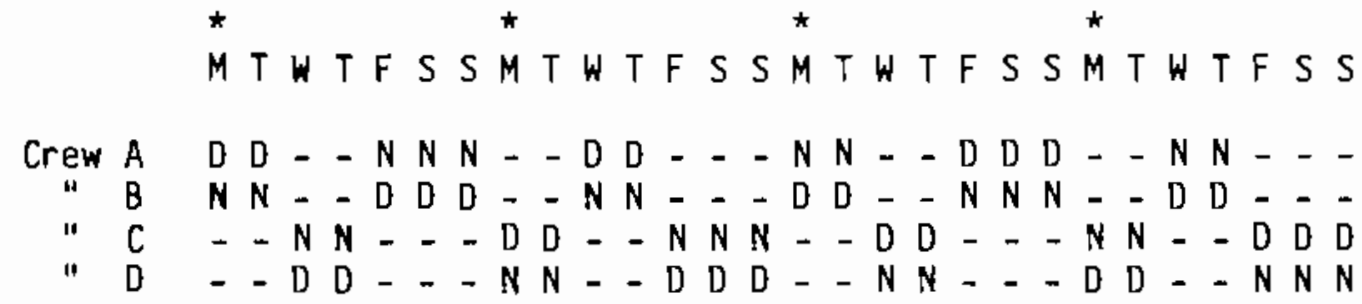

\section{LEGEND}

$D=$ Day shift

$N=$ Night shift

- = Day off

CHARACTERISTICS OF SCHEDULE

Hours per day $=12$

Number of crews $=4$

Length of cycle $=4$ weeks.

Total work hours in cycle $=(14$ days $\times 12 \mathrm{hrs})=168 \mathrm{hrs}$

Average hours of work per week $=(168 \mathrm{hrs} / 4 \mathrm{wks})=42 \mathrm{hrs} / \mathrm{wk}$.

*Source: Northrup, Wilson, and Rose, 1979. p. 315. 
SCHEDULE NO. 11

TWELVE-HOUR/DAY SCHEDULE FOR PETROCHEMICAL PLANTS IN UNITED STATES

"THREE ON, THREE OFF"

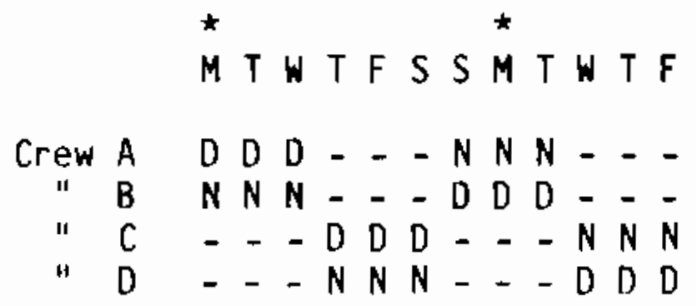

LEGEND

D = Day shift

$N=$ Night shift

- = Day off

\section{CHARACTERISTICS OF SCHEDULE}

Hours per day $=12$

Number of crews $=4$

Length of cycle = 12 Days.

Total work hours in cycle $=(6$ days $\times 12 \mathrm{hrs})=72 \mathrm{hrs}$

Average hours of work per week $=(72 \mathrm{hrs} \times 7 / 12)=42 \mathrm{hrs} / \mathrm{wk}$.

*Source: Northrup, Wilson, and Rose, 1979. p. 315. 
SCHEDULE N0. 12

TWELVE-HOUR/DAY SCHEDULE FOR PETROCHEMICAL PLANTS IN UNITED STATES "FOUR ON, FOUR OFF"

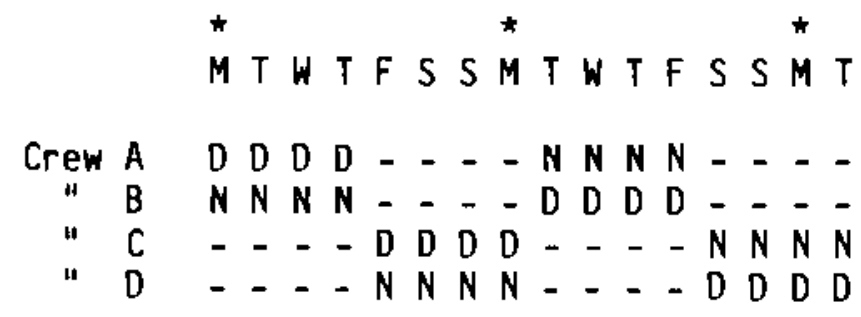

\section{LEGEND}

D = Day shift

$N=$ Night shift

- = Day off

\section{CHARACTERISTICS OF SCHEDULE}

Hours per day $=12$

Number of crews $=4$

Length of cycle $=16$ days.

Total work hours in cycle $=(8$ days $\times 12 \mathrm{hrs})=96 \mathrm{hrs}$

Average hours of work per week $=(96 \mathrm{hrs} \times 7 / 16)=42 \mathrm{hrs} / \mathrm{wk}$.

*Source: Northrup, Wilson, and Rose, 1979. p. 316 



\section{REFERENCES}

Bauman, M. B., R. F. Pain, H. P. Van Cott, and M. K. Davidson. 1983. Survey and Analysis of Work Structure in Nuclear Power Plants. EPRI NP-3141, Electric Power Research Institute, Palo Alto, California.

Brown, I. D., A. H. Tickner and D. C. V. Simmonds. 1970. "Effect of Prolonged Driving on Overtaking Criteria." Ergonomics. (13):239-242.

Buley, L. E. 1970. "Experience With a Physiologically Based Formula for Determining Test Periods on Long-Distance Air Travel." Aerospace Medicine. $41: 680-683$.

Chockie, A. D., et a1. 1984. Review of Maintenance Personnel Practices at Nuclear Power Plants. PNL-51 19, Pacific Northwest Laboratory, Richland, Washington.

Clarke Institute Consulting Group. 1983. Study of Job Stress in Ontario Hydro Operators. Clarke Institute, 250 College Street, Toronto, Ontario.

Colquhoun, W. P., M. J. F. Blake and R. S. Edwards, 1969. "Experimental Studies of Shift-Work III: Stabilized 12-Hour Shift Systems." Ergonomics. $12(6): 865-882$.

Colquhoun, W. P. and J. Rutenfranz (eds.) 1980. Studies of Shiftwork. Taylor and Francis Ltd., London, England.

Dobbins, D. A. et al, 1963. "Vigilance Under High-Way Driving Conditions". Perceptual and Motor Skills. 16:38.

Finlayson, F. C. and J. Ims. 1983. Nuclear Power Safety Reporting System. Volumes I and II, NUREG/CR-3119, Nuctear Regulatory Commission, washington, D.C.

Frese, M. 1984. "Shiftwork and the Length and Quality of Sleep." Journal of Occupational Medicine. 26(8):561-565.

Gerathewohl, S. J. 1974. "Simple Calculator for Determining the Physiological Rest Period After Jet Flights Involving Time Zone Shifts." Aerospace Medicine. pp. 28,37 .

Herbert, M. J. and W. E. Jaynes. 1964. "Performance Decrement in Vehicle Driving." Journal of Engineering Psychology. (3):1-8.

Higgins, E. A., W. D. Chiles, J. M. Mckenzie, P. F. Iampietro, et al. 1975. The Effects of a 12-Hour Shift in the Wake-Sleep Cycle on Physiological and Biochemical Responses and on Multiple Task Performance. Report No. FAA-AM75-10. Prepared for the U. S. Department of Transportation, Federal Aviation Administration, Office of Aviation Medicine, Washington, D.C. 
Hurst, R. 1976. Pilot Error: A Professional Study of Contributory Factors. Scribner, New York, New York.

Kelly, R. J. and M. F. Schneider. 1982. "The Twelve-Hour Shift Revisited: Recent Trends in the Electric Power Industry." In Shiftwork: Its Practices and Improvement. K. Kogi, T. Miura and H. Saito, eds., Center for Acadenic PubTications Japan, Tokyo, Japan.

Kogi, K., T. Miuro and H. Saito, eds. 1982. "Shiftwork: Its Practice and Improvement." Journal of Human Ergology, Vol. 11, Proceedings of the Sixth International Symposium on Night and Shiftwork, Center for Acadenic Publications, Tokyo, Japan.

Kogi, K., M. Takahashi and N. Onishi. 1975. "Experimental Evaluation of Frequent Eight-Hour Versus Less Frequent Longer Night Shifts." In Experimental Studies in Shift Work, W. P. Colquhoun, S. Folkard, P. Knauth and J. Rutenfranz, eds., pp. 103-112, Westdeutscher Verlag, Opladen, West Germany.

Lewis, P. M. 1985. Shift Scheduling and 0vertime: A Critical Review of the Literature. PNL-5391, Pacific Northwest Laboratory, Richland, Washington.

Lyman, E. G. and H. W. Orlady. 1981. Fatigue and Associated Performance Decrements in Air Transport Operations. NASA CR 166167, Aviation Safety Reporting System Office for Ames Research Center, Moffett Field, California.

Mackie, R. R., ed. 1977. Vigilance: Theory, Operational Performance, and Physiological Correlates. Published in coordination with NATO Scientific Affairs 0ivision, Plenum Press, New York, New York.

Mackie, R. R, and J. Miller. 1978. Effects of Hours of Service, Regularity of Schedules and Cargo Loading on Truck and Bus Driver Fatigue. Ruman Factors Research Inc. AvaiTable from the National Technical Information Service, Springfield, Virginia.

McGuire, M. V., M. E. Walsh and A. J. Boegel. 1984. The Operator Feedback Workshop: A Technique for Obtaining Feedback from Operations Personnel. NUREG/CR-3739, PNL-5124, U.S. Nuclear Regulatory Commission, washington, D.C.

Mckenzie, R. E. and L. L. Elliot, 1965. "Effects of Secobarbital and d-Amphetamine on Performance During a Simulated Air Mission." Aerospace Medicine. (36):774-779.

Melton, C. E., J. M. McKenzie, R. C. Smith, B. D. Polis and E. A. Higgins. 1973. Physiological, Biochemical, and Psychological Responses in Air iraffic Control Personnel: Comparison of the 5-Day and 2-2-1 Shift Rotation Patterns. FAA-AM-73-22, Federal Aviation Administration, Office of Aviation Medicine, Washington, D.C.

Mohler, S. R. 1976. "Physiological Index as an Aid in Developing Airline Pilot Scheduling Patterns." Aviation, Space, and Environ. Med. 47:238-247. 
Nichorson, A. N. 1972. "Duty Hours and Sleep Patterns in Aircrew Operating World-Wide Routes." Aerospace Medicine. 43-138-141.

Northrup, H. R., J. T. Wilson and K. M. Rose. i979. "The Twelve-Hour Shift in the Petroleum and Chemical Industries." Industrial and Labor Relations Review. 32(3):312-326.

Platz, 0., J. Rasmussen and P. Z. Skamborg. 1978. Response Times of Operators in a Control Room. Riso National Laboratories, DK400, Roskilde, Denmark.

Price, H. E., P. Wallace, N. Bauman and M. Smith. 1980. Review of Staffing Requirements for Near-Term Operating License Facilities. NUREG/CR-1764. Prepared by Bio Technology, Inc., Falls Church, Virginia, for the Nuclear Regulatory Commission, Washington, D.C.

Ray, J., 0. Martin and E. A. Alluisi. 1961. Human Performance as a Function of the Work/Rest Cycle. National Research Council Bulletin, Council Publication 882 , Washington, D.C.

Shannon, R. H. and N. E. Lane. 1971. A Survey of Major P-3 Accidents with Special Emphasis on Fatigue. Patrol ASW Development Group Report No. 40. Available from the Defense Technical Information Center, Cameron Station, Alexandria, Virginia.

U.S. Government. Code of Federal Regulations (CFR) Title 10 Energy. U.S. Government Printing office, Washington, 0.C.

U.S. Nuclear Regulatory Commission. 1980. Clarification of TMI Action Plan Requirements. NUREG-0737, U.S. Nuclear Regulatory Commission, Washington, D.C.

U.S. Nuclear Regulatory Commission. 1980. Criteria for Preparation and Evaluation of Radiological Emergency Response Plans and Preparedness in Support of Nuclear Power Plants. NUREG-0654, FEMA-REP-1, Rev. 1, U.S. Nuclear Regulatory Comission, Washington, D.C.

U.S. Nuclear Regulatory Commission. June 15, 1982. Generic Letter No. 8212. From Darrell G. Eisenhut, Director, Division of Licensing, U.S. Nuclear Regulatory Commission, Washington, D.C.

U.S. Nuclear Regulatory Commission. September 20, 1982. Generic Letter No. 82-16. From Darrell G. Eisenhut, Director, Division of Licensing, U.S. Nuclear Regulatory Commission, Washington, D.C.

U.S. Nuclear Regulatory Commission. 1983. Clarification of TMI Action Plan. Requirements for Emergency Response CapabiTity. NUREG-0737, Supplement 1, U.S. Nuclear Regulatory Commission, Washington, 0.C.

Vernon, H. M. 1945. "Prevention of Accidents." British Journal of Industrial Medicine. (2):3. 
Viteles, M. S. 1946. The Role of Fatigue in Pilat Performance. National Research Council Committee on Selection and Training of Pilots, Civil Aeronautics Administration, Washington, D.C.

Wilkinson, R. T. 1972. "Sleep Deprivation: Eight Questions." In Aspects of Human Efficiency: Diurnal Rhythm and Loss of Sleep. The English Universities Press Limited. Distributed in the United States by Crane, Russak, and Company, New York, New York.

Wilkinson, R. T., P. D. Tyler and C. A. Varey. 1975. "Duty Hours of Young Hospital Doctors: Effects on the Quality of Work." Journal of Occupational Psychology. 48:219-229.

Wojtczak-Jaroszowa, J. 1977. Physiological and Psychological Aspects of Night and Shift Work. National Institute for Occupational Safety and Health, Cincinnati, Ohio. Available for the Superintendent of Documents, U.S. Government Printing office, Washington, D.C.

Zagoruiko, N. G. and Y. Tambovtsev. 1982. "Aspects of Human Performance in an Intensive Speech Task." International Journal of Man-Machine Studies. $16: 173-181$.

Zamore, K. 1978. Shift Work and Well-Being. Studies on Blue Collar and White Collar Shift Workers. Laboratory Clinical Research, Karolinska Institute, Stockholm, Sweden. 
No. of

Copies

OFFSITE

30

D. Morisseau

Air Rights Building \#3

Mail Stop 5003A

4550 Montgonery Avenue

Bethesda, MD 20814

2 U.S. Nuclear Regulatory Commission

Public Document Room

Division of Technical

Information and

Document Control

Washington, DC 20555

R. Henderson

242 Dorothy Avenue

Ventura, CA 93003

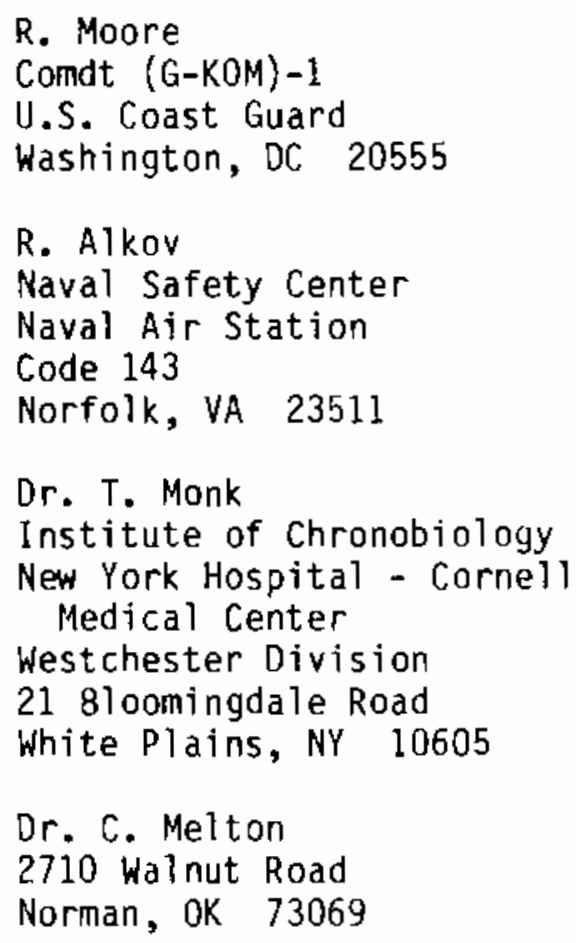

R. Moore

Condt (G-KOM) -1

U.S. Coast Guard

Washington, DC 20555

R. Alkov

Naval Safety Center

Naval Air Station

Code 143

Norfolk, VA 23511

Dr. T. Monk

Institute of Chronobiology

New York Hospital - Cornell

Medical Center

Westchester Division

21 8loomingdale Road

White Plains, NY 10605

Dr. C. Melton

2710 Walnut Road

Norman, OK 73069

No. of

Copies

Tony DiPalo

Division of Risk Analysis

Dffice of Nuclear Regulatory Research

U.S. Nuclear Regulatory Commission

5650 Nicholson Lane

Rockville, MD 20852

Dr. R. Curtis Graeber

200 Trysail Court

Foster City, CA 94404

Dr. W. Storm

Crew Technology Division

USAF SAM/UN

Brooks Air Force Base, TX 78325

Dr. G. Krieger

Boulder Medical Center, P.C.

2750 Broadway

Boulder, CO 80302

F. Schneider

Mantech

Suite 52

25 Wood Street

Toronto, Ontario M4Y 2P9 CANADA

2 Dr.M. J. Colligan

National Institute for

occupational Health and Safety

4676 Columbia Parkway

Cincinnati, OH 45226 


\section{ONSITE}

2 Human Affairs Research Centers

W. Rankin

4 Westinghouse Hanford Company

D. Swain (3)

Q. Baird

44 Pacific Northwest Laboratory

R. V. Badalamente

A. J. Boegel (9)

R. M. Fleischman/

H. Harty

V. E. Lee

P. M. Lewis (20)

M. F. Mullen

R. U. Sorenson

R. W. Vallario

S. C. Vickroy

R. D. Widrig

Publishing Coordination MH (2)

Technical Information (5) 



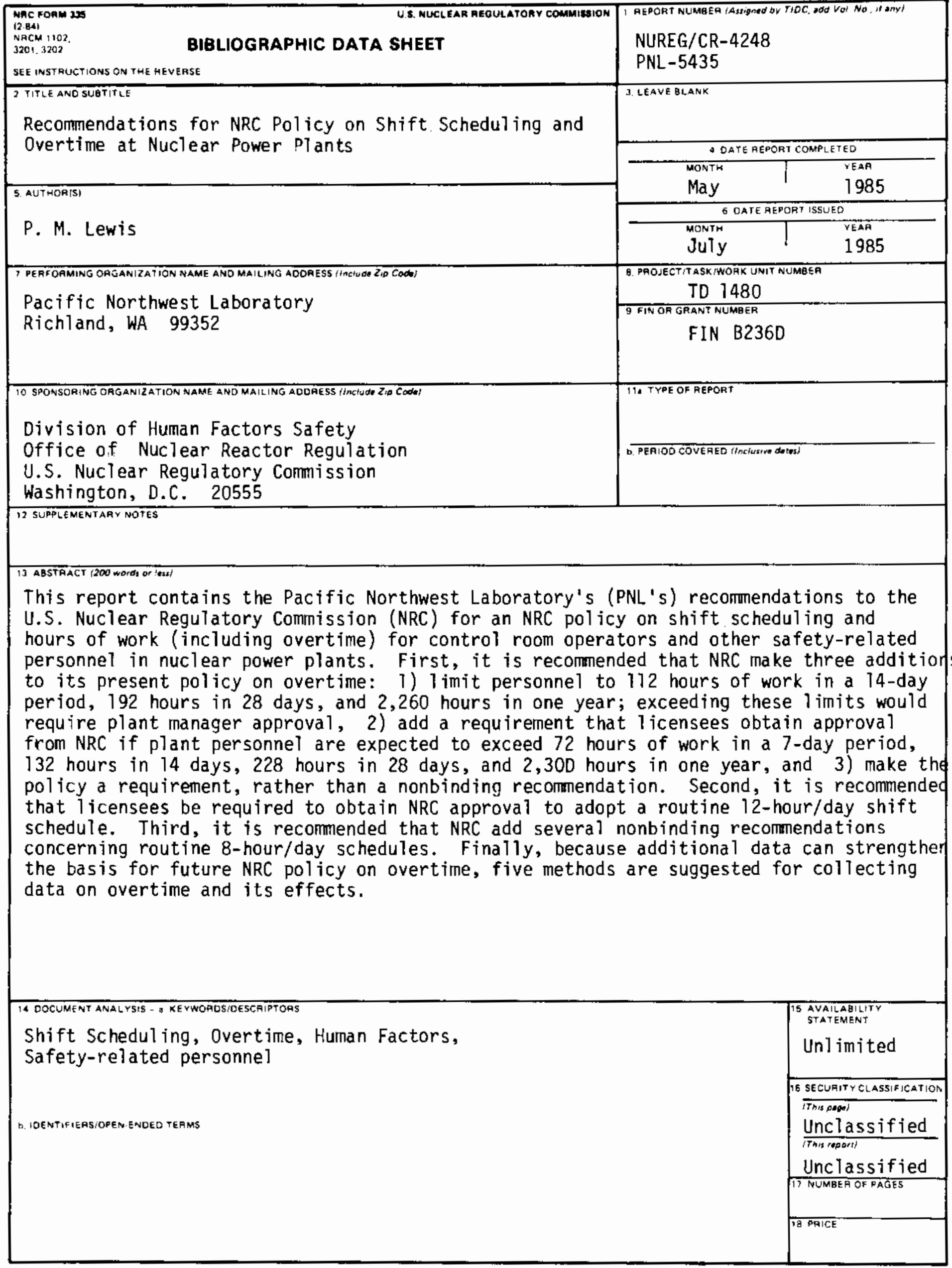


